\title{
Multidimensional Analysis of Vulnerability: Methodological Advances and a Case Study from Malawi.
}

\author{
PARK MCMILLAN MUHONDA \\ pmmuhonda@mix.wvu.edu
}

Follow this and additional works at: https://researchrepository.wvu.edu/etd

Part of the Human Geography Commons, Physical and Environmental Geography Commons, and the Spatial Science Commons

\section{Recommended Citation}

MUHONDA, PARK MCMILLAN, "Multidimensional Analysis of Vulnerability: Methodological Advances and a Case Study from Malawi." (2019). Graduate Theses, Dissertations, and Problem Reports. 7459.

https://researchrepository.wvu.edu/etd/7459

This Dissertation is protected by copyright and/or related rights. It has been brought to you by the The Research Repository @ WVU with permission from the rights-holder(s). You are free to use this Dissertation in any way that is permitted by the copyright and related rights legislation that applies to your use. For other uses you must obtain permission from the rights-holder(s) directly, unless additional rights are indicated by a Creative Commons license in the record and/ or on the work itself. This Dissertation has been accepted for inclusion in WVU Graduate Theses, Dissertations, and Problem Reports collection by an authorized administrator of The Research Repository @ WVU.

For more information, please contact researchrepository@mail.wvu.edu. 
Multidimensional Analysis of Vulnerability: Methodological Advances and a Case Study from Malawi.

Park M.N.M. Muhonda

Dissertation submitted

to the Eberly College of Arts and Sciences

at West Virginia University

in partial fulfillment of the requirements for the degree of

Doctor of Philosophy in

Geography

Brent McCusker, Ph.D., Chair

Jamison Conley, Ph.D.

Eungul Lee, Ph.D.

Bradley Wilson, Ph.D.

Edward Carr, Ph.D.

Department of Geology and Geography

Morgantown, West Virginia

2019

Keywords: Malawi, livelihood vulnerability, spatial vulnerability analysis, adaptation to climate change, local perceptions, climate variability

Copyright 2019 [Park M.N.M. Muhonda] 


\section{Abstract \\ Multidimensional Analysis of Vulnerability: Methodological Advances and a Case Study from Malawi.}

\section{Park M.N.M. Muhonda}

Since 1990s rural households in Malawi, constituting $85 \%$ of the population, have experienced deepening livelihood vulnerability, often manifested as persistent food insecurity. Livelihood crises have since been blamed on or attributed directly to weather perturbations/climatic shocks i.e. El-Nino induced climate variability/drought conditions. This study revealed that persistent livelihood crisis in rural Malawi cannot be attributed to or squarely blamed on weather shocks alone, rather it is at the intersection of various livelihoods shocks that rural livelihood vulnerability in Malawi is exacerbated i.e. worsening and deepening.

Thus, rural livelihood vulnerability to climate shocks in Malawi is manifest not in isolation but in relation to a wide range of other shocks and stressors. At the intersection of interests to promote private sector driven system, to achieve food security in the short term, and to push hybrid seed as an appropriate technology for smallholders, smallholder farming has become specialized into maize monoculture, eroding crop and variety diversity. Maize however is not drought resistant, and to maintain yields requires fertilizer and fresh hybrid seeds each year. Maize monoculture has increased vulnerability to fluctuations in weather and market. Rural livelihoods vulnerability in Malawi is further compounded by land inadequacy for smallholder production. Most smallholders do not have sufficient land on which they can produce enough food to feed the average family and earn income throughout the year (Harrigan 2008). Still, the collapse of ADMARC (the agriculture marketing board) under structural adjustment programs has left smallholders at the mercy of unscrupulous traders and unruly free market forces.

This brings the question of rural livelihoods vulnerability analysis in Malawi squarely into the purview of multidimensional analysis. Following the IPCC conceptualization of vulnerability as a function of exposure to climate hazards, on the one hand, and the sensitivity and adaptive capacity of the society on the other, this dissertation research applies a multidimensional lens to rural livelihood vulnerability analysis in Malawi to develop a better understanding of climatic shocks/perturbations mediating rural livelihoods and holistic approaches (i.e. that include both climatic hazard and differential social vulnerability) to vulnerability mapping - to leverage effective adaptation to climate change

With a series of primary and secondary data analyses the dissertation asserts/argues that effective adaptation to climate change is contingent on local farmers perception (e.g. Le Dang et al 2014; Teye et al 2014; Boissiere et al 2013). Farmers perceptions reflect local concerns and tend to form the basis/context in which their adaptation strategies emerge and or the conceptual framework in which farmers are willing to accept or not adaptation strategies (e.g. Carr and McCusker 2009).

Through farmers perceptions the study reveals that local farmers are sensitive and knowledgeable of the changing climatic conditions in their areas. If adequately harnessed such practical knowledge of local weather condition can facilitate effective and successful adaptation. Though vulnerability mapping as a field is maturing, a number of issues remain that need to be addressed for the field to advance, including increasing the degree of collaboration with end users, greater attention to map communication, moving beyond the map as the final product, work on validation 


\section{DEDICATION}

With deepest and sincerest gratitude to God Almighty, I would like to dedicate this piece of work to the servant of God Prophet T.B. Joshua. I thank God for using you to show me that indeed with Jesus Christ all things are possible. 


\section{Acknowledgement}

I would like to acknowledge the guidance and support of my supervisor, Brent McCusker, who through funding he acquired from USAID graciously supported me to do this research in Malawi and financed all my $\mathrm{PhD}$ program. I am also deeply and greatly thankful to Brent McCusker for the excellent mentor he has been to me from the beginning to the very end of my $\mathrm{PhD}$ program and for supporting me in career path.

Many thanks also to my dissertation committee Bradley Wilson, Eungul Lee, Jamison Conley and Edward Carr for their dedicated support during the foundational reading, research, and writing processes. I appreciate each of you on this committee for your precious time, your counsel and guidance, and your immeasurable help all through.

Also, many thanks to USAID and Department of Geology and Geography for all the support

I also am heavily indebted to James Chimphamba (my supervisor during my undergraduate studies) who commended me to Brent McCusker and with whom I and Brent McCusker did field work together in Malawi.

I would also like to thank the enumerators who assisted in the field work and all the communities that participated in this research. I couldn't have done this without you.

I would like to thank my wife Rhoda and Lucy my daughter for enduring my absence in Malawi and for tirelessly supporting me in this endeavor ever since joining me in US. Your love, presence and support kept me going. Thanks to my daughter Hope, the joy of your coming gave me more strength to move on.

Finally, my family and friends, I really appreciate your support. To my family, my mother Fyness Nyakawamba, my sister Pachalo Mapunda and my brother Millen Mapunda thank you so much for your prayers and to my friends Joshua Lohnes and his family, Eleanor Green and her family, Edith Vehse, Leah, Laura and Lya and so many, many more there are no words to express my gratitude for your immeasurable support. 


\section{Table of Contents}

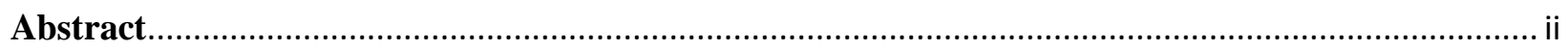

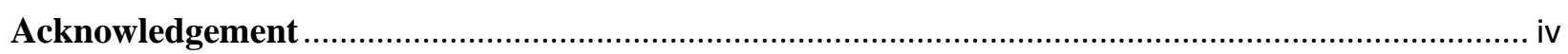

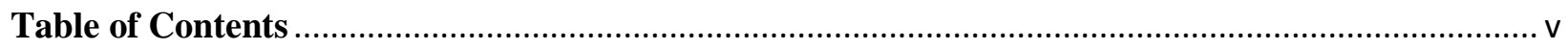

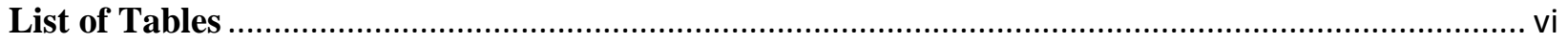

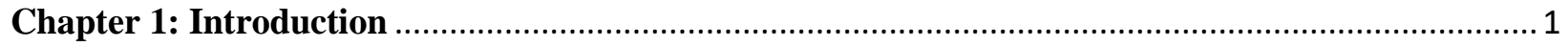

Chapter 2: Has the Rainfall in Malawi Changed, and Do Farmers Perceive Change?...................... 7

Chapter 3: The Variability of Rainfall in Malawi and its Links to Sea-Surface Temperatures

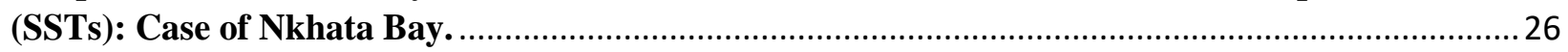

Chapter 4: Climate Vulnerability Mapping: A Systematic Review and Future Prospects...............43

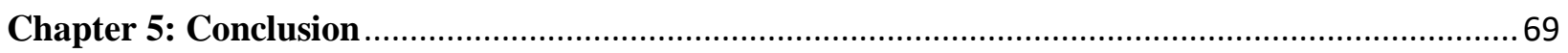




\section{List of Tables}

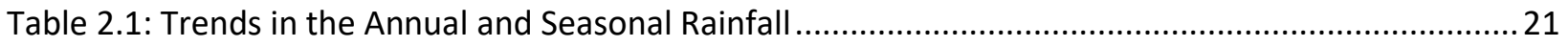

Table 3.1: Correlation between regional rainfall index and SSTs anomalies...........................................38

Table 4.1: Search results using online search engines: the Web of Science and Google Scholar (June 2016).

Table 4.2: Categories and components of uncertainty in geospatial data (after MacEachren et al. 2005). 


\section{List of Figures}

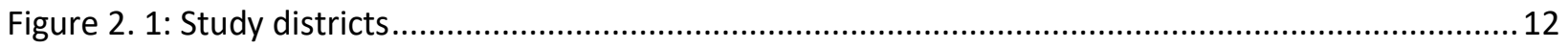

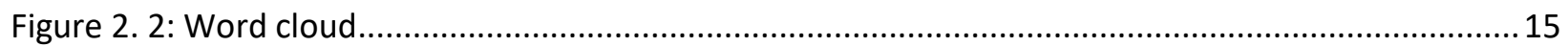

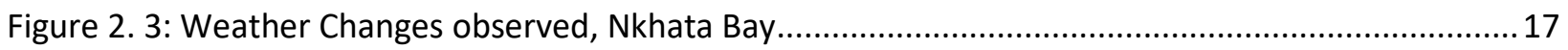

Figure 2. 4: Weather Changes observed, Balaka ................................................................................ 17

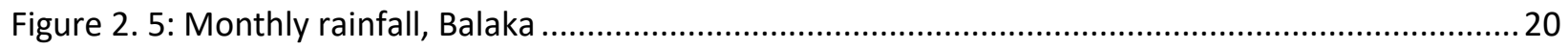

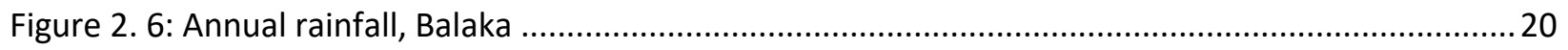

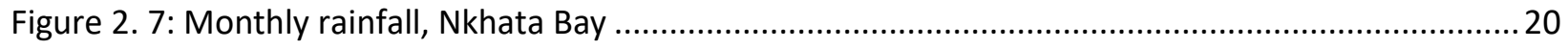

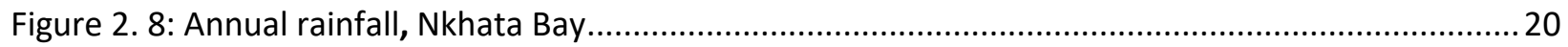

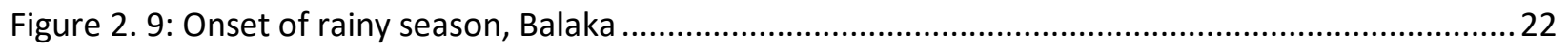

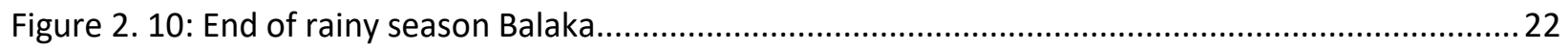

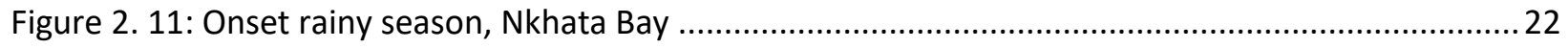

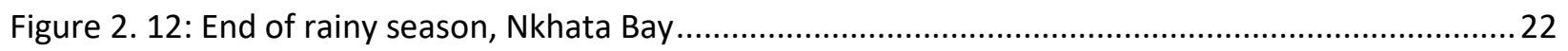

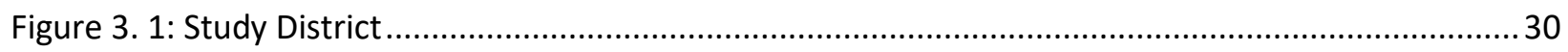

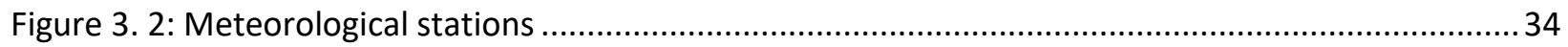

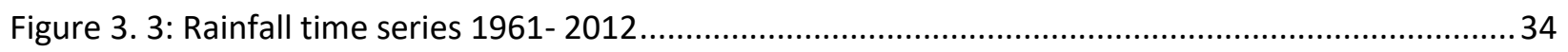

Figure 3. 4: Rainfall \& Nino 3.4 time series 1961- 2012 .................................................................... 35

Figure 3. 5: Spatial association of precipitation and El Nino phenomenon.............................................36

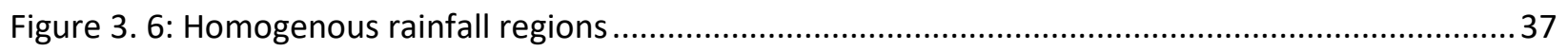

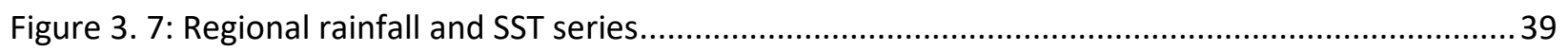

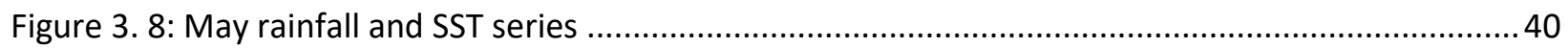

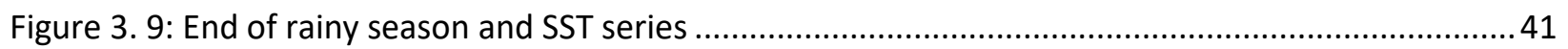

Figure 4. 1: Examples of vulnerability maps .............................................................................. 46

Figure 4. 2: Studies selection criteria for the vulnerability mapping systematic review ..........................48

Figure 4. 3: Studies by Continent, Level of Analysis, and Discipline .....................................................52

Figure 4. 4: Summary of the studies in terms of (a) method of spatial analysis, (b) valued attribute, and

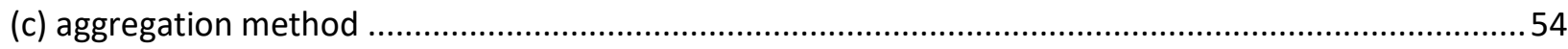

Figure 4. 5: Summary of the studies, clockwise from upper left, in terms of (a) timeframes of analysis

(\%), (b) temporal nature of the climate parameters considered (\%), (c) spatial data layers or parameters

considered (no.), and (d) climate-related phenome ........................................................................56

Figure 4. 6: Diagram from Kienberger et al. 2016 illustrating the elements contributing to an agricultural

vulnerability index, including weighting of the variables and components ...........................................63 


\section{Chapter 1: Introduction}

Since 1990s rural households in Malawi, constituting $85 \%$ of the population, have experienced deepening livelihood vulnerability, often manifested as persistent food insecurity. For the past 15 years the government has declared a national disaster five times due to food insecurity/livelihood failure: 2002; 2005; 2012, 2015; 2016. Livelihoods crises are also manifested in a steep increase in food prices, which, for example, in 2002 left around 3.5 million people food insecure. Livelihood crises have since been blamed on or attributed directly to, by government/authorities, weather perturbations/climatic shocks i.e. El-Nino induced climate variability/drought conditions.

Others have argued/contend that the worsening repercussions of and deepening rural livelihoods vulnerability cannot be explained by unkind weather/climatic perturbations alone. In Malawi, smallholder farmers are not new to climate uncertainty. Over the centuries rural agricultural system has evolved to cope with fluctuating environmental conditions. Through empirical, indigenous knowledge, smallholder farmers have developed mechanisms, such as localized crop and varietal diversity, to mediate livelihoods through perturbing environments. Up to 1994, Malawi was food self-sufficient and, in many years, had surplus to export. However, these long-held coping mechanisms have in the recent past been quickly eroded (Brooks 2014). At the intersection of interests to promote private sector driven system, to achieve food security in the short term, and to push hybrid seed as an appropriate technology for smallholder farmers, smallholder farming has silently become specialized, with significant emphasis on maize production creating maize monoculture, eroding crop and variety diversity. Overall, it is estimated that $97 \%$ of smallholder farmers across the county grow maize, and more than half of households grow no other crops. Only $10 \%$ of these maize growers are net sellers, with as high as $60 \%$ being net buyers" (Chinsinga 2012). Maize however is not drought resistant, and to maintain yields, it requires fertilizer and fresh hybrid seeds each year. According to Brooks (2014), specialization in agriculture increases vulnerability to fluctuations in weather and market.

Rural livelihoods vulnerability in Malawi is further compounded by land inadequacy for smallholder production. Malawi is densely populated, in fact is the second most densely populated country in southern Africa (Malcomb 2014; World Bank 2018; UN 2018). Most smallholder 
farmers do not have sufficient land on which they can produce enough food to feed the average family and earn income throughout the year (Harrigan 2008). In 2000 arable land, hectares per person, was estimated at 0.2 ha. With the ever-increasing population, rising by $35 \%$ since 2008 , landholding size per person is quickly diminishing. Because of pressure on land there is no opportunity for smallholder farmers to fallow or practice rotation to restore soil fertility.

Still, some schools of thought attribute rural livelihoods crisis in Malawi to economic policy reforms under structural adjustment programs (Chirwa et al. 2005). Since the removal of universal fertilizer subsidy in 1994/95, fertilizer has become unaffordable to many farmers. Targeted subsidy introduced in 2004/5 is marred with program performance issues (Asfaw et al. 2017; Chibwana et al. 2012; Dorward and Chirwa 2011). Besides high prices of inputs like fertilizer, the collapse by donors of ADMARC - the agriculture marketing board (under structural adjustment programs) has put smallholder farmers at the mercy of unscrupulous traders and unruly free market forces. Smallholder farmers get low produce prices due to unfair trading practices and monopsony power of private traders. These private traders sell back maize in the lean season at abnormally high prices that the poor cannot afford (GRAIN 2010; Mvula et al. 2003).

Thus, rural livelihood vulnerability to climate shocks in Malawi is manifest not in isolation but in relation to a wide range of other shocks and stressors. This brings the question of rural livelihoods vulnerability analysis in Malawi squarely into the purview of multidimensional analysis. Following the IPCC conceptualization of vulnerability as a function of exposure to climate hazards, on the one hand, and the sensitivity and adaptive capacity of the society on the other, and based on our qualitative interaction with smallholder farmers in southern and northern Malawi, this dissertation applies a multidimensional lens to understand rural livelihood vulnerability to climate shocks in Malawi and analyze common approaches to mapping vulnerability, their strengths and limitations.

Smallholder agriculture in Malawi is rainfed and is especially susceptible to adverse drought. Rainfed agriculture in Malawi is finely tuned to climate as it relies on the regular onset of rainfall and a reliable distribution through the rainy season (e.g. Sivakumar et al. 2005, Arthur 2003). Agricultural livelihoods in Malawi are thus very sensitive to weather shocks. This study seeks to develop a better understanding of climatic shocks/perturbations mediating rural livelihoods 
and holistic approaches (i.e. that include both climatic hazard and differential social vulnerability) to vulnerability mapping.

A commonplace approach to holistic vulnerability analysis and mapping is to aggregate various dimensions into a single index. This approach, however, while may be more elaborate on the theoretical side and an improvement of the efforts that focus on exposure to natural hazard, is marred with measurement/quantification and communication issues. On the one hand, aggregated measures essentially reduce the multifaceted socio-ecological vulnerability to unidimensional. On the other hand, the unitless aggregated index reduces the richness of and obscures information regarding the original variables. Furthermore, unitless aggregated vulnerability values may return similar scores in two locations where vulnerability is driven by very different processes - for example, forest loss or drought (Füssel, 2009; Yohe \& Tol, 2002). Besides the problem of measurement, quantification, efforts to analyze and map vulnerability are mired by issues of data quality. Vulnerability mapping studies traditionally rely on remotely sensed and climatological data. Absent from these analyses are local details regarding the actual exogenous shocks reported by households over time. In a review of 45 vulnerability mapping studies, Preston, Yuen, and Westaway (2011) found that very few studies used actual data on exogenous shocks and socioeconomic factors reported by households.

The question therefore persists, and we apply this question to Malawi, how can we better understand rural livelihoods vulnerability in Malawi to leverage (to enable smallholder farmers to effectively adapt) effective adaptation to climate change? This dissertation provides a series of primary and secondary data analyses that examine different aspects of this question. Livelihood adaptation to climate change literature asserts that effective adaptation to climate change is contingent on local farmers perception (e.g. Le Dang et al 2014; Teye et al 2014; Boissiere et al 2013). Farmers perceptions reflect local concerns and tend to form the context in which their adaptation strategies emerge and or the conceptual framework in which farmers are willing to accept or not adaptation strategies (e.g. Carr and McCusker 2009; Byg and Salick 2009; Yaro 2003; Campos et al 2014).

This research thus begins in Chapter 2 with an analysis of local farmers perception of climate change in Malawi and check the validity of local perception against meteorological observations. It is structured as $\mathbf{3}$ closely related articles. The first article delves into actual lived experiences 
about climate variability among local farmers to better understand environmental context i.e. climatic conditions in which livelihood vulnerability is generated. It investigates the changing rainfall patterns by addressing the following two questions: Is the local climate of Balaka and Nkhata Bay changing? Are local farmers able to perceive the changes? Farmers perceptions reflect local vulnerabilities and concerns, actual impact of climate on their livelihoods. Effective adaptation depends on deep knowledge of vulnerability. Understanding farmers perceptions of the changing climatic conditions is thus essential to policy makers and to adaptation research (Le Dang et al. 2014). Teye et al. (2014) assert that effective adaptation to climate change is contingent on the perception of farmers. Boissiere et al. (2013) also argued that knowing farmers' perceptions of climate change is helpful in developing strategies to support adaptation to climate change. According to Le Dang et al. (2014) any attempt to understand adaptive behavior patterns should come after understanding vulnerability i.e. farmers perception of climate change.

Although Malawi is heavily dependent on rainfed agricultures and is prone to rainfall variability, very little is known about the factors governing rainfall variability i.e. variability in its climate has not been widely studied. Known studies include Nicholson et al. (2014); Ngongondo et al. (2011); Jury and Mwafulirwa (2002); and Jury and Gwazantini (2002). Malawi's rainfall regime falls in a climatic transition zone between Southern Africa and Eastern Africa. In a given year, southern Malawi may experience different weather conditions from northern Malawi suggesting that the rainfall regimes may be different. Thus, Malawi merits much more detailed study than regional studies which usually report only average climatic conditions. Chapter $\mathbf{3}$ builds on earlier studies on climate variability. It investigates the association between rainfall variability in Malawi and sea surface temperature (SST) over the south-central Indian Ocean and Nino 3.4 time series at country and local scales. Onset, intensity, length of the growing and rainy seasons, dry spells i.e. length of dry spells, and their frequencies are analyzed to understand how changes in the agriculturally relevant rainfall characteristics are associated with or mediated by SST patterns.

The dissertation research then builds on a systematic review of current practices in vulnerability analysis and mapping to improve on ways to better analyze and map rural livelihoods vulnerability to climate change in Malawi. Chapter 4 is a systematic review of current practices in climate vulnerability mapping and provide recommendations that chart the way forward for future efforts. A review of state of the art in vulnerability analysis and mapping reveals critical point/observation 
that while studies on climate vulnerability have made valuable contribution to our understanding of vulnerability analysis and mapping few or no studies have considered exposure to non-climatic stressors, such as economic downturn or health crises, in addition to climatic stressors. Adopting the framing of vulnerability, which include both climate hazard (or exposure) and differential social vulnerability (i.e. socioeconomic characteristics affecting the susceptibility of certain populations to climate change impacts and related risks), necessitates vulnerability mapping to consider exposure to non-climatic stressors, such as economic downturn or health crises, in addition to climatic stressors. Measuring and mapping vulnerability is a top research priority (PROVIA 2013). Maps have been used to identify areas of vulnerability to climate hazards such as flood, drought, and sea level rise (Notenbaert et al. 2010). End users have found the information contained in vulnerability maps useful for planning adaptation assistance (de Sherbinin et al. 2017), understanding the underlying factors contributing to vulnerability (Preston et al. 2009). Given the research and policy priority given to mapping vulnerability, it is imperative to develop a better understanding of suitable approaches to vulnerability mapping across a range of scales, regions, climate hazards, and thematic foci. While a number of studies have made valuable contributions to our understanding of vulnerability mapping, there remains a need for a comprehensive review of the state of the art in mapping social vulnerability to climate change to chart the way forward for future efforts.

This dissertation concludes by summarizing key findings related to climatic shocks/perturbations mediating rural livelihoods and holistic approaches to vulnerability mapping to leverage effective adaptation to climate change. Through farmers perceptions the study revealed that local farmers are sensitive and have detailed knowledgeable of the changing climatic conditions in their areas. If adequately harnessed such practical knowledge of local weather condition can facilitate effective and successful adaptation. Correlation analysis has shown that the changing rainfall conditions over Malawi i.e. year to year variability and dry conditions are associated with sea surface temperature (SST) i.e. the El Nino Southern Oscillation and south-central Indian Ocean SST. The dissertation has also revealed that vulnerability mapping as a field is maturing, but a number of issues remain that need to be addressed for the field to advance, including increasing the degree of collaboration with end users, greater attention to map communication, moving beyond the map as the final product, work on validation. 
Many outcomes will result from this dissertation. Although rural livelihoods vulnerability is a significant topic of interest in Malawi and has received widespread attention from donors, NGOs, and the government, studies on Malawi's rural livelihoods vulnerability are very scarce in the literature. This dissertation will contribute to understanding local farmers environmental conditions mediating their livelihoods and the context in which adaptation takes place. As pointed out by Ribot (2014), there is need for a clear understanding of causes of rural livelihoods vulnerability before adaptation. The dissertation will also directly contribute to improving vulnerability mapping. Better and suitable approaches to vulnerability mapping can make significant contributions to enabling society to effectively adapt, or to signal where adaptation may face sufficiently high barriers. Thus, better understanding of geography of rural livelihood vulnerability in Malawi can help with programming, identification of groups of people to be targeted with adaptation interventions and monitoring progress towards adaptation. 


\title{
Chapter 2: Has the Rainfall in Malawi Changed, and Do Farmers Perceive Change?
}

\begin{abstract}
Increased frequency of occurrence of weather perturbations is negatively affecting livelihoods in southern Africa. With single season rainfed agriculture which is finely tuned to climate as it relies on the timely onset of rainfall and its regular distribution through the rainy season, livelihoods in Malawi are especially vulnerable to adverse weather conditions. This paper explores the lived experiences and perceptions about weather pertubation among local farmers in Malawi. Farmers“ perceptions reflect local concerns, thus, provide context in which adaptation strategies emerge. Understanding farmers' perceptions of the changing climatic conditions is essential to policy makers and to adaptation research. As asserted by Teye et al. (2014) effective adaptation to climate change is contingent on the perception of farmers. Thus, perceiving climate variability is the first and critical step in the process of adaptation. The present study uses household surveys and focus group discussions from Balaka in southern Malawi and Nkhata Bay in northern Malawi to investigate farmers' perception of the changing rainfall patterns and compare with meteorological observations. The main findings are a) local farmers in both Balaka and Nkhata Bay are sensitive and knowlegeable of climatic conditions in their areas and have observed that rainfall patterns have changed; b) local farmers perceptions of climate change are consistent with meteorological observations.
\end{abstract}

\section{INTRODUCTION}

While some people (particulary in the developed world) are still skeptical about climate change, experiences of rural smallholder farmers in southern Africa, especially Malawi, attest to the saying that the one who feels it knows it. Increased frequency of occurrence of weather perturbations is negatively affecting livelihoods in southern Africa. As a rainfed, agro-based economy, Malawi is especially more vulnerable to adverse conditions. Single season (November to April) rainfed agriculture constitutes the source of livelihoods for about $85 \%$ of the population. The rainfed agriculture in Malawi is finely tuned to climate as it relies on the timely onset of rainfall and its regular distribution through the rainy season (e.g. Sivakumar et al. 2005, Arthur 2003). In this 
paper, I will explore the lived experiences and perceptions about weather pertubations among local farmers in Malawi.

In the recent past, Malawi has been experiencing frequent occurence of adverse weather conditons which have negetively impacted livelihoods and often rendered the nation food insecure (UNOCHA 2016; USAID 2018). In the past 15 years, the government has declared a national disaster four times (i.e Febreuary 2002; October 2005; January 2015; April 2016) as a result of adverse weather conditions. Enhancing and broadening our understanding of the temporality of rainfall in Malawi is thus central to improving/supporting peoples livelihoods.

Although climate and rainfall variability is a significant topic of interest in Malawi and has received widespread attention from donors, NGOs, and the government, studies on Malawi's rainfall are very scarce in the literature. While Ngondondo et al. (2011) investigated the spatial and temporal rainfal patterns and Nicholson et al. (2014) analysed the interannual rainfall variability, few attempts have been made to understand the actual lived experiences and perceptions about climate variability among local farmers at local level in Malawi.

As the literature on farmers perceptions on climate change has matured, the validity/accuracy of the peceptions has been debated. Panda (2016) observed that there is a dearth of concrete findings that link between farmers' perception on changing climate and meteorological data. Literature on farmers' pereceptions has also higlighted the importance of percetions about climate change on farmers' adaptation actions. Deressa et al. (2011) found that in Ethiopia, farmers that perceived decreasing rainfall undertook adaptation actions. According to Ogalleh et al (2012), farmers use their perceptions to make decisions on coping and adapting. Since farmers perceptions reflect local concerns, farmers perceptions of climate change tend to form the context in which adaptation strategies emerge or the conceptual framework in which farmers are or are not willing to accept adaptation strategies (e.g. Byg and Salick 2009; Yaro 2013; Campos et at. 2014).

Understanding farmers " perceptions of the changing climatic conditions is essential to policy makers and to adaptation research (Le Dang et al. 2014). Studies on farmers perception enable policy makers to design relevant policies as they understand what farmers adapt to. As asserted by Teye et al. (2014) effective adaptation to climate change is contingent on the perception of farmers. Boissiere et al. (2013) also argued that knowing how farmers perceive climate change is 
helpful in developing strategies to support adaptation to climate change. According to Le Dang et al. (2014), any attempt to understand adaptive behaviour patterns should come after understanding how climate variability is perceived by farmers. Thus, perceiving climate varibility is the first and critical step in the process of adaptation.

The present study, using household surveys, focus group discussions and meteorological observations from Balaka in southern Malawi and Nkhata Bay in northern Malawi, investigates the changing rainfall patterns at local level. The main findings are a) local farmers in both Balaka and Nkhata Bay are sensitive and knowlegeable of climatic conditions in their areas and have observed that rainfall patterns have changed; b) local farmers perceptions of climate change are consistent with meteorological observations. These two areas make ideal case studies for studying changing rainfall patterns and farmers' perceptions because they are suitable for comparison as they represent geographies with contrasting natural environment conditions and social-cultural and livelihood system, this study zeroes in on the following specific questions: is the local climate of Balaka and Nkhata Bay changing? Do the local farmers perceive the changes? Given that Malawi has been exposed to frequent adverse climatic conditions and that understanding of climate variability remains limited, this study will be useful in understanding the rainfall pattern, and in achieving effective adaptation to climate change in Malawi. The rest of the paper is organized as follows. Section 2, lays out the context for the study by describing the study area, data sources, and data analysis methods used in the study. Section 3 presents results and discussion and discusses how smallholder farmers perceive climatic changes that have occurred for the past 46 years against meteorological observations. Section 4 briefly concludes the study.

\section{STUDY AREA}

The study is situated within the context of Malawi (latitudes $9-17^{\circ} \mathrm{S}$ and longitudes $32-36^{\circ} \mathrm{E}$ ), in southern Africa. Malawi is landlocked bordered by Mozambique, Zambia and Tanzania. With a total area of $118,484 \mathrm{~km}^{2}\left(29,604 \mathrm{~km}^{2}\right.$ of which is water, mainly Lake Malawi) and an estimated population of 18 million (2016), Malawi is the most densely populated country in southern Africa. It experiences semi-arid tropical wet and dry climate, also called savanna. The rainy season is from November to April and the dry season is from May to October. Mean annual rainfall is in the order of $800 \mathrm{~mm}$ to over $1600 \mathrm{~mm}$ (Nicholson et al. 2014). The average daily minimum and maximum temperatures in November, the hottest month, are $17^{\circ} \mathrm{C}$ and $29^{\circ} \mathrm{C}$ respectively; those in July, the 
coolest month, are $7^{\circ} \mathrm{C}$ and $23^{\circ} \mathrm{C}$. Due to variations in altitudes there are wide differences in climate across the country. According to Ngongondo et al. (2011) the climate of Malawi is mostly influenced by the north-south migration of the intertropical convergence zone (ITCZ) and its topography. Rainfall is erratic, floods and droughts occur more often.

The economy is undiversified and highly dependent on rain-fed agriculture. Agriculture accounts for more than $30 \%$ of Growth Domestic Product (GDP), $85 \%$ of the labor force and $83 \%$ of foreign exchange earnings. Agricultural production is predominantly smallholder and subsistent, characterized by low levels of input and output. Smallholder farmers produce about 80 percent of Malawi's food. The main agricultural products grown by smallholder farmers are maize, tobacco, cassava, groundnuts, pulses, sorghum and millet, rice, bananas, sweet potatoes and cotton. Livestock accounts for less than 7\% of the agricultural GDP in Malawi. Only 4\% of the households own cattle. A tiny fraction, about $2.3 \%$ of arable land is irrigated. And only around 3.3 percent of all rural households are beneficiaries of the irrigation schemes. Given the lack of irrigative infrastructure agriculture is highly dependent on suitable weather conditions and is thus particularly highly vulnerable to weather shocks such that success of crop production is almost entirely linked with weather conditions.

As in most of southern Africa, rural livelihoods in Malawi depend heavily but not solely on rainfed agriculture. At the intersection of interests to promote private sector driven system, to achieve food security in the short term, and to push hybrid seed as an appropriate technology for smallholder farmers, the once diversified smallholder farming has gradually become specialized, with significant emphasis on maize. Estimates show that maize farming covers more than $70 \%$ of the arable land (GoM, 2006). And according to Chinsinga et al. (2012) an estimated $97 \%$ of smallholder farmers across the county grow maize, and more than half of households grow no other crops. Maize monoculture agricultural system has made rural livelihoods fragile and more vulnerable to weather perturbations. Cassava production is relatively high in Karonga and Nkhata Bay districts in the northern region. With comparatively low requirement for water, labor, and inputs, cassava helps smallholder farmers ensure local food security in the event of maize crop failure and maize price increases. Most smallholder farmers draw their income from sale of crops mainly tobacco, cotton, and also food crops. The market for the two major cash crops, tobacco and cotton, is unpredictable and is affected by international factors beyond the country's control. On 
the other hand, the market for crops is mainly in the country's urban centers, so is predictable and is relatively stronger in the south and center than in the north. Supply however, tends to exceed demand everywhere and farmers returns are therefore generally very low. Consequently, rural household incomes are very low. Rural households also draw income from off-farm sources of casual labor (ganyu), sale of firewood, charcoal, and from migrant remittances from family members working elsewhere. In the lakeshore areas especially, southern region rural households generate income from fishing, including fishing 'ganyu' and fish trading. In the Shire Highlands especially the Thyolo-Mulanje Tea Estate area, most households are estate workers.

Two case study sites were selected, Balaka in the south and Nkhata Bay in the north, to explore and gain insight into actual lived experiences and local perception about the weather perturbations. These two study areas were purposively selected because they represent geographies with contrasting natural environment (biophysical conditions), livelihood systems and cultural and socioeconomic characteristics. They are ideal case studies for exploring climate variability as they epitomize a range of socio-ecological environments applicable to most parts of Malawi. 


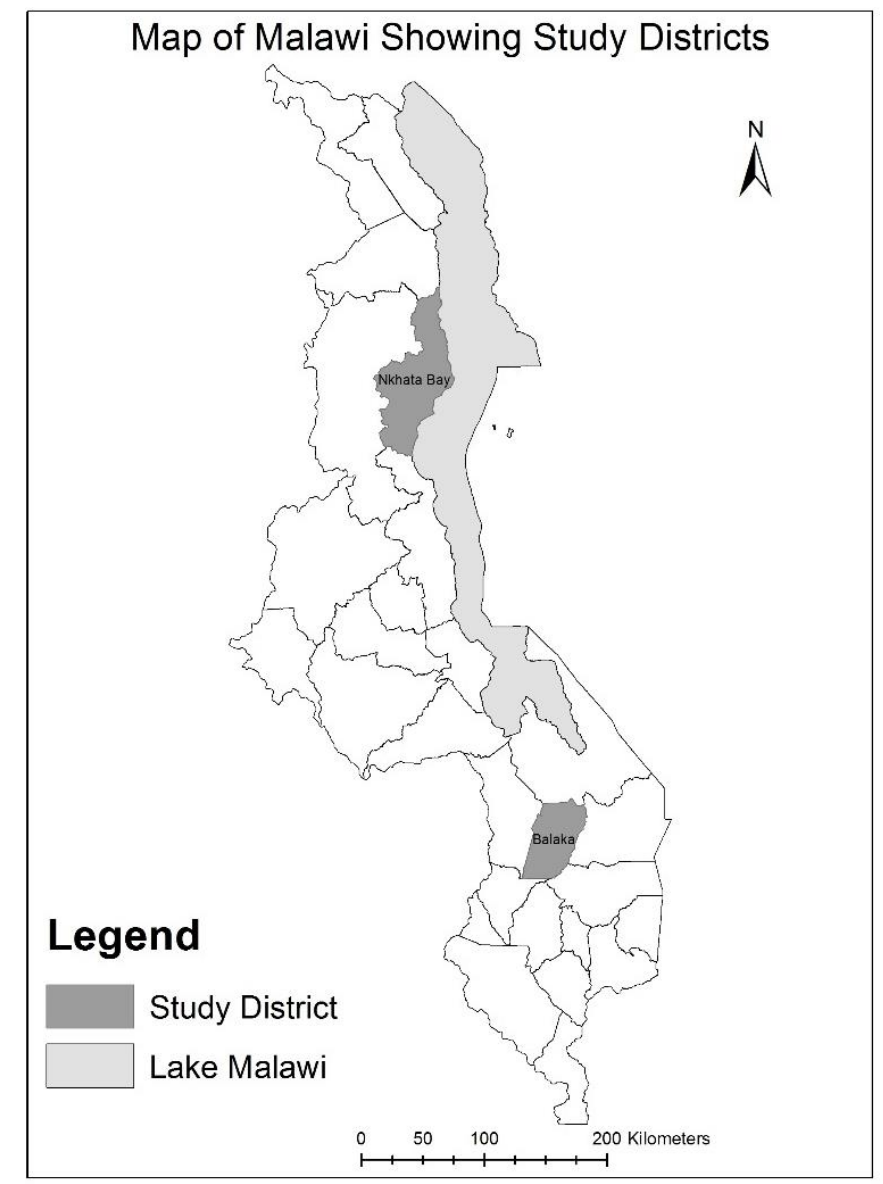

Figure 2. 1: Study districts

Nkhata Bay is located in the northern region of Malawi. It is characterized by high rainfall and rocky soils and comprises an escarpment leading down from the Viphya Mountains to the lakeshore. The average annual rainfall is $1598 \mathrm{~mm}$. The average temperature is between $23.5^{\circ} \mathrm{C}$. Besides having a fairly moist climate; rainfall is also spread out over a longer period than in other parts of the country. With high rainfall but poor soils, cassava is the dominant crop in the area. Other crops grown in the area include maize, sweet potatoes, rice, and bananas. Animal traction and livestock production are also limited. Local livelihoods vary according to ecological factors, i.e. topography and ecosystems in which the communities are located. Those along the lake are engaged primarily in fishing. Fishing is undertaken throughout the year, but peaks from midNovember to March following the rains. Generally, the area is described as 'food-rich' but 'cashpoor.' Like most parts of the northern region, Nkhata Bay area is largely rural (not urbanized) and commercially isolated with poor road network and there are limited markets for the agricultural produce. There are few sources of income available besides the sale of crops. 
On the other hand, Balaka is located in the southern region of Malawi. It has a relatively dry climate and is ecologically fragile and susceptible to frequent droughts. The average annual rainfall is $971 \mathrm{~mm}$. The average temperature in Balaka is $23.1^{\circ} \mathrm{C}$. The area is characterized by nearsubsistence farming, with fishing on a small scale amongst those living close to the Shire River. Crop production is relatively low due to agricultural droughts. The main crops include cotton, maize, and sweet potatoes. Unlike Nkhata Bay, Balaka is highly populated and connected to markets in the country's region with biggest urban population as well as its largest commercial sector. The 'poor' households earn income through ganyu, petty trade, firewood and charcoal burning and other collection-activities, feeding the market in the southern region's urban centers. Market prices of staple food vary seasonally. Prices are lowest during the harvesting period and highest during the 'hunger' season, which is between December and February. Most local markets are managed by private traders (i.e. following liberalization).

Based on our knowledge of the study districts through in-depth interviews in the localities we identified 3 communities in each study area. The communities were purposively selected to ensure adequate representation of the study districts. We then randomly selected households in each community.

\section{DATA COLLECTION}

A mixed methods approach was used to collect data. To draw on their complementarities, we conducted quantitative household surveys and also focus group discussions to explore and explain survey results. Six communities, three in Balaka and three in Nkhata Bay, were purposively selected to gather data on local farmers' perceptions about weather perturbations. In order to ensure adequate representation and minimize idiosyncrasies, study communities were selected to include all different socio-economic as well as biophysical characteristics. A systematic sampling technique was used within the communities to select the households. The survey was designed to include both male and female headed households. The heads of household were interviewed. If the household had the father and mother around, both were interviewed. A total of 515 households participated in the surveys. In the Nkhata Bay 298 households were interviewed: 103 females and 193 males. In Balaka 217 households were interviewed: 88 females and 129 males. The interviews were conducted by trained field assistants in the local languages of Tumbuka in the north and Chichewa in the south by trained field assistants. 
A total of 20 focus group discussions were conducted to gain deeper insights into farmers' perception regarding climate conditions. The focus group discussions included people of different social status i.e. traditional leaders and ordinary men and women, young and elderly, natives and immigrants to capture the different perceptions. The number of participants in each focus group discussion (FGD) ranged from 8 to 14. A total of 244 participated in the focus group discussions:106 males and 138 males. A discussion guide was used to facilitate and moderate the discussions which generally took about two-three hours.

The climatological data used in this study was obtained from the Malawi Department of Climate change and Meteorological Service. It included the continuous 46 years (i.e. for the period between 1970 and 2016) monthly and daily rainfall observations collected from Balaka and Nkhata Bay meteorological stations. Quality control of the data was largely carried out by the Malawi Department of Climate change and Meteorological Service. However, we noticed about 5 randomly missing entries in the daily rainfall data for Nkhata Bay which were reported as blanks. We applied the more flexible methods of group mean and regression to replace the missing entries. The two methods gave almost similar values for the missing entries.

\section{DATA ANALYSIS}

Data analysis was conducted to compare and validate farmers perceptions with meteorological observations, looking for agreement or disagreement. Exploratory and summary statistics were used to explore and analyze quantitative (household survey) data on perceptions of farmers on climate variability and change. Qualitative data was analyzed thematically. The transcribed discussions were rigorously coded, ordered and structured into specific themes. Key themes included among others: irregular timing and distribution of rainfall - change of the rainfall calendar, in which the rains start late and end early, frequent occurrence of dry spell, rains not coming at the right stage of crop production; reduced amount of rainfall; increased occurrence of lightning and thunderstorms; and increasing temperature.

Qualitative data was analyzed thematically. Through an iterative process, transcribed focus group discussions were explored, queried, visualized, and coded in NVivo 12. Word frequency query was conducted as preliminary analysis to get an overview of the discussions highlighted rains; 
changes; timing - start, end, early, late; planting; heavy, severe intensity - as most occurring themes, as displayed in the Word Cloud below.

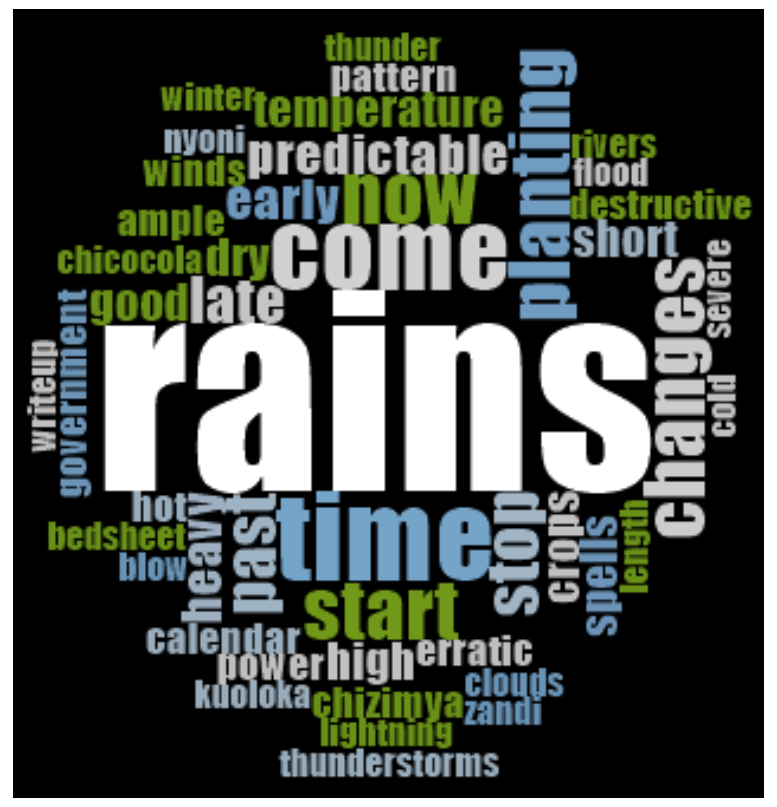

Figure 2. 2: Word cloud

These were then coded into specific themes which included: timing of rainfall; distribution of rainfall; change of planting/farming calendar; changes in the amount of rainfall; occurrence of extreme event; impact on farming activities among others.

Climatological data analysis involved the use of normalized precipitation anomaly series and Mann-Kendall test to understand temporal rainfall characteristics. The normalized rainfall anomaly series were used to assess inter-seasonal and annual rainfall variability. Mann-Kendall (MK) test was used to assess temporal trends in rainfall data (meteorological observations) at annual, seasonal, monthly and daily scales. MK is a non-parametric test, which is robust, insensitive to missing data and outliers and is recommended by World Meteorological Organization (WMO) for trend analysis in meteorological data (e.g. Ngongondo et al. 2011; WMO 1988). Several studies have employed MK to assess trends in rainfall and temperature data (e.g. Taylor and Loftis 1989; Yu et al. 1993; Xiong and Guo 2004; Basistha et al. 2009). MK was complemented with Sen's slope estimation to quantify the slope of the trends.

The acf () and pacf () functions in $\mathrm{R}$, which compute the autocorrelation and partial autocorrelation corresponding to the time series, were used to visually investigate the presence of serial correlation 
among the annual, seasonal, monthly and daily precipitation levels. Inspection of the serial correlation was conducted prior to applying Mann-Kendall test to ensure that the right measures are taken, specifically to use Mann-Kendal test in conjunction with bootstrapping in the case of the presence of significant serial correlation to correct for the P-value of the test for serial correlation.

\section{RESULTS}

\subsection{Climate change and variability: farmers' perception}

Although farmers from both locations i.e. Balaka and Nkhata Bay had difficulties defining the term "climate change", the household surveys and the focused group discussions showed that the they are more aware and sensitive to the changes in rainfall patterns that have occurred in their areas affecting their livelihoods when the term "rainfall changes" is used in questions. The household surveys show that almost all the surveyed smallholder farmers from both locations have observed changes in climatic conditions particularly rainfall. In Balaka, 208 (96\%) households indicated that rainfall has changed. In Nkhata Bay, a large share of households 290 (97\%) also reported that rainfall has changed.

Despite the geographic, biophysical, and social-cultural context differences between the regions, the farmers perceptions of the changing climatic conditions were comparable in the two case studies. In Balaka many smallholder farmers, about $41 \%$ observed that compared to the past rainfall has become more erratic meaning there is no predictable and reliable rainfall calendar any more. "In the past", farmers observed, "rains used to begin and fall consistently, now there are frequent and extended dry spells". This was followed by perceptions that the rainy season has shortened or reduced (i.e. 18\%), and that there is a late onset of rainfall (13\%), and that rainfall events were oftentimes more intense (12\%). Farmers reported that rainfall used to start in October and fall through to May. Unlike the past when they could grow two crops in a season as the season was long, now the rain ends well before crops mature. A small number (8\%) reported that rainfall has decreased. In Nkhata Bay a large number of smallholder farmers (31\%) perceived that rainfall is often intense and associated with strong winds, lightning and thunder. This was followed by perceptions that the rainfall was erratic (25\%), and that rainy season has shortened (17\%), and that rainfall start late $(11 \%)$. A considerable number $(7 \%)$ also reported that rainfall has decreased 
(Figures 2.3 and 2.4). To a large extent men and women stressed similar concerns about the changing rainfall patterns.

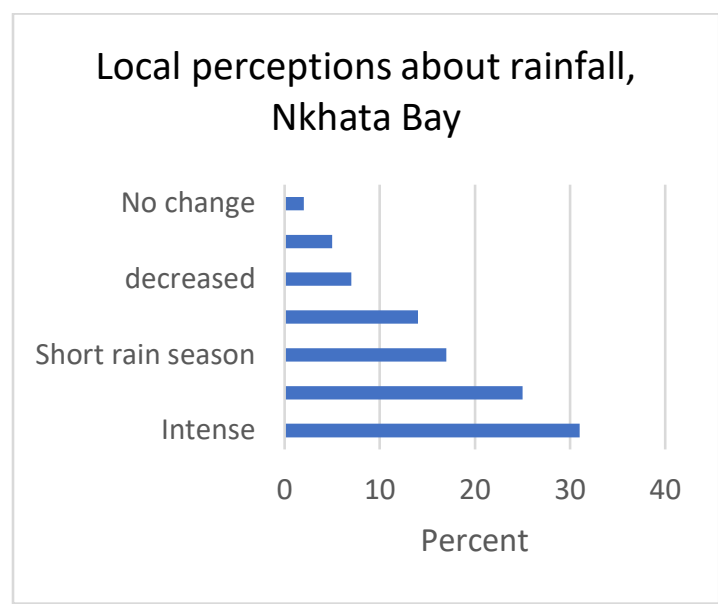

Figure 2. 3: Weather Changes observed, Nkhata Bay

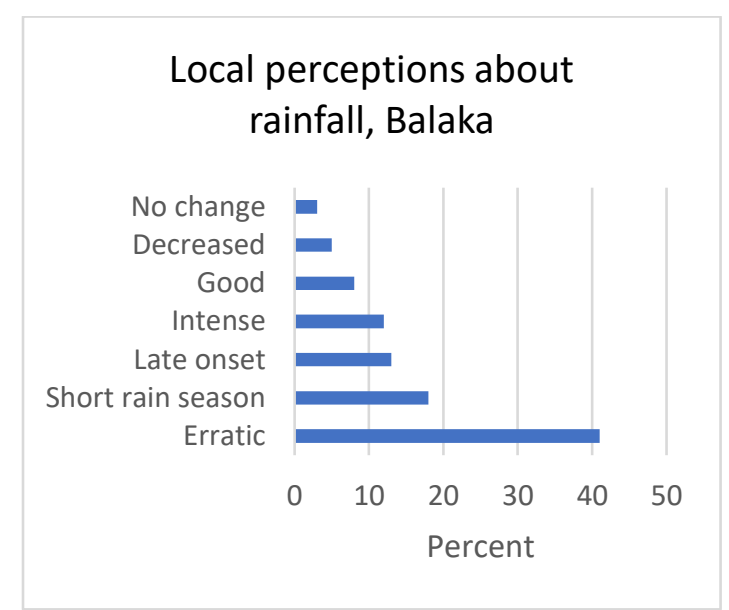

Figure 2. 4: Weather Changes observed, Balaka

Through focused group discussions smallholder farmers were able to expound on their actual lived experiences with regard to their perceptions about climate change. In the focused group discussions, farmers explained that they used to receive regular and reliable seasonal rainfall - the right amount of rainfall and on time. They mentioned that in the past rainfall would start in October or early November and they would plant by November, but now rains start in December. In Kavuzi, Nkhata Bay, for example, one farmer highlighted:

"It used to be that the very early rains called 'chicocola nyoni' would fall in June and July, and then by mid-October we would receive the first rains locally called 'chizimya lupya'. The main rains called 'kuoloka' would fall from November to January; In March and April we would have heavy rains called 'zandi' and the rivers would also flood." [old man].

Farmers further emphasized that the rainy season was shorter now and the frequency of dry spells has increased. Farmers explained that they used to have rains starting after mid-October through to late April or early May which would amply support more than one crop in a season. Nowadays, the rainy season is short, rain start in December, often punctuated with severe dry spells and ends 
early March. One older man in Mpamba, Nkhata Bay cited the dry spell that occurred in the 2014/2015 season as an example:

"This rainy season we had first rains on the 16th of October, so we planted because we are used to planting with early rains and we are also advised by agricultural extension officer to plant early. But then there were no rains up to the 21 st December and the temperature was very high in between" [very old man].

Farmers mentioned that the reduced amount but also the irregular timing and distribution of rainfall is negatively affecting their farming activities. One woman lamented: 'even when the rain come, it does not help us as it does not come at right stages of crop production, particularly maize crop.' Some farmers complained about incessant rainfall at harvest time, when they expect no rain, which destroy the little crop that managed to mature.

Farmers, further, commented that unlike in the past when they used to have proper amount of rain, almost every month in the rainy season now the rains are unpredictable. Often when they are expecting rain, they instead experience lightning and thunder and very strong winds that blow the clouds away, which stops the rains. In Sanga, Nkhata bay (along Lake Malawi) the locals mentioned that frequent occurrence of strong winds over the lake in the rainy season negatively affects their fishing livelihoods.

Apart from changing rainfall patterns farmers also mentioned about increasing temperature. Farmers in Mpamba, Nkhata Bay, for example, recounted :

'We were blessed with good climate here in Mpamba, it used to be cool in the winter months, but it is no longer the same, temperatures get very high all year round such that we don't even sleep with a bedsheet'.

\subsection{Climate change and variability: meteorological observations}

Results of the analysis of the monthly mean rainfall (for the period 1970 - 2016) reveal that there are differences in the distribution of rainfall between the two study sites. In Balaka, rainfall is concentrated in the months of November to March. The peak rainfall occurs in January. In Nkhata Bay, on the other hand, rainfall is spread in the months of November to May, with maximum rainfall occurring in March. Nicholson et al. (2014) in their study of mean rainfall climatology of Malawi also observed similar patterns that along the northern lakeshore region maximum rainfall 
occurs in March, and it is one of the wettest parts of the country with the longest rainy season. For the southern regions, they also observed that peak rainfall occurs in January. Mean rainfall analysis also revealed high year to year rainfall variability for both locations, Balaka and Nkhata Bay (Figures $2.5 ; 2.6 ; 2.7 ; \& 2.8$ ). 


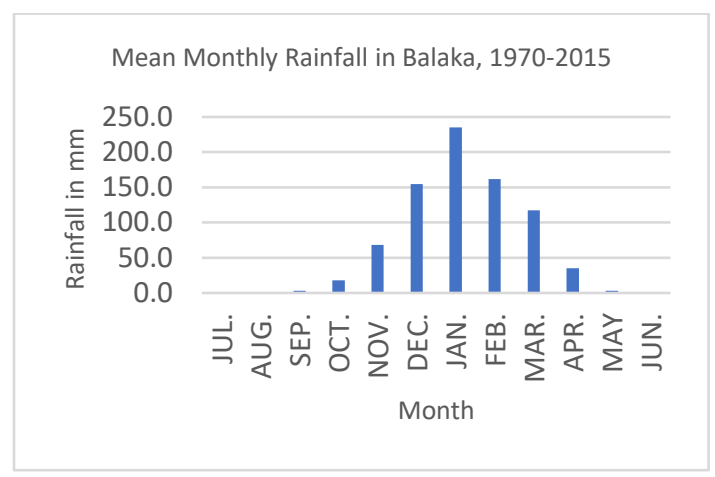

Figure 2. 5: Monthly rainfall, Balaka

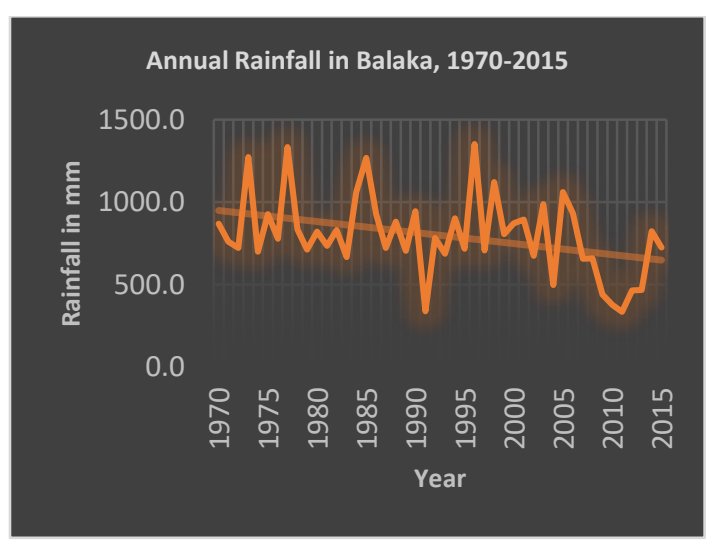

Figure 2. 6: Annual rainfall, Balaka

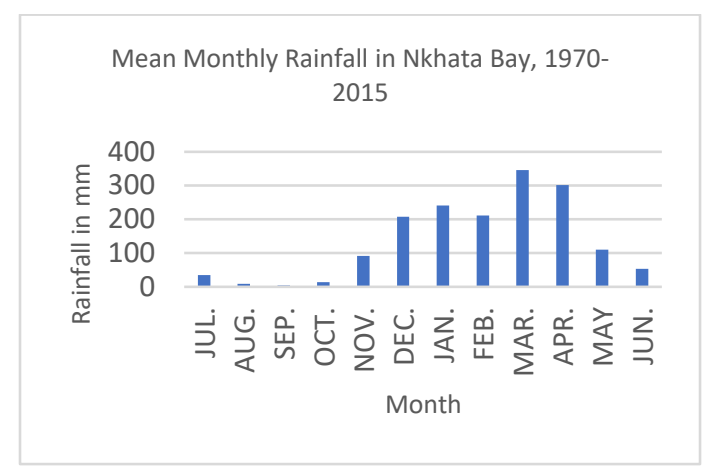

Figure 2. 7: Monthly rainfall, Nkhata Bay

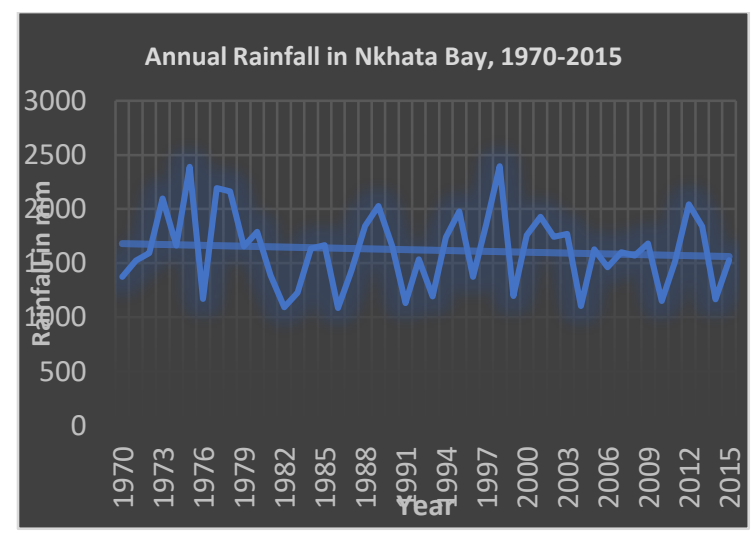

Figure 2. 8: Annual rainfall, Nkhata Bay

The results of MK test on rainfall series in Balaka show that rainfall has decreased over the period 1970 - 2015 (see Table 1 below). Annual and seasonal (November through April) rainfall series demonstrates significant decreasing annual and seasonal rainfall trends at average rates of $-5.8 \mathrm{~mm}$ /year and $-5.9 \mathrm{~mm} / \mathrm{season}$, respectively. Monthly analysis of seasonal rainfall series (not shown here) shows significant downward trends in November, December, February, March, and April at average rates of $-1.1,-2.0,-1.7,-1.7$ and -0.7 , respectively. Only the month of January demonstrated a positive trend, but it was not statistically significant. Daily analysis of the rainfall series also demonstrates statistically significant decreasing trends in the number of rain days 
annually and seasonally as well as for the months of November, March, December (marginal) and April (marginal) (not shown here).

Statistical analysis of meteorological data from Nkhata Bay also reveal decreasing trend in precipitation between 1970 and 2015. Annual and seasonal (November through April) rainfall series demonstrates decreasing annual and seasonal rainfall trends at average rates of $-1.8 \mathrm{~mm} /$ year and $-1.3 \mathrm{~mm} / \mathrm{season}$ ), respectively. While the annual and seasonal rainfall series show decreasing trends, this downward trend is not statistically significant at 5\% level. Statistically significant decreasing trend, however, is demonstrated for the monthly analysis of seasonal rainfall series for December, March and May (marginal) at average rates of -2.4, -2.98, and -1.3, respectively. The month of March also revealed a significant decreasing trend in the magnitude of rain events. Statistically significant decreasing trends in number of rain days were demonstrated for the month of April.

Table 2.1: Trends in the Annual and Seasonal Rainfall

\begin{tabular}{|c|c|c|c|c|}
\hline Study site & Annual/Seasonal & MK & $P$ value & Sen's slope \\
\hline Balaka & Annual & -0.233 & $0.023^{*}$ & -5.756 \\
\hline 1970 - 2015 & Seasonal (November - April) & -0.233 & $0.023 *$ & -5.896 \\
\hline Nkhata Bay & Annual & -0.044 & 0.677 & -1.781 \\
\hline $1970-2015$ & Seasonal (November - April) & -0.037 & 0.712 & -1.281 \\
\hline
\end{tabular}

In order to get an overview of the start and end of rainy season from the meteorological observations, the definitions of onset and end of a rainy season by Tadross et al. (2009) were followed. According to Tadross et al. (2009) the onset of a rainy season is once $25 \mathrm{~mm}$ of rainfall has accumulated within 10d, without 10 consecutive dry days $(<2 \mathrm{~mm})$ occurring afterward. The end of a rainy season is defined as 3 consecutive dekads (after February 1) of $<20 \mathrm{~mm}$ each. The statistical analysis of the meteorological daily rainfall observation between 1970 and 2015 demonstrates that onset and end of the rainy season in Balaka and Nkhata Bay have shifted. Figures 
$2.9 ; 2.10 ; 2.11 ; \& 2.12$ show an increasing trend in the number of days between actual day of onset and the expected date of onset (i.e. after mid-October) and decreasing trend in the number of days between $1^{\text {st }}$ February and the end date of the rainy season for both locations, Balaka and Nkhata Bay. The changes however are statistically significantly only in Balaka and not in Nkhata Bay.

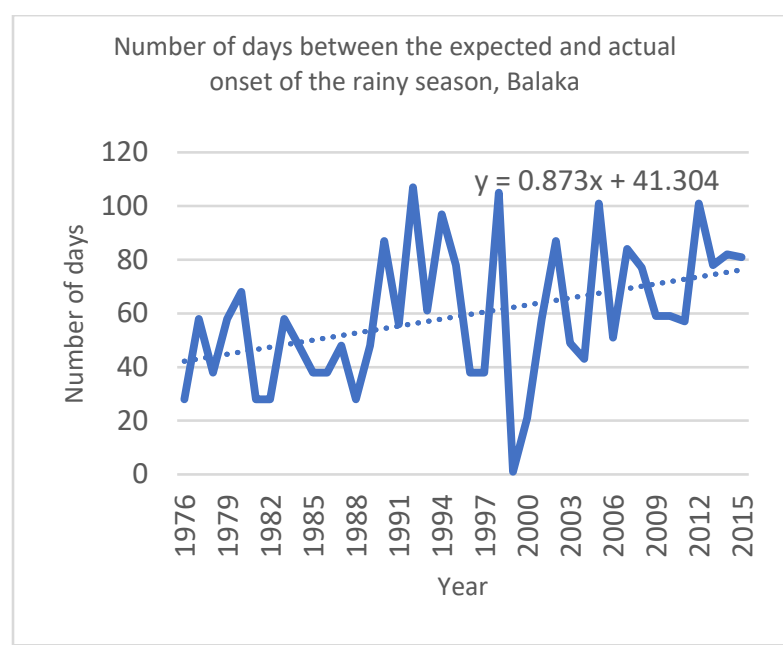

Figure 2. 9: Onset of rainy season, Balaka

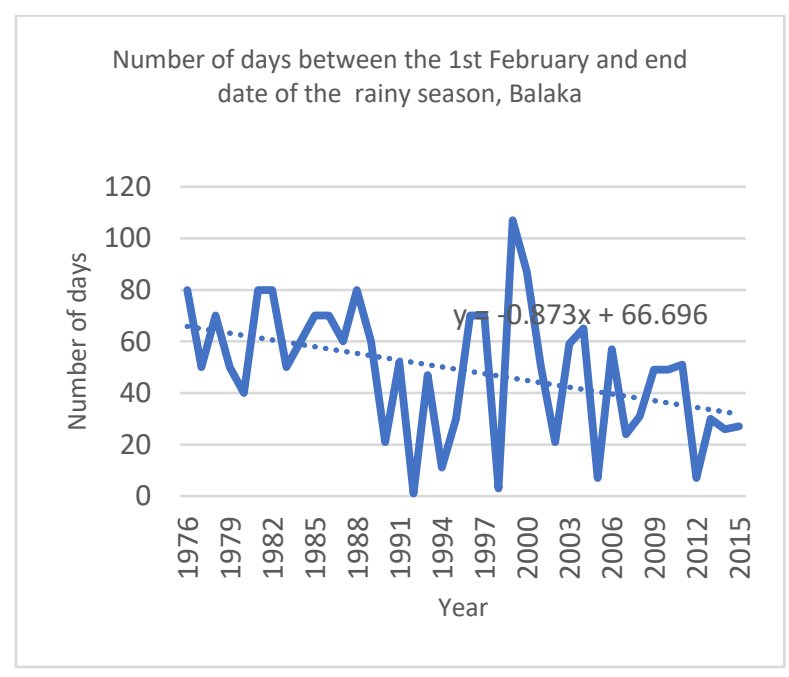

Figure 2. 10: End of rainy season Balaka

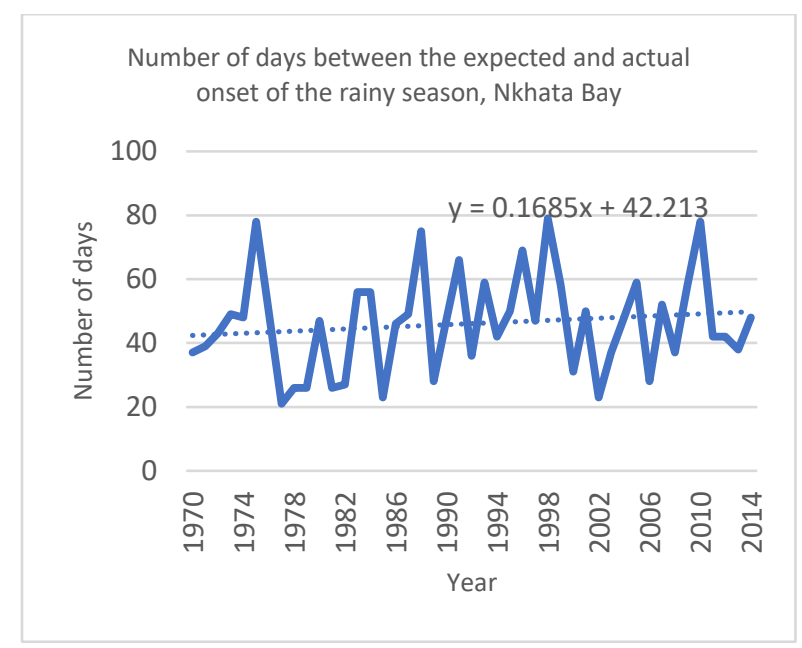

Figure 2. 11: Onset rainy season, Nkhata Bay

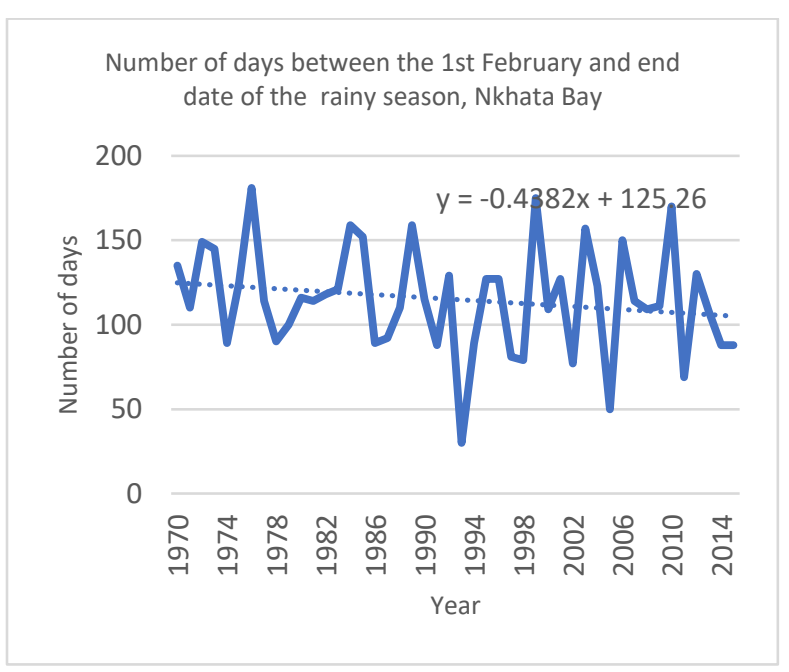

Figure 2. 12: End of rainy season, Nkhata Bay 


\subsection{Climate change and variability: perception \& meteorological observations}

Farmers' perceptions about climate variability and change had been considered less reliable (e.g. Held et al. 2005, Weber 2010). This assertion has been consolidated by studies that have found inconsistencies between local perceptions and meteorological data and questioned the validity of local perceptions (e.g. Hansen et al. 2004; Sanchez-Cortes and Chavero 2011; Sivakumar et al. 2005; Maddison 2006; Van Aalst et al. 2008; Ovuka and Lindqvist 2000), however, this is in sharp contrast to the results of our study. The results of our study illustrate that local farmers are sensitive and aware of the changes in the climatic conditions occurring in their areas.

Our study supports observations that local farmers are knowledgeable of the changes in the climatic conditions occurring in their areas. The results of our study show that local farmers' perceptions about rainfall variability and change in Balaka and Nkhata Bay are comparable with the meteorological observations. Farmers perceptions that rainfall has decreased closely corroborate with actual rainfall data from Department of Climate Change and Meteorological Services, which show a decreasing trend in precipitation between 1970-2016. Our findings of downward trend in precipitation resonates with the trends established by Ngongondo et al. (2011). Ngongondo et al. (2011) analyzing the temporal rainfall pattern for Malawi also observed decreasing trend in precipitation. Consistent with meteorological observations local farmers also correctly perceived that the rainfall pattern has changed such that the rainy season has shortened with rains starting late and ending early so the number of days in the rainy season have decreased. Furthermore, in line with farmers perceptions statistical analysis (SPI) of actual rainfall data show that frequency of dry spells in the rainy season have also increased over the period 1970-2016, with the increase mostly after 1990 .

While statistical analysis demonstrates that all the observed change in precipitation are statistically significant at $95 \%$ level for Balaka, not all observed changes in precipitation are statistically significant in Nkhata Bay at 95\% level. Farmers, perceptions of decreased precipitation might have been influenced dominantly by the statistically significant downward rainfall trend for the month of December. For the most part local farmers in the north plant their crops in December and 
bearing in mind that planting is tied to adequate rainfall, it is not surprising that local farmers interpreted the rainfall changes that have occurred in December as decreasing seasonal or annual rainfall. A significant decline of rainfall in March might have also influenced farmers' perceptions. As observed earlier, and also as established by Nicholson et al. (2014), March is the month when seasonal rainfall is at its peak in Nkhata Bay. Failure to see river flooding or at least flowing to their full capacity made farmers to perceive that rainfall has decreased.

The consistency of local perceptions with meteorological observation sturdily demonstrates that local perceptions about climatic conditions are reliable and valid. For centuries, from generation to generation, small holder farmers in Malawi have mainly depended on rainfall for their livelihoods. Farmers have, over the years, developed in-depth knowledge of their local climatic conditions, no wonder they are able to correctly notice changes in rainfall taking place in their areas. The results of our study thus agree with Maddison (1996), who also argued that people who depend on rainfall for their livelihoods are more likely to notice changes in climatic conditions. With low coverage (low network of rain gauges) meteorological stations, local perceptions serve, in many areas, as the only detailed source of information about climate variability change. Furthermore, together meteorological observation and local perceptions can provide more valuable insights.

Even though climate change is bringing climatic conditions beyond what local farmers have experienced in the past i.e. past climate perturbations, local farmers usually draw from their knowledge and perceptions to respond to climate shocks. As pointed out by Boissiere et al. (2013) farmers use local knowledge to interpret and respond to environmental perturbations. External intervention for facilitating local adaptation to climate change in Balaka and Nkhata Bay thus are more likely to be successful if they build on this existing knowledge of rainfall by the locals. Local knowledge can be useful for designing policy for dealing with impact of climate change. The strategies and initiatives to support local adaptation should be tailored according to local perception. With better and deeper understanding of local situations the local players (traditional leaders and politicians), government departments, as well as international organizations and civil society could be more effective and better leveraged to mediate local interventions, including rural livelihood coping and adaptation strategies, safety net programming, and food security and policy formulation. In essence, local knowledge is central to shifting from the usual and dominant 
unrealistic and palliative "top-down" perspective and measures driven by global climatic model scenarios to working from the "bottom-up".

\section{SUMMARY AND CONCLUSION}

This study attempted to examine farmers' perceptions of changes in precipitation and compared them with meteorological rainfall observations. The analysis aimed to assess if rainfall in the study areas is changing and if farmers are able to perceive the changes correctly. The study revealed that almost all the farmers in both locations, Balaka and Nkhata Bay are sensitive and knowledgeable of the climatic conditions in their areas and observed that rainfall has changed. Although local farmers did not have written records but rather based their perceptions on experience, when perceptions were compared with meteorological observations, the analysis indicated that what local farmers observed in both locations was consistent with meteorological observations. In Nkhata Bay it seems farmers perception of declining rainfall was largely shaped and influenced by changes observed in rainfall amount in December when they expect to plant their crops and March when they expect rivers to flood. The correctness at which local farmers perceived the changes in rainfall sturdily support the assertion that local perception of climate change is reliable and consistent with meteorological observations.

Local farmers provided more detailed information about changes in climatic conditions especially rainfall in their areas. We posit policy makers can and should harness such detailed, extensive, and correct knowledge of local weather condition that local farmers possess to facilitate effective and successful adaptation. To ricochet the arguments raised before (at the beginning), policies or initiatives and strategies that are tailored on local perceptions are more accepted. Local farmers react to change that they observe, adaptation strategies must be specific t locations needs. Thus, while climate change is global, adaptation policies and initiatives or strategies that are not tailored to local need are likely to flop. Building adaptation programs on local perceptions ensure local agreement and participation. Since local perceptions are an essential component of a local response, it is our recommendation that policy makers tap into local perceptions across the country such as unearthed in this study in order to facilitate and achieve sustainable and successful adaptation to climate change. 


\title{
Chapter 3: The Variability of Rainfall in Malawi and its Links to Sea-Surface Temperatures (SSTs): Case of Nkhata Bay.
}

\begin{abstract}
Year to year variability of Malawi rainfall and its possible association with sea surface temperature (SST) i.e. the El Nino Southern Oscillation (ENSO) and south-central Indian Ocean SST is investigated. Correlation analysis is employed to diagnose the link between annual/seasonal and monthly variability of precipitation over Malawi and Nino 3.4 index and south-central Indian Ocean SST for the period 1961-2012. Results show that anomalously warm SST over the southeastern Indian Ocean and the tropical Pacific Ocean, typical of El Nino conditions, is associated with dry conditions over a greater part of Malawi. The association between ENSO and occurrence of dry conditions in Malawi however is not uniform, both spatially and temporally; in some cases, there is a strong correlation, and other cases show moderate to no association, or the reverse. A relatively strong positive correlation between rainfall and Nino 3.4 SST is observed in the northern part of Malawi close to Tanzania and negative values are observed in the central and southern part of the county. In some parts of there is a recognizable negative association between rainfall variability at seasonal and monthly time scales, with south-eastern Indian Ocean SST time series after 1980.
\end{abstract}

\subsection{INTRODUCTION}

Climate change is one of the major environmental issues affecting southern Africa. Studies indicate that southern Africa is warming at range from $0.2{ }^{\circ} \mathrm{C}$ to more than $0.5{ }^{\circ} \mathrm{C}$ per decade (Hulme et al., 2001). The warming is accompanied by extensive changes in precipitation. Jenkinsi et al (2002) observed that rainfall has reduced substantially over the last 60 years. Available projections suggest that southern Africa, in general, will experience drier and more extreme conditions and increased frequency of drought (Wang 2005; Moise and Hudson 2008; Shefield and Wood 2008). In recent past, for example, different parts of southern Africa have been affected by devastating floods and severe droughts. There were devastating floods in 2015 and 2001 in southern Malawi and in southern Mozambique respectively and also more recently, in 2019. Severe droughts occurred 2015/16, 2003/4, 2002/3, and 1991/2 across the region. In some part of the region i.e. over parts of Botswana and Zimbabwe rainfall rates have declined, with decreases 
of more than $0.4 \mathrm{~mm} \mathrm{day}^{-1}$ (Hulme (1992). According Funk et al. (2008) the region is also experiencing a decrease in growing-season rainfall since 1980s.

Looming climate change is a serious threat to people's livelihoods in southern Africa as rain-fed agriculture constitutes a major source of livelihoods in the region (Arthur 2003). Agriculture in the region is finely tuned to climate, dependent on the timely onset of rainfall and its regular distribution through the rainy season. Even a slow, small change towards a worsening climate can increase climatic risks (Sivakumar et al. 2005, 53) on crop and livestock production. Changing climatic conditions are also associated with increased risk of livestock stress and diseases, and crop pests and diseases. For commercial crops, extreme events such as cyclones, droughts and floods lead to larger damages than only changes of mean climate (Zhao et al. 2005). Climate change is also negatively impacting on economies in the region, in 1992 for example drought reduced the GDP of Zimbabwe and Zambia by 8-9\% (Benson and Clay 1998).

Studies associated rainfall variability in southern Africa with changing SST patterns in the Equatorial Pacific and Indian Oceans (e.g. Nash and Enfield 2008; Cook et al. 2004; Allan et al. 2003; Mason 1995; Walker 1990; Lindesay 1988; Rocha and Simmonds 1997; Funk et al. 2008; and Chan et al. 2008; Van Loon and Shea, 1985; Nicholson and Entekhabi, 1986; Ropelewslu and Halpert, 1987, 1989; Janowiak, 1988). Lindesay (1988), for example, associates around $20 \%$ of the variance in late austral summer rainfall in the region with the Southern Oscillation Index. Usman and Reason (2004) also observed that there is a coherent and marked relationship between occurrence of dry spells and Nino 3.4 sea surface temperature (SST) anomalies. Rocha and Simmonds (1997); Funk et al. (2008); and Chan et al. 2008) have observed that, anomalously warm SST in the central Indian Ocean, which are partially independent of ENSO, dominate the rainfall response in southern Africa. According to Rocha and Simmonds (1997) and also Funk et al. (2008) rainfall deficit over Southern Africa is as a result of the SST warming in the central Indian Ocean, which sets up cyclonic low-level circulation anomalies over the ocean.

Although vulnerability to climate variability and extreme climate events is a major concern for southern Africa, efforts to understand climate variability and change are relatively sparse relative to other parts of the world (e.g. Desanker and Justice 2001; Sivakumar et al. 2005). Efforts to understand rainfall variability have mainly focused on regional studies. Little to no comparable knowledge exists at local or country scale regarding rainfall variability. Due to high spatial and 
temporal heterogeneity of rainfall over southern Africa (more heterogeneous than any other regions of the world), regional based studies or regional mean rainfall condition are less useful and applicable to agricultural livelihood activities. For many parts of southern Africa, changes in the mean rainfall vary on relatively small spatial scales and sometimes give rise to endemic droughts (Shongwe et al. 2009), countries face sometimes both floods and drought in different parts in a given year (Jury et al. 2006).

Thus, more focused rainfall studies are necessary to complement the regional studies and provide a more comprehensive understanding of rainfall characteristics. This is particularly essential for countries such as Malawi with an economy that is agriculturally based, and with agriculture that is predominantly rainfed (i.e. about 90\%). Single rainy season - (November to April) - rainfed subsistence agriculture constitutes almost the only source of livelihoods for about $85 \%$ of the population. With rainfed agriculture that is finely tuned to climate, increased frequency of occurrence of weather perturbations is negatively affecting people's livelihoods and the economy in general. Since 2000, Malawi has more than four times experienced livelihood failure in the form of a national food shortage. In 2015, floods and heavy rainfall affected about one million people, destroyed crops and property. Poor rains during 2015-2018 reduced water levels in the Shire River negatively affecting generation of electricity, causing serious power shortages with severe impacts on the economy. An understanding of rainfall at finer temporal and spatial resolution would more effectively contribute to a better understanding of rainfall variability and more useful for and applicable to smallholder farmers' adaptation needs.

Although Malawi is heavily dependent on rainfed agricultures and is prone to rainfall variability, very little is known about the factors governing rainfall variability i.e. variability in its climate has not been widely studied. Known studies include Nicholson et al. (2014); Ngongondo et al. (2011); Jury and Mwafulirwa (2002); and Jury and Gwazantini (2002). Malawi's rainfall regime falls in a climatic transition zone between Southern Africa and Eastern Africa. In any given year, southern Malawi may experience different weather conditions from northern Malawi suggesting that the rainfall regimes may be different. Thus, Malawi merits much more detailed study than regional studies which usually report only average climatic conditions. 
The present study builds on earlier studies on climate variability. We investigate the association between rainfall variability in Malawi and Nino 3.4 SST time series at country scale and SST over the south-central Indian Ocean time series at local scales. The duration or length of growing/rainy season, the length of dry spells, and their frequencies are analyzed to understand how changes in agriculturally relevant rainfall characteristics are associated with or mediated by SST patterns. The rest of the paper is organized as follows: Section 2 lays out the context for the study and describes the study area; Section 3 describes the data source and data analysis methods used in the study; Section 4, examines the changing rainfall patterns and the association with SST anomalies and how local smallholder farmers livelihoods are mediated by the changing SST patterns; and finally, Section 5 briefly concludes the study.

\subsection{STUDY AREA}

The study focuses on Malawi (Figure 3.1 below). Landlocked and with a population of about 18 million, Malawi is located in tropical south eastern Africa, latitudes 9-17 ${ }^{\circ} \mathrm{S}$ and longitudes $32-$ $36^{\circ} \mathrm{E}$. It covers an area of $118,484 \mathrm{~km}^{2}$. Lake Malawi, part of the Great African Rift Valley, covers two-thirds the length of the country in the east. To the west, Malawi rises to a plateau of $1,500 \mathrm{~m}$ with north-south oriented mountains reaching 2,500m (Jury and Mwafulirwa 2002). With a varied topography, the main landforms are the highlands, escarpments, plateaux, lakeshore, the upper Shire Valley, and the lower Shire Valley. 


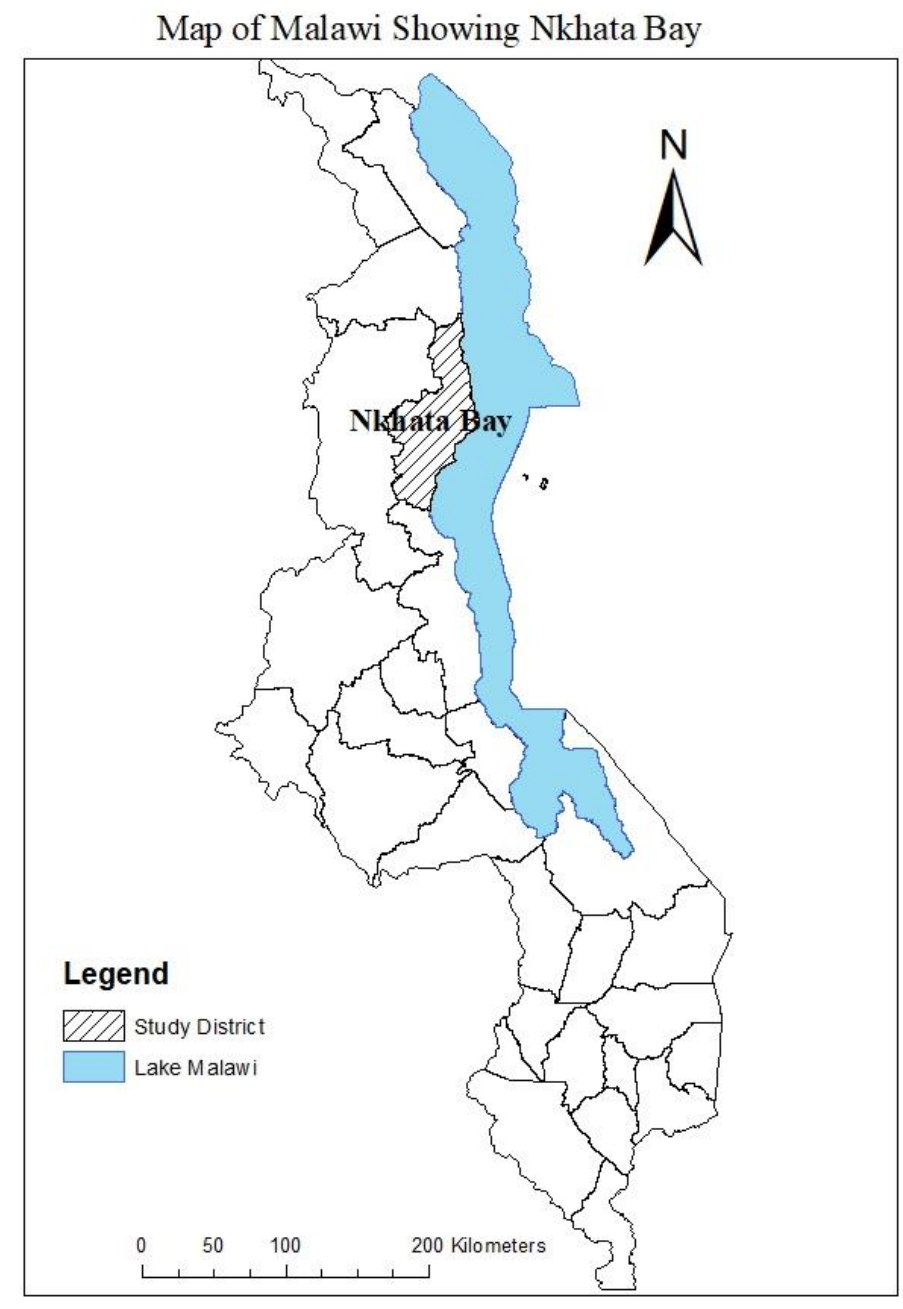

Figure 3. 1: Study District

Generally, the country experiences savanna climate with a single rainy season from October to March. Mean annual rainfall is in the order of $800 \mathrm{~mm}$ to over $1600 \mathrm{~mm}$ (Nicholson et al 2014). Average daily minimum and maximum temperatures in November, the hottest month, are $17^{\circ} \mathrm{C}$ and $29^{\circ} \mathrm{C}$ respectively; in July, the coolest month, temperature ranges from $7^{\circ} \mathrm{C}$ to $23^{\circ} \mathrm{C}$. Due to variations in altitudes there are wide differences in climate across the country. According to Ngongondo et al. (2011) the climate of Malawi is mostly influenced by the north-south migration of the intertropical convergence zone (ITCZ), the subtropical low-pressure belt, and Malawi's topography. 
Highly dependent on agriculture, Malawi's economy and rural livelihoods are largely undiversified. Rain fed smallholder subsistence agriculture (dependent on single rainy season) is the main livelihood source. Smallholder production is characterized by low output levels because of shortage of land due to high population density and rapid population growth and also low inputs, due to poverty. Smallholder farmers, however, produce about 80 percent of Malawi's food. The main agricultural products grown by smallholder farmers are maize, tobacco, cassava, groundnuts, pulses, sorghum, millet, sweet potatoes, and cotton. Maize is the main staple, covering about $76 \%$ of smallholder farmland. Tobacco is the dominant cash crop, providing $71 \%$ of export earnings and accounts for $60 \%$ of the country's earnings. Livestock accounts for less than $7 \%$ of the agricultural GDP in Malawi. Only 4\% of the households own cattle. A bout $2.3 \%$ of arable land is irrigated, and only around 3.3 percent of all rural households are beneficiaries of the irrigation schemes. Given the lack of irrigative infrastructure, agriculture is highly dependent on suitable climatic conditions and thus particularly highly vulnerable to weather shocks i.e. success of crop production is almost entirely linked with weather conditions.

Nkhata Bay district was selected as a case study to explore and gain insight into local weather. Located in the northern region of Malawi, Nkhata Bay is characterized by high rainfall and rocky soils and comprises an escarpment leading down from the Viphya Mountains to the lakeshore. The annual rainfall amount varies between $750 \mathrm{~mm}-1500 \mathrm{~mm}$. The annual temperature is between $27-$ $29^{\circ} \mathrm{C}$. Besides having a fairly moist climate; rainfall is also spread out over a longer period than in other parts of the country. With high rainfall but poor soils, cassava is the dominant crop in the area. Other crops grown in the area include maize, sweet potatoes, rice, and bananas. Animal traction and livestock production is also limited. Local livelihoods vary according to ecological factors, i.e. topography and ecosystems in which the communities are located. Those along the lake are engaged primarily in fishing. Fishing is undertaken throughout the year, but peaks from mid-November to March following seasonal rains.

\subsection{DATA AND METHODS}

The study utilizes several rainfall and sea surface temperature data sets. Meteorological rainfall data consisting of daily and monthly totals for 75 stations obtained from the National Meteorological Services. Figure 3.2 shows the locations of the meteorological stations used in the study. Monthly Hadley Centre Global sea surface temperature (HadISST) data set for the period 
1970 -2013 was extracted for south-central Indian Ocean (over a rectangular grid area 0-15 $\mathrm{S}, 60-$ $90^{\circ} \mathrm{E}$ ) using GrADS from the National Oceanic and Atmospheric Administration (NOAA) website: https://agupubs.onlinelibrary.wiley.com/doi/full/10.1029/2002JD002670. Containing data since 1871 to present at monthly time steps, HadISST provides the longest gridded SST data available at spatial resolution of $1^{\circ} \times 1^{\circ}$.

In this study station rainfall data is aggregated into four homogeneous regions - based on Nicholson et al 2014 - to explore rainfall patterns. Annual rainfall at each station is normalized to obtain the annual rainfall index (ARI) using the following procedure:

$\mathrm{ARI}=\quad \mathrm{R}-\mu \mathrm{R}$

$\sigma R$

Where: ARI is the annual rainfall index; $\mathrm{R}$ is the annual rainfall; $\mu_{\mathrm{R}}$ is the mean annual rainfall; and $\sigma_{\mathrm{R}}$ is the standard deviation of the annual rainfall values

The annual and seasonal rainfall indices for all stations in a region are spatially averaged to get the annual regional rainfall indices (ARRI) for the regions. Using similar procedure as (1), seasonal rainfall index was calculated. The annual values in (1) were replaced with a seasonal mean and a seasonal standard deviation.

The Indian Ocean SST is expressed as a 'normalized' anomaly: a departure from the long-term mean (1970 to 2013 ) over a rectangular grid area $0-15^{\circ} \mathrm{S}, 60-90^{\circ} \mathrm{E}$, divided by the standard deviation of SST over a rectangular grid area $0-15^{\circ} \mathrm{S}$ during this same period. The rectangular grid area is defined on the basis of previous studies (e.g. Funk et al. 2008). Nino 3.4 index time series for the sea surface temperature for the Tropical Pacific Ocean for the period $1970-2013$ were obtained from the National Oceanic and Atmospheric Administration (NOAA) from Climate Prediction Centre. 
A compound smoother $4253 \mathrm{H}$ or a five-point running mean was applied to the normalized precipitation series to visually explore the temporal variability and identify extreme dry conditions. The resulting rainfall pattern was compared with the normalized Indian Ocean SST time series and Nino 3.4 index to investigate associations between rainfall variability and SST. Rainfall time series in each region were then correlated with SSTs anomalies to provide quantitative measures of association between rainfall variability in Malawi and SST anomalies.

A nonparametric trend statistic, Mann-Kendall's tau (MK) for monotonic trends was used to assess temporal trends in the rainfall at fine temporal and spatial scales. MK is robust, insensitive to missing data and outliers and is recommended by WMO for trend analysis in meteorological data (e.g. Ngongondo et al. 2011; WMO 1988). MK also enables comparison of trends across different part of the region as it standardizes the trend between -1.0 and 1.0. Since MK does not give an indication of the magnitude of trend, it was complemented with Sen's slope estimation to quantify the slope of the trends. Trends for rainfall components relevant to farming activities such as onset, intensity, duration of seasonal rain, and wet and dry spells were analyzed and compared with SST anomalies. 


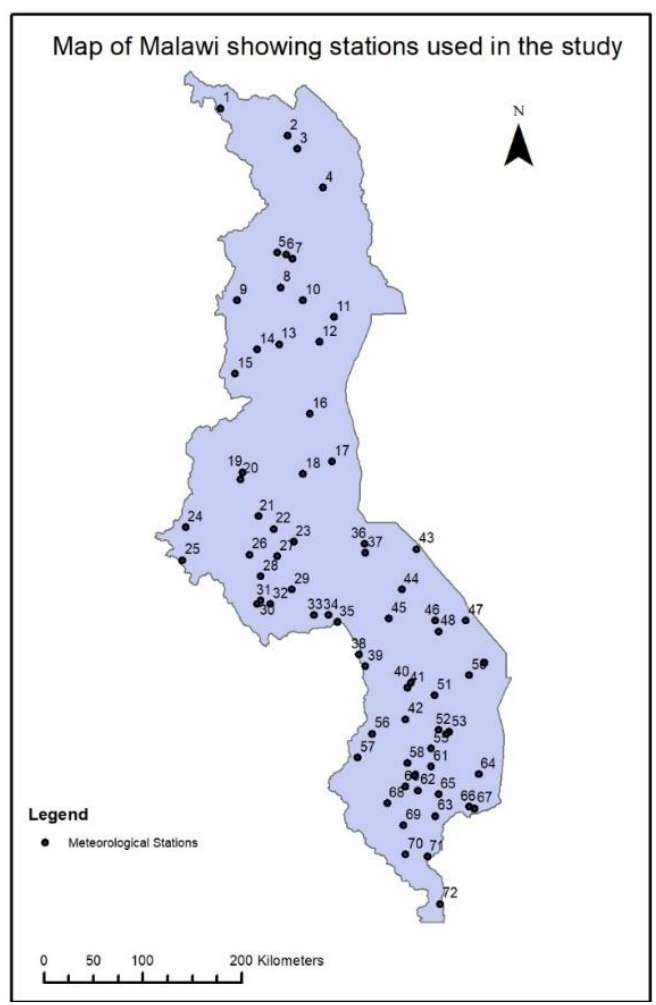

Figure 3. 2: Meteorological stations

\subsection{RESULTS AND DISCUSSIONS}

\subsection{Temporal variability of rainfall in Malawi}

Variability of rainfall at the inter-annual scale is plotted to explore temporal rainfall pattern. Annual rainfall series smoothed with a compound smother $4253 \mathrm{H}$ and a 5-point running mean show that rainfall over Malawi is highly variable (Figure 3.3)

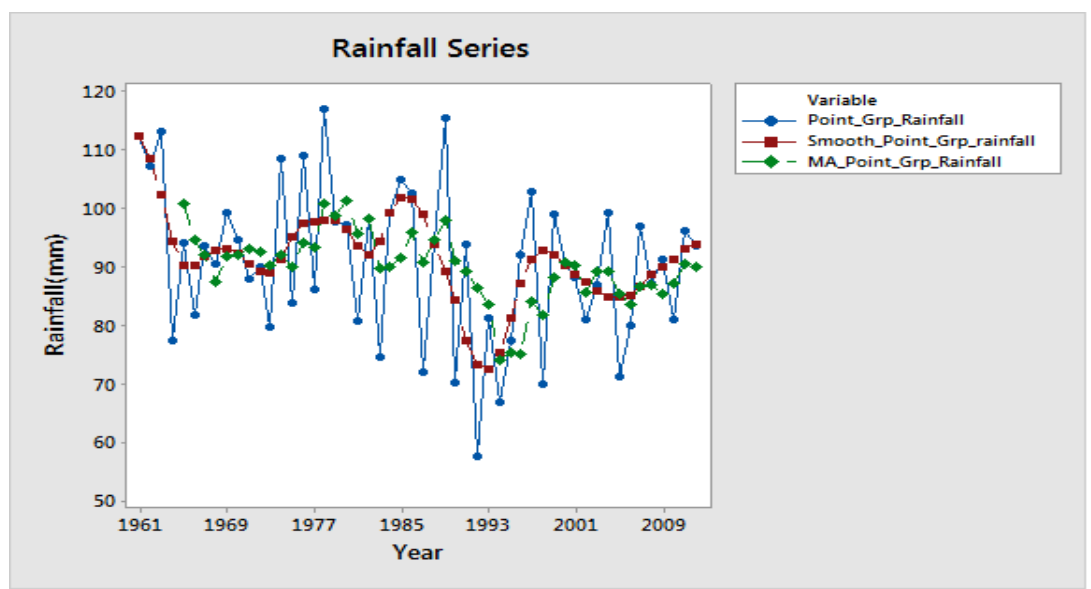

Figure 3. 3: Rainfall time series 1961- 2012 
Rainfall series anomalies averaged over Malawi during the 1961 to 2012 period is compared with Niño 3.4 SST anomalies to explore possible association. Figure 3.4 reveals a recognizable relationship between rainfall variability over Malawi and Niño 3.4 SST beginning in the 1980s. Since around 1980s there is decreased (increased) rain when the Nino 3.4 time series is positive (negative). Thus, El Niño years are associated with dry conditions (e.g. 1993, 1994, 1995 and 1997), whereas La Niña years are linked with wet conditions (e.g. 1985, 2009). However, years prior to 1980s showed no association between the rainfall and Nino 3.4 series.

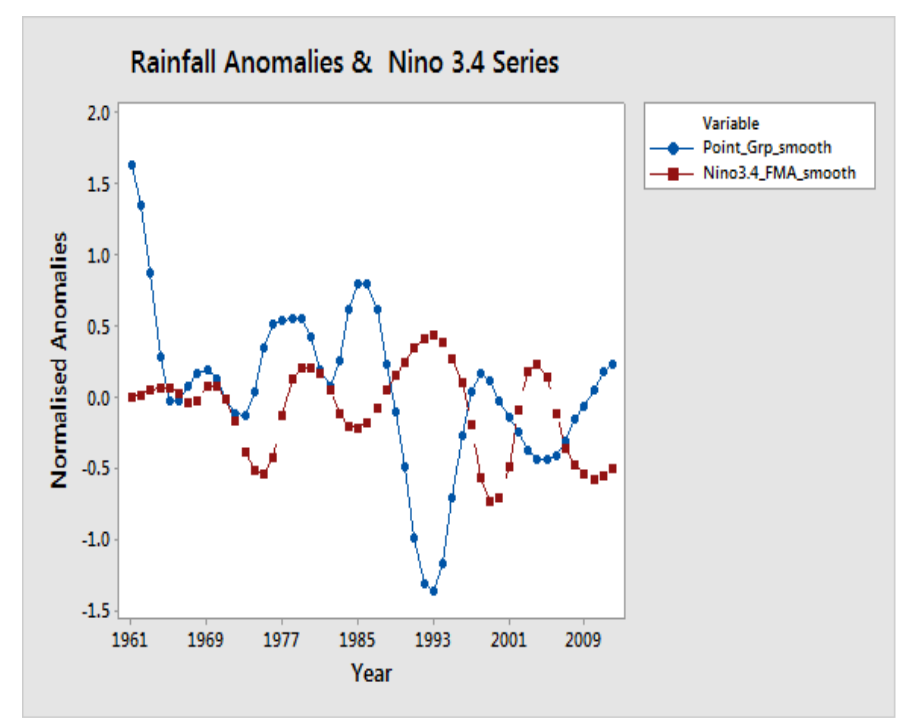

Figure 3. 4: Rainfall \& Nino 3.4 time series 1961- 2012

Further analysis reveals increased frequency of occurrence of dry conditions as in 1990, 1991,1992, 1993, 1994 and 1995 (Figure 3.4). Our observation agrees with Nicholson et al. (2014) who had observed that southern region of Malawi in the last two decades experienced several intense drought years. Funk et al (2008) and also Rocha and Simmonds (1997) studying rainfall variability over south-eastern Africa attributed occurrence of dry conditions to anthropogenic warming of the SSTs in the tropical Pacific and Indian Oceans, typical of ENSO events. They assert that warming of the south-central Indian Ocean $\left(0-15^{0} \mathrm{~S}, 60-90^{\circ} \mathrm{E}\right)$ which is linked to ENSO reduce onshore moisture transport and increases maritime precipitation, which is statistically and dynamically related to continental rainfall declines in southeastern Africa. Seleshi and Demaree (1995) also attributed decrease in rainfall in Ethiopia and Eritrea to the global climate change, which they assert, is perhaps enhanced by the ENSO phenomenon. 


\subsection{Spatial variability of rainfall in Malawi}

Exploring spatial link between annual variability of precipitation over Malawi and Nino 3.4 index for the period 1961-2012 show that association is not uniform across the country (Figure 3.5).

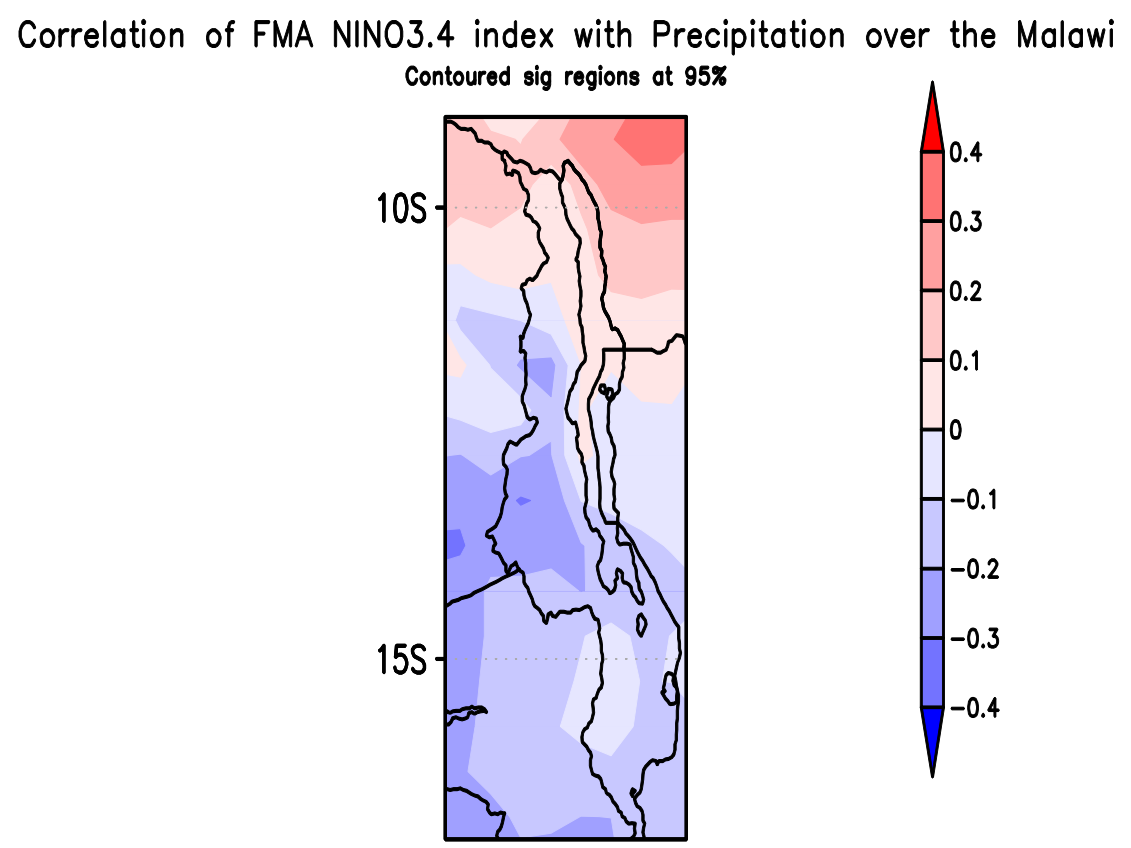

Figure 3. 5: Spatial association of precipitation and El Nino phenomenon

Anomalously warm SST in the tropical pacific, typical of El Nino conditions is associated with dry conditions over southern and central Malawi i.e. a greater part of Malawi. Similar conditions however have different effects in the northern part of the county. In the north El Nino condition or anomalously warm SST in the tropical eastern pacific is associated with wet conditions. Thus, there is a positive correlation between rainfall and Nino 3.4 SST in the northern part of Malawi close to Tanzania and negative correlation between rainfall and Nino 3.4 SST in the southern and central parts of Malawi. Above average wet conditions in southern and central regions, loosely, are associated with La Nina condition i.e. negatives Nino 3.4 index.

These findings for both temporal and spatial variability agree with Nicholson et al. (2014) who observed that rainfall variability in Malawi is not homogeneous. Northern Malawi has particularly diffrerent rainfall regime from that of central and southern regions. Jury and Mwafulirwa (2002) 
noted that northern Malawi lies near the transition zone of ENSO influence. The differences in rainfall regimes between southern/central Malawi and northern Malawi as observed in the present study and also previous studies, therefore suggest that it is essential therefore that national initiatives and efforts in response to rainfall variability should take into consideration these local variations.

\subsection{Local rainfall patterns and their association with SSTs}

Association between rainfall variability and SST was further analyzed at the lowest possible spatial scale. Following the homogenous rainfall regions delineated by Nicholson et al. (2014), four rainfall regions (Figure 3.6) were identified to explore the association between rainfall variability at local scale and El Nino phenomena or south-central Indian Ocean SST.

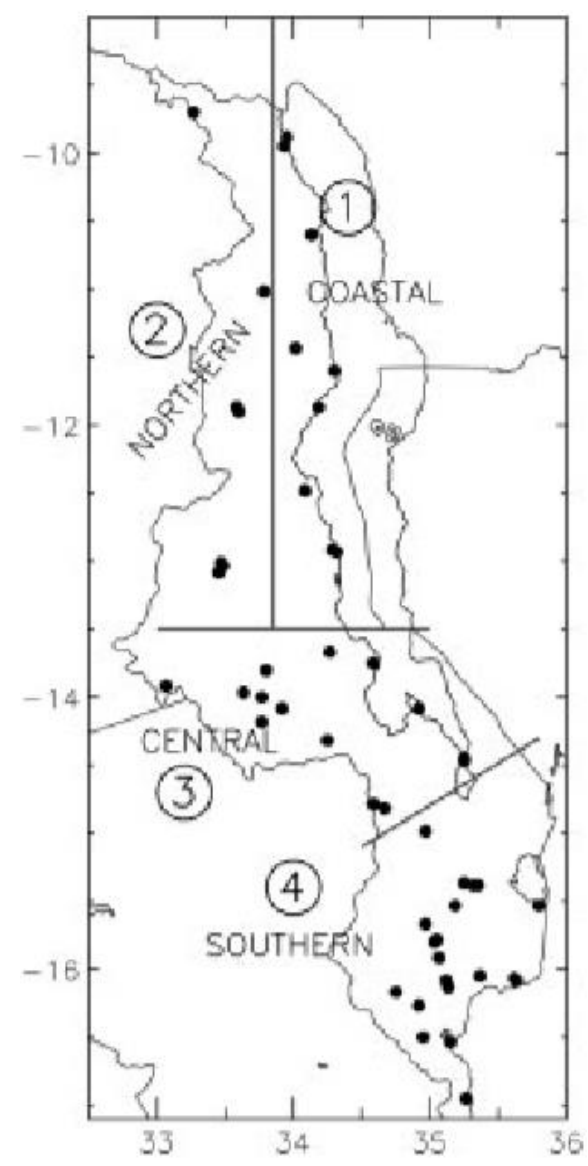

Figure 3. 6: Homogenous rainfall regions

(Source: Nicholson et al 2014) 
Computing the association between regional rainfall index and SSTs anomalies in all the four rainfall regions reveal recognizable association particularly after 1980s. Regional rainfall indices are negatively correlated to both the ENSO SST index and the Indian Ocean SST index. Correlation tends to be high with Indian Ocean particularly for rainfall regions 1 and 2 (Table 3.1). However, for rainfall regions 3 and 4 correlation is particularly high with Nino 3.4 (Table 3.1). In the four regions the highest correlation is between rainfall region 1 and the Indian ocean SST with correlation value of -0.745 . The corresponding correlation value for association between rainfall region 1 and the Nino 3.4 is -0.552. A similar pattern is seen in rainfall region 2 where corresponding correlation values for association with the Indian ocean SST and with the Nino 3.4 are -0.509 and -0.276 respectively.

On the other hand, the correlation value for association between rainfall region 3 and the Nino 3.4 is -0.592 while the corresponding correlation value for association with Indian ocean SST is-0.363. A comparable association is observed in rainfall region 4 where corresponding correlation values for association with the Nino 3.4 are -0.430 and with Indian ocean SST is -0.148 respectively. Comparison of the correlation coefficient values suggest that effects of the Indian Ocean SST in the northern region of Malawi are stronger than those of ENSO SST. In southern and central region, correlation of regional rainfall indices with the Nino 3.4 is found to be relatively higher than that of the Indian Ocean SST, with the Indian Ocean SST having the weakest influence in the central region.

Table 3.1: Correlation between regional rainfall index and SSTs anomalies

\begin{tabular}{lrr}
\hline & Indian Ocean SST & Nino 3.4 \\
\hline Region 1 & -0.745 & -0.553 \\
\hline Region 2 & -0.509 & -0.276 \\
\hline Region 3 & -0.363 & -0.592 \\
\hline Region 4 & -0.148 & -0.430 \\
\hline
\end{tabular}

Variability of rainfall in region 1, which has the highest correlation value of -0.745 between rainfall and the Indian ocean SST was plotted to display the temporal pattern of rainfall in the region (Figure 3.7). Figure 3.7 support the results of the previous studies (e.g. Funk et al 2008; Rocha and Simmonds 1997) that anthropogenic warming of the SSTs in the south-central Indian Oceans, is associated with decreasing rainfall over region 1. Figure 3.7 also supports the findings of 
previous studies which suggested that the Indian Ocean contributes more to regional rainfall variability in southern Africa (Goddard and Graham 1999; Goddard et al. 2001)

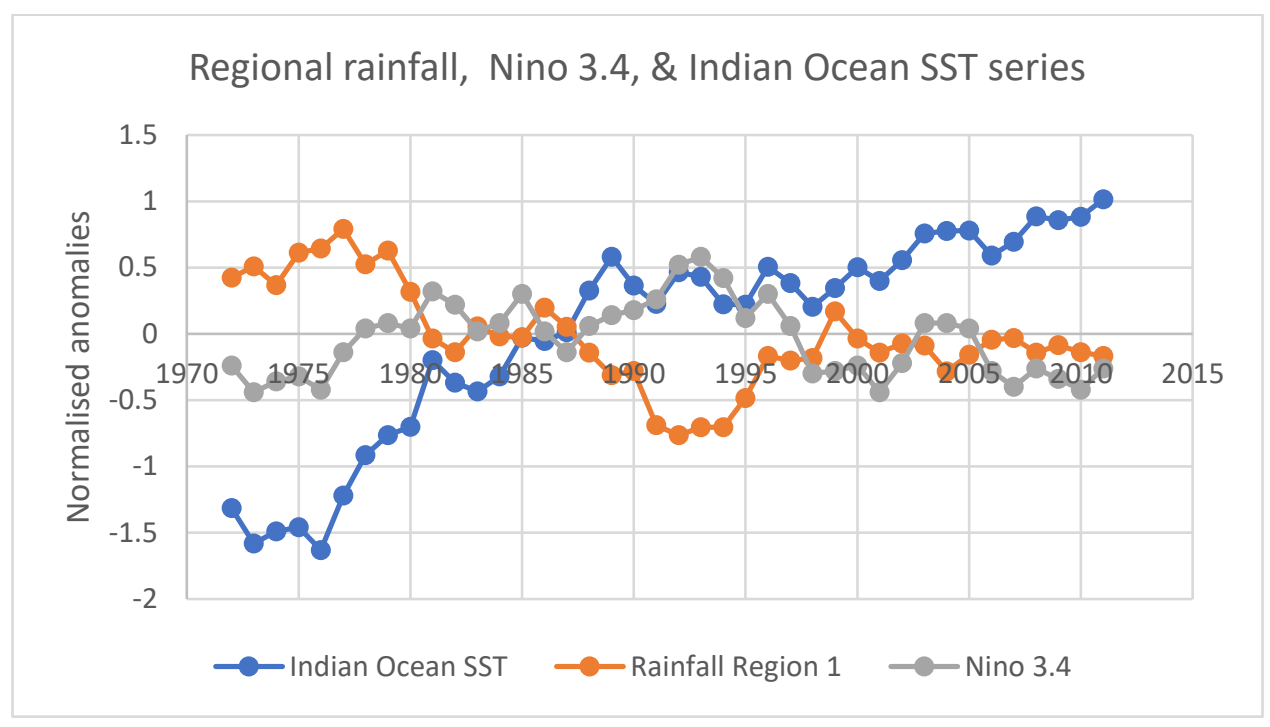

Figure 3. 7: Regional rainfall and SST series

\subsection{Monthly variability of rainfall and its association with SST}

Variability of rainfall and its association with SST anomalies was also analyzed at monthly time scale. Analysis of rainfall at monthly time scale is more appropriate for or applicable to agricultural livelihoods. For crops such as Maize, the staple for Malawi, the timing of rainfall fluctuations in a season may have adverse implications on the crop. Shortage of moisture at some stages in the growth of maize, particularly seed germination and milking stage may lead to failure of the crop. Nkhata Bay is one of the wettest parts of the country with the longest rainy season. Unlike the rest of the country where the rain season whereby the rain season is for 5 months from November April, in Nkhata Bay rainfall is concentrated in the months of November to May, with maximum rainfall occurring in March. Correlation analysis show that the decreasing monthly rainfall series are associated with the increasing south-central Indian Ocean SST series. Association is not evenly distributed throughout the rainy season. The beginning in which December has the strongest correlation and end of the rainy season are most sensitive to the southern eastern Indian Ocean SST. However, the association is much more concentrated in the late months of the season i.e. March, April and May. Corresponding correlation values for November - May are -0.387, - 0.674 , 
$-0.390,-0.079,-0.459,-0.428$, and -0.585 respectively. December has the strongest correlation the associations. February have the weakest association. Since 1980s there is recognizable association between increasing south-central Indian Ocean SST and decreasing rainfall in May in Nkhata Bay (Figure 3.8).

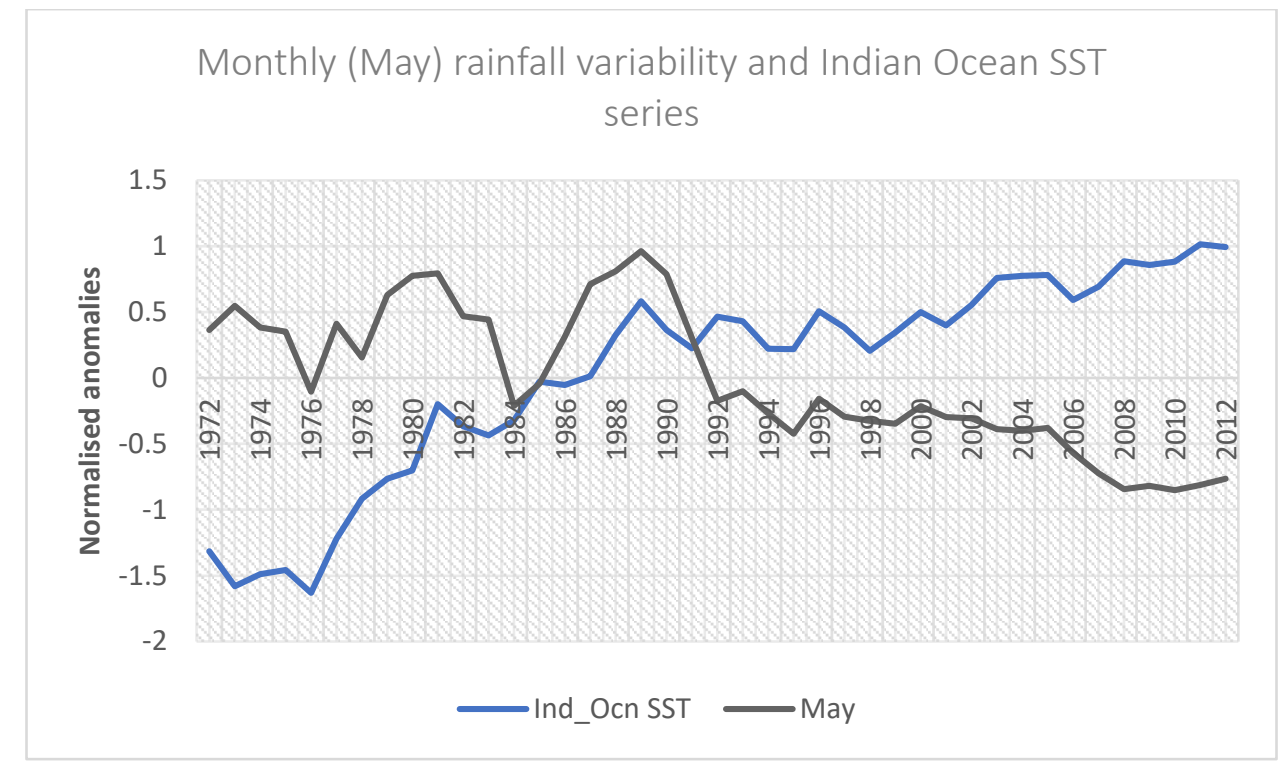

Figure 3. 8: May rainfall and SST series

Although rains at the height/middle of the season seem virtually unaffected, sensitivity of precipitation at the beginning and end of the rainy season to increasing SST of southern eastern Indian Ocean have serious practical implication for smallholders. As Funk et al 2008 pointed out the trend persist or intensify. Increased likelihood of failure or decreasing precipitation at the beginning and end of the rainy season implies shortening of the growing season. Local farmers in Nkhata Bay and Balaka in chapter 2 had observed that rainfall season is shortening. Farmers observation were substantiated by meteorological records which showed a decreasing trend in the number of days between $1^{\text {st }}$ February and the end date of the rainy season for both locations, Balaka and Nkhata Bay. Further analysis (Figure 3.9) show that the length of the growing/rainy season (i.e. decreasing trend in the number of days between $1^{\text {st }}$ February and the end date of the rainy season) is negatively associated with increasing SST over the south-central Indian Ocean. 


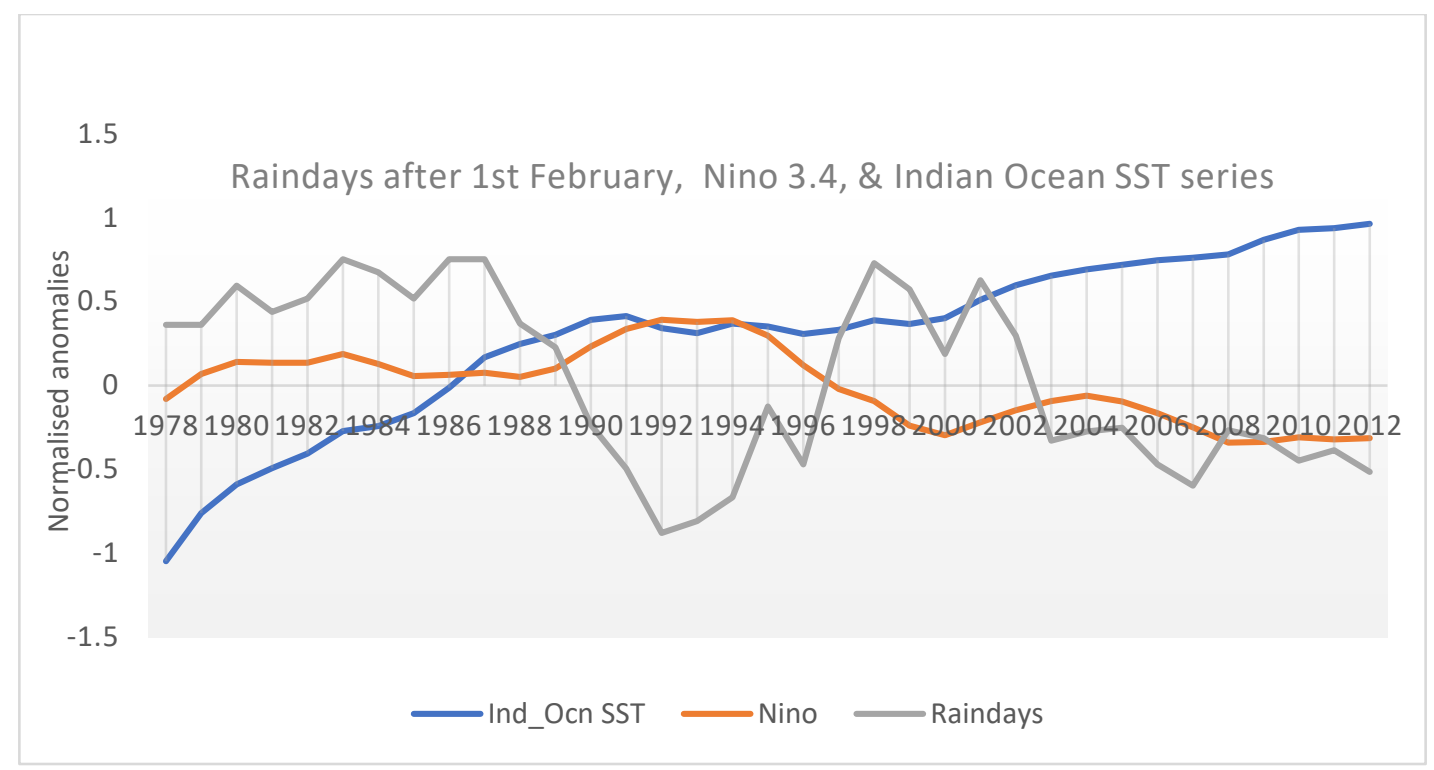

Figure 3. 9: End of rainy season and SST series

With the specialized agriculture (i.e. maize monoculture) which is sensitive to moisture deficits, the increased frequency of occurrence of weather perturbations is negatively affecting people's livelihoods. With the knowledge that the anthropogenic warming of the south-central Indian Ocean will persist or intensify, there is fear that without effective adaptation, the rural livelihoods crisis is likely to persist.

\subsection{CONCLUSION}

The study has shown that rainfall in Malawi is highly variable in time and space. Rainfall variability in Malawi is associated with SSTs specifically El Nino Southern Oscillation (ENSO) and south-central Indian Ocean SSTs. The study has also revealed that there is a tendency for precipitation variability in the central and southern regions of the country to be negatively linked Nino 3.4. Thus, anomalously warm SST in the tropical pacific are closely linked with occurrence of dry conditions over a larger part of Malawi. However, the association between ENSO and occurrence of dry conditions over Malawi is not uniform. Over the southern and central Malawi occurrence of dry conditions is associated with El Nino condition. La Nina years are linked with wet conditions. However, there is a relatively strong positive correlation between rainfall and El Nino condition i.e. positive Nino 3.4 SST in the northern part of Malawi close to Tanzania. La 
Nina years are linked with dry conditions. While some places show a strong correlation, and other places show moderate to no association, or the reverse. The study has also established that at local level in the north rainfall variability is strongly associated with south-central Indian Ocean SST while in the south rainfall variability is strongly associated with El Nino phenomenon. Perhaps most importantly, there are strong indications that variability is not distributed evenly throughout the rainy season. Instead, rains at the middle of the rainy season are less associated with the SST, whereas precipitation at the beginning, and particularly at the end, of the season are most prone to failure or are more sensitive to SST anomalies. 


\title{
Chapter 4: Climate Vulnerability Mapping: A Systematic Review and Future Prospects
}

Co-Authors: A. de Sherbinin, A. Bukvic, G. Rohat, M. Gall, B. McCusker, B. Preston, A. Apotsos, C. Fish, S. Kienberger, P. Muhonda, O. Wilhelmi, D. Macharia, W. Shubert, R. Sliuzas, B. Tomaszewski, S. Zhang

\begin{abstract}
Maps synthesizing climate, biophysical and socioeconomic data have become part of the standard tool-kit for communicating the risks of climate change to society. Vulnerability maps are used to direct attention to geographic areas where impacts on society are expected to be greatest and that may therefore require adaptation interventions. Under the Green Climate Fund and other bilateral climate adaptation funding mechanisms, donors are investing billions of dollars of adaptation funds, often with guidance from modelling results, visualized and communicated through maps and spatial decision support tools. This paper presents the results of a systematic review of 84 studies that map social vulnerability to climate impacts. These assessments are compiled by interdisciplinary teams of researchers, span many regions, range in scale from local to global, and vary in terms of frameworks, data, methods, and thematic foci. The goal is to identify common approaches to mapping, evaluate their strengths and limitations, and offer recommendations and future directions for the field. The systematic review finds some convergence around common frameworks developed by the Intergovernmental Panel on Climate Change, frequent use of linear index aggregation, and common approaches to the selection and use of climate and socioeconomic data. Further, it identifies limitations such as a lack of future climate and socioeconomic projections in many studies, insufficient characterization of uncertainty, challenges in map validation, and insufficient engagement with policy audiences for those studies that purport to be policy relevant. Finally, it provides recommendations for addressing the identified shortcomings.
\end{abstract}




\section{Visual abstract}

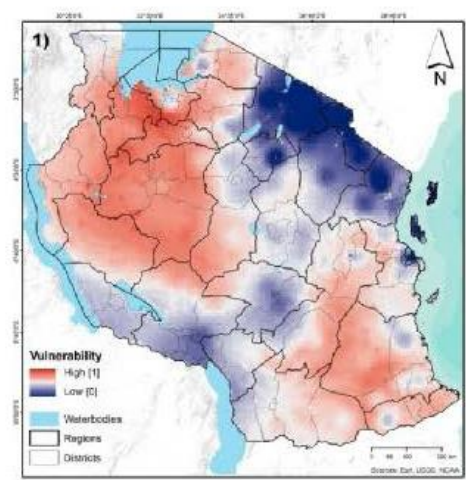

Vulnerability to Malaria in Tanzania, circa 2010 (Hagenlocher and Castro 2015)

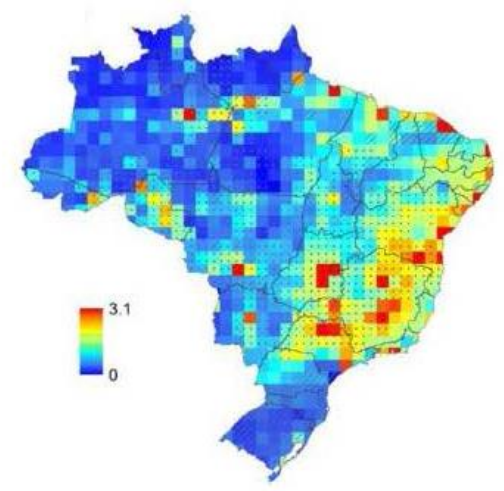

Socio-Climatic Vulnerability Index for Brazil circa 2010; hatching indicates regions where climate projection-related uncertainty is high (Filho et al. 2016)

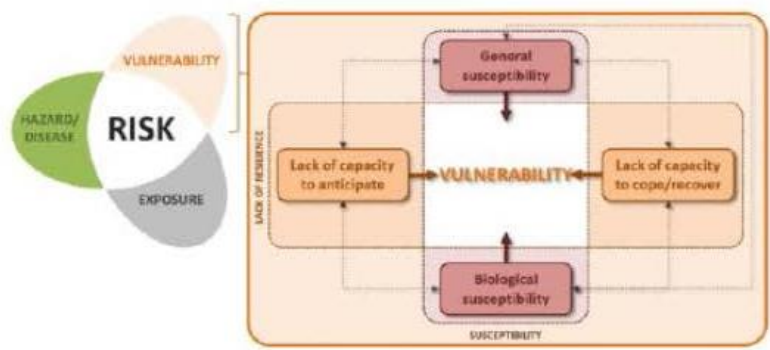

Example vulnerability and risk framing for malaria (Hagenlocher and Castro 2015)

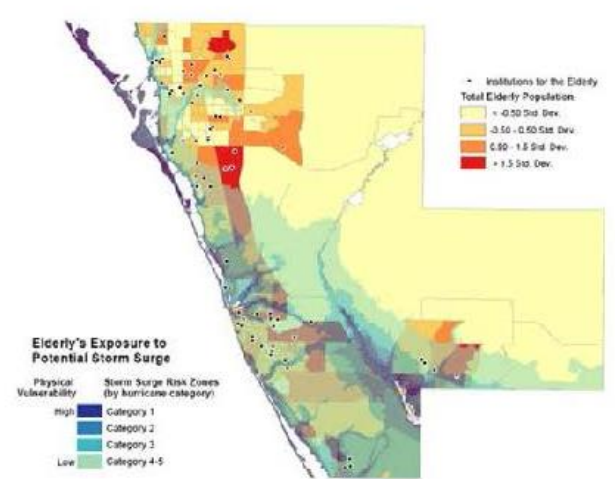

Physical vulnerability of the elderly to potential storm surge in Sarasota County, circa 2010 (Wang and Yarnel 2012)

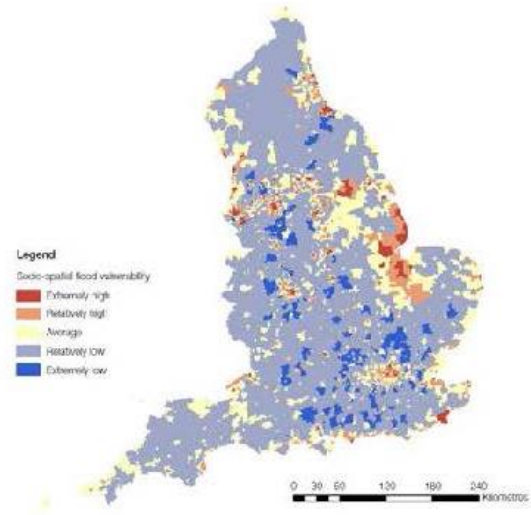

Socio-spatial flood vulnerability in England (Lindley et al. 2011)

Maps of climate vulnerability have addressed a range of issues, such as (clockwise from upper left) vulnerability to malaria, socioeconomic vulnerability to future climate risks, vulnerability to floods, and vulnerability of elderly to storm surge, with a range of framings (center). 


\section{INTRODUCTION}

With the advent of the Green Climate Fund and other bilateral climate adaptation funding mechanisms, donors are directing billions of dollars of adaptation funds toward high need areas based on climate vulnerability assessments, including climate vulnerability maps (Muccione et al. 2016, Klein 2009). The United Nations Environment Programme's (UNEP) Research on Climate Change Vulnerability, Impacts and Adaptation (PROVIA), a comprehensive effort to assess the state of vulnerability assessment for adaptation planning, states explicitly that measuring and mapping vulnerability is a top research priority (PROVIA 2013). Maps have been used to identify areas of social vulnerability to climate hazards such as flood, drought, and sea level rise (Notenbaert et al. 2010, Lam et al. 2015, Islam et al. 2013) and health impacts such as malaria (Hagenlocher \& Castro 2015), dengue (Dickin et al. 2013), extreme heat (Reid et al. 2009, Weber et al. 2015) and food insecurity (Kok et al. 2010, Thornton et al. 2008, van Wesenbeeck et al. 2016) (Figure 4.1). End users have found the information contained in vulnerability maps useful for planning adaptation assistance (de Sherbinin et al. 2017), understanding the underlying factors contributing to vulnerability (Preston et al. 2009), emergency response and disaster planning (Blaikie et al. 1994), risk communication and informing risk-reduction decision-making (Patt et al. 2005, Edwards et al. 2007), and land use management (UNDP 2010). Given the research and policy priority given to mapping vulnerability, it is imperative to develop a better understanding of suitable approaches to vulnerability mapping across a range of scales, regions, climate hazards, and thematic foci. 


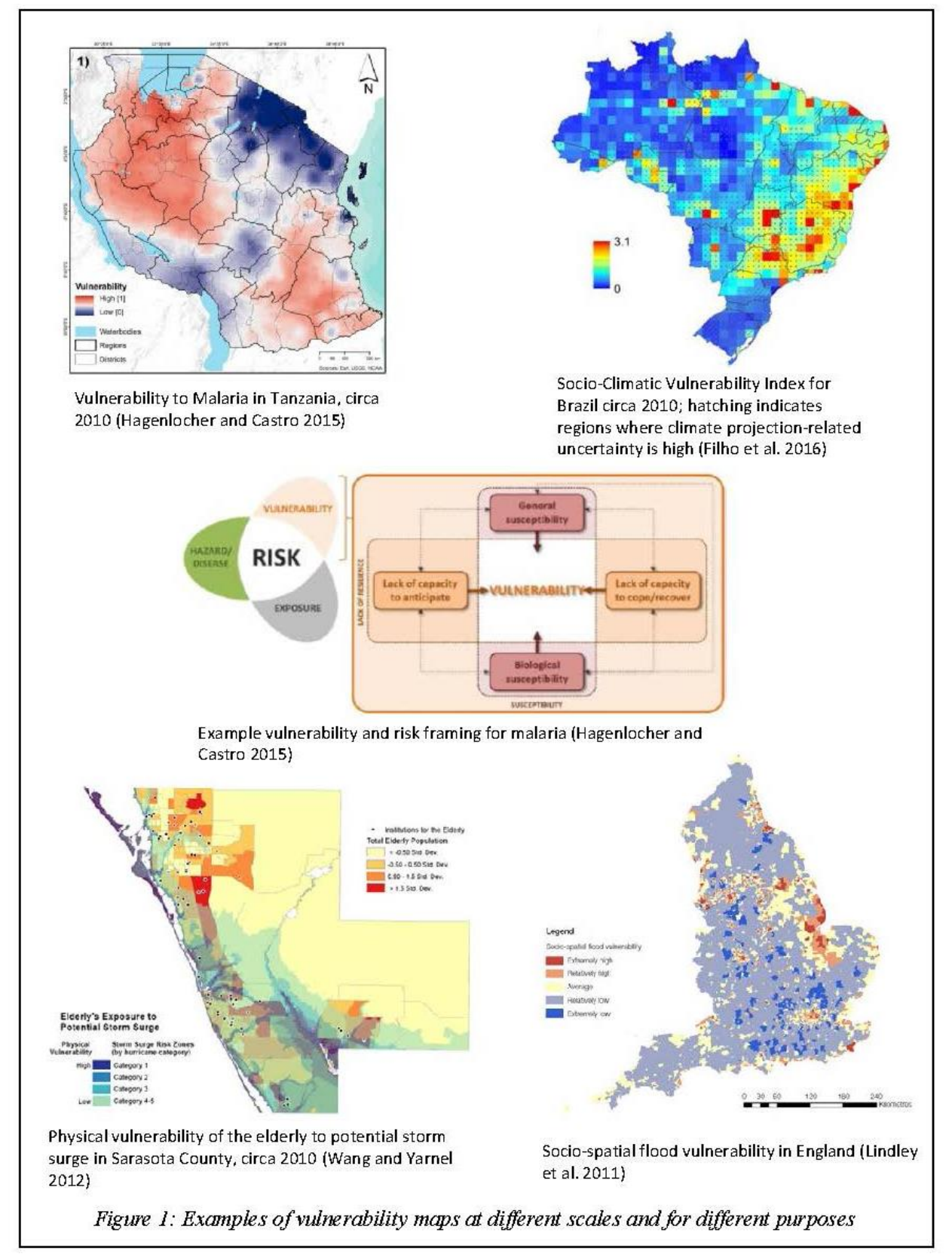

Figure 4. 1: Examples of vulnerability maps

Several literature reviews exist in allied areas. For example, Preston et al. (2011) reviewed the state of climate vulnerability mapping up until 2010 based on a sample of 45 studies that, contrary to this paper's focus on social vulnerability, included the vulnerability of economic sectors and ecosystems. de Sherbinin (2013) examined 15 global and nine regional hotspots mapping studiesincluding some derived purely from climate model outputs and others using process-based models to understand water or food system impacts - to identify common issues in underlying approaches 
and regions at risk from the most severe climate impacts. Kienberger et al. (2013) evaluated 20 mapping studies in respect to their treatment of scale, time periods covered, vulnerability and hazard focus, methods, and map products. Gall et al. (2015), based on a review of 1,006 journal articles, evaluated the degree to which disaster risk research is truly integrated across scales, stakeholders, knowledge domains, disciplines, and methods. Rufat et al. (2015) analyzed 67 flood disaster case studies with regard to measurement approaches for social vulnerability to floods. Rasanen et al. (2016) evaluated 125 climate vulnerability studies to identify interacting factors that affect vulnerability. And finally, Jurgilevich et al. (2017) reviewed 42 sub-national climate risk and vulnerability assessments to assess the degree to which changes over time (dynamics) were incorporated. While all of these studies have made valuable contributions to our understanding of vulnerability mapping and interdisciplinary research, there remains a need for a comprehensive and systematic review of the state of the art in mapping social vulnerability to climate change.

To bridge this gap, we systematically assessed 84 vulnerability mapping studies with the goal of encouraging further methodological refinement and identifying outstanding examples that could help to guide future work in this area. This study has three objectives: 1) characterize current practices in climate vulnerability mapping, 2) identify best practices and limitations, and 3) provide recommendations that chart the way forward for future efforts. This paper is organized as follows. The next section reviews the methods employed. This is followed by a characterization of the studies, a review of the current state of practice, and assessment of policy relevance. The last section points to future directions for research and practice followed by brief conclusions.

\section{MATERIALS, METHODS AND DATA}

The systematic review of vulnerability mapping case studies presented here draws on metaanalytical and synthesis methods (Qin and Grigsby 2016, Magliocca et al. 2015, Berrang-Ford et al. 2015). This included the development of study selection criteria, a standardized vulnerability mapping evaluation protocol, and a thematic coding scheme.

We adopt a broad definition of vulnerability, which is the degree to which a system or population is likely to experience harm due to exposure to perturbations or stress (Turner et al. 2003). For our selection criteria, studies had to include both climate hazard (or exposure) and differential social vulnerability. Climate hazard could be represented by past, present, or future climate variability, 
extremes, and change (trends or delta), and in some instances the hazard could be a function of climate extremes in combination with other factors such as land use changes that increase susceptibility to, e.g., floods and landslides. Social vulnerability, on the other hand, had to account for socioeconomic characteristics or institutional dimensions affecting the susceptibility of certain populations to climate change impacts and related risks (i.e., differential vulnerability) (Soares et al. 2012), and not simply population exposure. Figure 4.2 shows the mapping case study selection criteria applied in this project.

Mapping studies that met the aforementioned criteria were further screened for the following considerations: vulnerability assessment portrayed in cartographic form; mapping units based on subnational ecological/administrative units or grid cells; and publication after the Intergovernmental Panel on Climate Change (IPCC) fourth assessment report (AR4) public release (2007 and onwards). Because important literature in this area is in the form of reports to development agencies, we also reviewed policy reports, white papers, dissertations, and books/atlases in addition to peer-reviewed journal articles. In cases where vulnerability assessments were published in more than one format (e.g., report and peer-reviewed journal publication), all publications were treated collectively as a singular study.

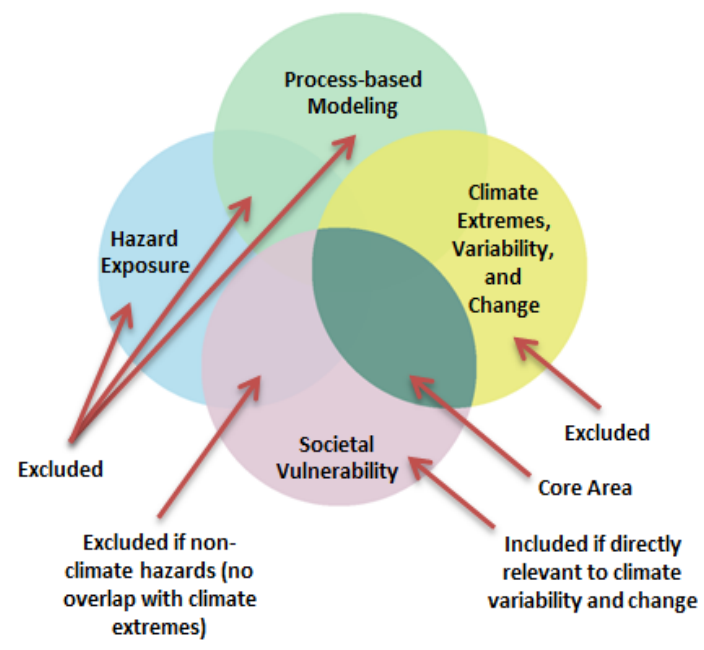

Figure 4. 2: Studies selection criteria for the vulnerability mapping systematic review

As shown in Fig. 2, we excluded studies that considered only the aggregate exposure of populations to climate hazards or that addressed social vulnerability without reference to climate impacts. We also excluded process-based modeling efforts that used climate model outputs for crop, hydrological or other studies relating to the vulnerability of biophysical systems. We chose 
to limit our research to English language literature since it is the dominant language of international science. To identify candidate studies, we conducted searches on Google Scholar and the Web of Science using combinations of the keywords "vulnerability mapping", "climate change", and "social vulnerability" (restricting searches to studies published after January 2007).

Table 1 shows that depending on the combination of terms used, the two search engines yielded results ranging from 129 to more than 10,000 entries. Owing to our interest in including gray literature such as reports produced by or for development agencies, we chose to use Google Scholar, focusing on the union of the three search terms (Table 1, row 3). We sorted the Google Scholar search results by relevance, and then evaluated the studies individually. Only studies that fully met our criteria were retained. Our total sample included 84 studies covering a range of geographic regions, thematic areas, and spatial scales (see Supplementary Online Materials (SOM) for details on the search methods, and Table S1 for the full list). The final sample comprised 62 journal articles, 18 reports, two white papers, one book chapter, and one dissertation. 
Table 4.1: Search results using online search engines: the Web of Science and Google Scholar (June 2016).

\begin{tabular}{|l|l|l|}
\hline Search keywords & $\begin{array}{l}\text { Web of } \\
\text { Science }\end{array}$ & $\begin{array}{l}\text { Google } \\
\text { Scholar }\end{array}$ \\
\hline "vulnerability mapping" & 10,087 & $>4,000$ \\
\hline "vulnerability mapping", "climate change" & 639 & 2,100 \\
\hline $\begin{array}{l}\text { "vulnerability mapping", "climate change", "social } \\
\text { vulnerability" }\end{array}$ & 129 & 547 \\
\hline
\end{tabular}

To develop the evaluation protocol, we collated available guidance regarding vulnerability assessment and mapping as well as the mapping of information for communication and decisionsupport (BMZ 2014, de Sherbinin 2014, Preston et al. 2011, Fussel 2007). The criteria included aspects such as clear identification of the external hazard and valued attributes of the socioeconomic system, a sound conceptual framework, evaluation of data layers, testing of alternative integration and aggregation schemes, proper selection and use of climatic data, sensitivity analysis, communication of study limitations and uncertainty, input data citation, and adherence to basic cartographic conventions. The authors and four additional experts (see acknowledgments) then qualitatively examined the selected vulnerability mapping studies to benchmark the state of practice. Additional fields were included for thematic coding, such as disciplines of authors, region, and spatial extent. The evaluation protocol and thematic coding scheme were developed and implemented in Google Forms (see SOM Box S1 for the full list of fields and response options). While only the 84 studies published during the decade from 2007 to 2016 formed the basis for our statistical characterization of the literature (Section 3), more recent studies are used to illustrate good vulnerability mapping practice.

Initially, at least two coders reviewed each study. The evaluation criteria ranged from objective 'facts' to items that required some degree of subjective interpretation by the expert coders. In order to harmonize the coding for these subjective items, the authors met at a workshop in May 2017 and individual coders resolved differences through a re-review of the case studies. 


\section{RESULTS}

\subsection{Characteristics of the Studies}

Geographic coverage. Our sample covered a wide range of geographic regions (Fig. 4.3). Only five studies were global in scope. Of the non-global studies, 35\% were situated in Africa, 20\% each featured Asia and North America, followed by Europe (15\%), Oceania (5\%), and South America (3.8\%). In terms of country coverage, many studies are focused on the U.S. (10), followed by Germany (5), Australia, India, and Nigeria (4 each).

Top journals. The top five publication outlets of the sampled climate vulnerability assessments were Natural Hazards (8 studies), Climatic Change (6), Applied Geography (5), Global Environmental Change (3), and Natural Hazards and Earth System Sciences (3). The studies appear in a total of 38 different journals, with a strong representation of geography, health and interdisciplinary journals focusing on climate change or natural hazards.

Level of analysis. The level of analysis varied widely, and a few studies used multiple levels. The majority of studies in our sample were focused on local areas (e.g. watersheds or municipalities) (26 studies). The remainder bounded their mapping at global (6), continental (5), regional (10), national (19), and subnational (e.g., state or provincial) (18) levels (Table S1). Whatever the level, all studies examined units within those bounding areas, either using natural/administrative units or grids (see scale of analysis below).

Study goals. Authors cited a number of purposes for undertaking vulnerability mapping, and most studies cited more than one. Hotspots identification was the primary purpose of many studies (57 total), followed by adaptation targeting (37), methodological refinement (34), disaster risk reduction (34), spatial/development planning (21), strategic planning (12), baseline assessment (11), advocacy (6), and monitoring and evaluation (2).

Valued attributes. The studies in our sample cited a variety of valued attributes (i.e., the system or thing that may be harmed or lost owing to climate impacts) with most addressing more than one. Health was pre-eminent among them (35 total; heat-stress and nutrition led the list), followed by social impacts ( 33 total; poverty and demographic change were most often the focus), livelihood impacts (31 total; especially agricultural livelihoods), economic impacts (20 total; especially assets), and ecosystems as they relate to human wellbeing (5). 


\subsection{The State of Practice}

Here we assess the studies in terms of interdisciplinarity, vulnerability framing, indicators and aggregation approaches, data and projections, and treatment of uncertainty.

Interdisciplinarity. The field of vulnerability mapping is highly interdisciplinary; out of 80 studies with multi-authorship, 57 (71\%) had authors from two or more fields of study. Geographers were disproportionately represented in our sample, with $45 \%$ of lead authors from that discipline (Figure 4.3), followed by earth and environmental science (14\%), economics (10\%), agronomy and engineering ( $6 \%$ each), and a smattering of other disciplines. The disciplinary background of the authors appears to influence the degree to which the climatic exposure versus social vulnerability aspects were emphasized in the study. In some studies, the social vulnerability aspects were developed in great detail, but climate exposure metrics were weak (e.g., Kienberger et al. 2012, Udoh 2015, Lawal and Arokoyu 2015). In other studies, the opposite was the case (e.g., Kim et al. 2015, Piontek et al. 2013).

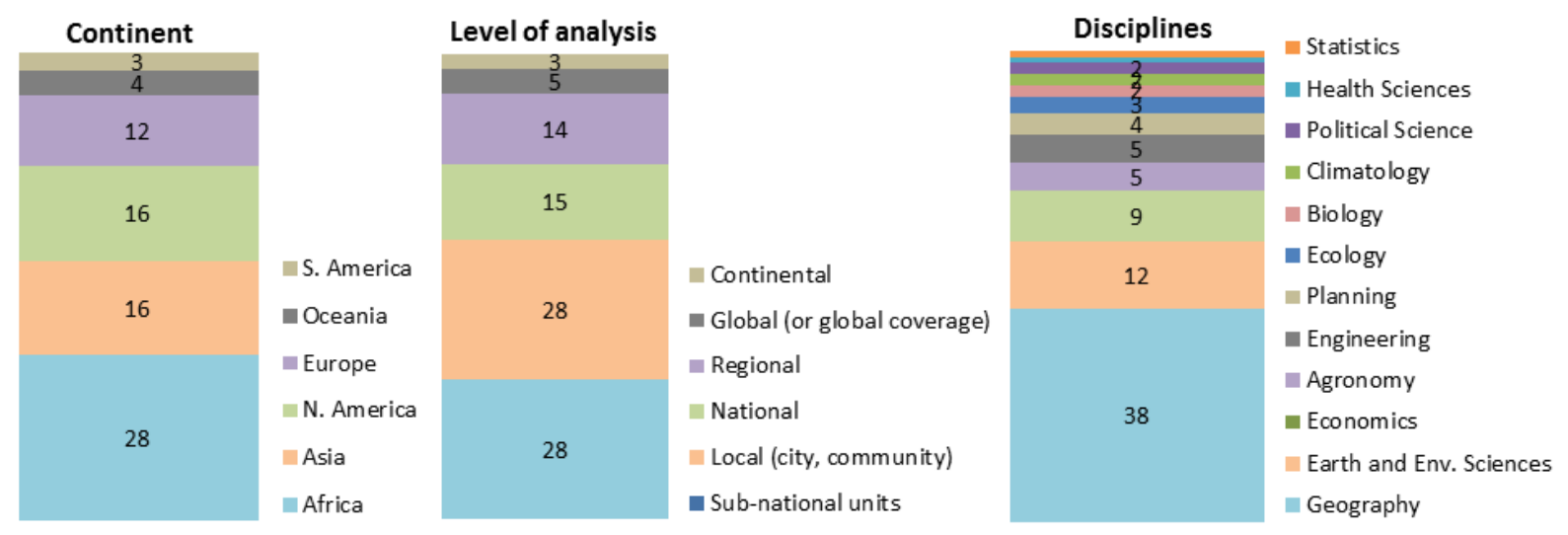

Figure 4. 3: Studies by Continent, Level of Analysis, and Discipline

Vulnerability framing. Close to $60 \%$ of the studies draw on the framings of vulnerability and risk developed by the IPCC Working Group II across several assessment reports. The IPCC Third Assessment Report (TAR) and AR4 vulnerability frameworks (McCarthy et al. 2001 and Parry et al. 2007, respectively) identify vulnerability as a function of exposure to climate hazards, on the one hand, and the sensitivity and adaptive capacity of the system or society on the other. In 2012, the IPCC Special Report on Extremes (IPCC 2012) introduced a risk framework, also adopted by the Fifth Assessment Report (AR5) (Oppenheimer et al. 2014), which distinguished between 
exposure and vulnerability, the latter combining the sensitivity and adaptive capacity elements of the earlier frameworks. The "vulnerability" element in this risk framing thus represents social vulnerability or other types of vulnerability (e.g., ecosystems or infrastructure), depending on the study. Some argue that this more clearly separates out the climatological/hazard elements from the system being exposed (Cardona et al. 2012). While both risk and vulnerability framings may include social vulnerability, risk management tends to focus on the probability distributions of extreme weather events and long term trends of certain magnitudes, which is vital for disaster preparedness and infrastructure construction, whereas vulnerability assessments tend to emphasize underlying factors that put people and infrastructure at risk (de Sherbinin 2014).

Of the studies in our sample, one-third used the IPCC AR4 vulnerability framework (Parry et al. 2007), 17\% utilized the very similar IPCC Third Assessment Report (TAR) vulnerability framework (McCarthy et al. 2001), and 10\% utilized different risk frameworks, including the AR5 risk framework. The only studies in our sample that explicitly adapted the SREX framework were Kienberger and Hagenlocher (2014), Hagenlocher and Castro (2015), and de Sherbinin et al. (2014a). A number of studies mapped risk more broadly (Carrao et al. 2016, Aubrecht \& Özceylan 2013, Poompavai and Ramalingam 2013, Scheuer et al. 2011, Johnson et al 2009). Another 3.5\% used livelihood frameworks (Carney et al. 1998), and 36.5\% used a variety of custom or derivative framings. For example, some studies (e.g., Behanzin et al. 2016, Papathoma-Koehle et al. 2007) developed their own vulnerability framing, or adapted frameworks developed by others (e.g., Wang \& Yarnal 2012, Fekete 2009).

Whatever the choice of framework, it needs to be "fit for purpose" in terms of illuminating the features of interest in the complex coupled human-environment system. At a minimum, any quantitative vulnerability assessment requires definition of the system of analysis (what is vulnerable?), the valued attributes of concern (why are they important?) (Figure 4.4), the external hazard (to what is the system vulnerable?), and a temporal reference (when?) (Füssel 2007). Preston et al. (2009) also note that when vulnerability mappers engage with stakeholders, including decision-makers, the framing must take into account their needs and desired outcomes. Participation of end users can ensure that the choice of framework and subsequent assessment process meets users' needs and increases the usability of map products. 

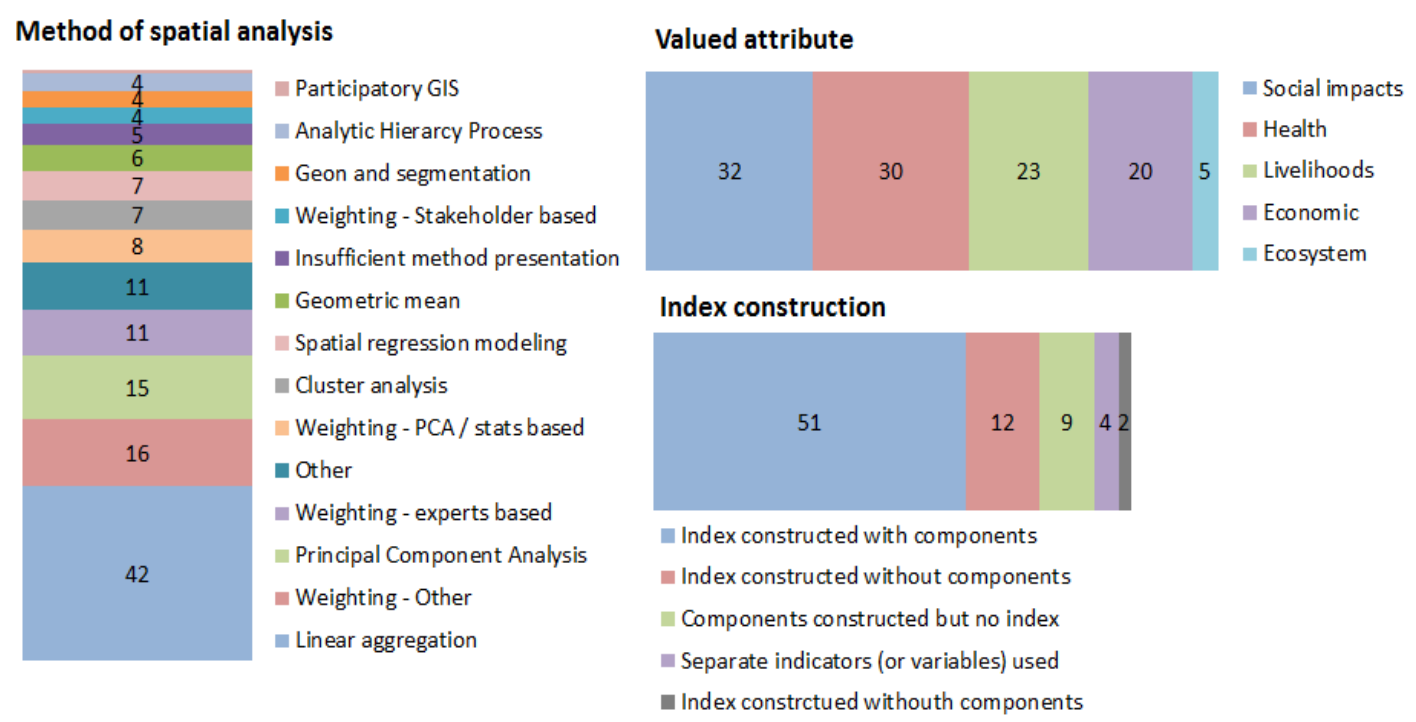

Figure 4. 4: Summary of the studies in terms of (a) method of spatial analysis, (b) valued attribute, and (c) aggregation method

Non-Climate Indicators. In general, authors relied upon census or survey data for socioeconomic indicators as proxies for sensitivity and adaptive capacity (Hinkel 2011), and only rarely collected data (e.g., Kienberger 2012). Common proxies for social vulnerability included age, race, income, and education, which are readily available parameters. Rarely were outcome measures such as malnutrition, body mass index, or morbidity employed (e.g., van Wesenbeeck et al 2016, de Sherbinin et al. 2014b). Furthermore, papers varied in their consideration of past literature to identify relevant drivers of vulnerability; for example, Tapia et al. (2017) conducted an exhaustive literature review of 150 studies to identify climate impact chains in Europe cities and to select indicators of vulnerability across multiple exposure types. Non-climate biophysical indicators included land use and land cover (50\% of studies), geographic proximity to physical features (e.g., coasts, rivers, roads) (38\%), or vegetation types (26\%), soil (19\%), and topography (12\%) (Fig. 5). With the exception of Rasanen et al. (2016), no studies considered exposure to non-climatic stressors, such as economic downturn or health crises, in addition to climatic stressors.

Fekete (2012) notes common problems of socioeconomic data include measurement errors, biased samples, geographic gaps, missing values, infrequency of updates, data decay and inappropriate normalization. To obtain more frequently updated socioeconomic parameters, there are growing efforts to use remotely-sensed proxies for poverty, such as housing structure in slums (Ebert et al. 
2009) or "nightlights poverty" (Davies et al. 2010), as well as for other parameters (de Sherbinin et al. 2015). None of the studies in our sample used other non-traditional data sources such as cellphone call detail records and recharge rates or geo-located social media, though these data sources are showing increasing promise for mapping daily mobility patterns related to hazard exposure as well as vulnerability (Yu et al. 2018).

Climate-related parameters and projections. The climatic variables and climate-related processes and phenomena of greatest interest included temperature and precipitation (48\% of studies each), flood (44\%), drought (21\%), sea level rise (13\%), cyclones (12\%), storm surge $(10 \%)$, heatwaves $(7 \%)$, coastal or riparian erosion $(6 \%)$, bushfires $(6 \%)$, and landslides $(6 \%)$ (Figure 4.5). Among 31 papers that incorporated climate data, 35\% incorporated long-term climatic averages, followed by daily data (32\%), monthly and annual data (13\% each), and seasonal parameters $(6 \%)$.

Most vulnerability mapping studies focused on the present-day climate or recent past (Jurgilevich et al. 2017). Thirty-one studies (36\%) included future projections, and of these $70 \%$ used climate projections but no socio-economic projections; $17 \%$ included both climate and socio-economic projections; $6.5 \%$ employed socioeconomic projections only; and $6.5 \%$ used scenarios of sea level rise. For those that did utilize future climate projections, 38\% had ensemble scenarios (multimodel, multi-scenario) based on the mean values (e.g. Filho et al. 2016, Torres et al. 2012, Thorton et al. 2008), whereas the remainder used one model, a practice generally discouraged by the climate science community (Knutti et al. 2010). For example, the European Spatial Planning Observation Network (ESPON) Climate report used only one model and one scenario: the COSMO Climate Limited-area Modelling (CCLM) and the special report on emissions scenarios (SRES) A1B (ESPON 2013). Several other studies also used only the SRES A1B scenario (Holsten and Kropp 2010, Lissner et al. 2012, Busby et al. 2014, Corobov et al. 2013). The use of single models with one scenario makes it difficult to characterize uncertainty (see below). In our sample, only Liu et al. (2008), Müller et al. (2014), and de Sherbinin et al. (2014b) used multiple scenarios with confidence intervals bounding the results. A more recent study (Mani et al. 2018) used 11 GCMs, selected on their ability to reproduce past climate, to project climate changes over South Asia, and a few other studies in our sample (e.g., Busby et al. 2014, Torres et al. 2012, Preston et al. 2008) approach best practices by employing state-of-the-art modeling of future climate. 

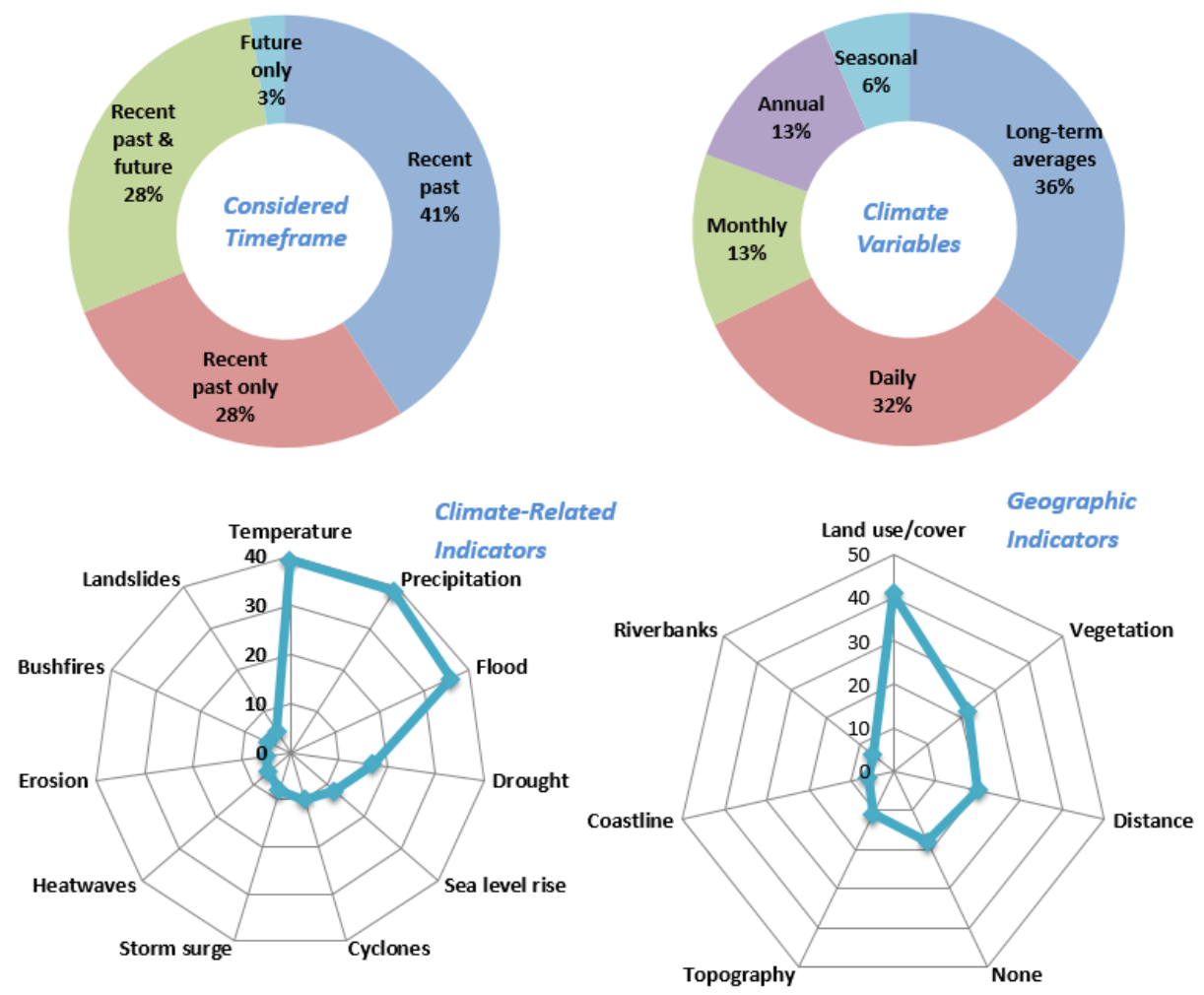

Figure 4. 5: Summary of the studies, clockwise from upper left, in terms of (a) timeframes of analysis (\%), (b) temporal nature of the climate parameters considered (\%), (c) spatial data layers or parameters considered (no.), and (d) climate-related phenome

In terms of downscaling, $11 \%$ of the studies used coarse spatial resolution ( 0.5 to 1 degree) global climate models (GCMs), 7\% used downscaling -- dynamical (1) or statistical (5) -- and 6\% used regional climate models (RCMs) at moderate to fine spatial resolution. The appropriateness of GCMs for local-level assessments is a matter of debate; for broader continental-scale studies these may be sufficient, but for any smaller regions or areas with significant topography, it is generally desirable to use downscaled climate projections or RCMs (Trzaska and Schnarr 2014). While GCMs may not adequately represent local climatic conditions, the uncertainty introduced by different downscaling methods need to be taken into consideration (Barsugli et al. 2013).

Aggregation methods. The sample of case studies presented a variety of methods for data analysis and aggregation, with index construction being the most common. Sixty-one percent of the studies produced a vulnerability index with sub-components (i.e., hierarchical models), whereas 14\% developed indices without components, $11 \%$ produced components but no overall index, and $5 \%$ 
featured separate indicators (or variables) without indices. An index was calculated for $2 \%$ of studies but without presentation of the components. Only $7 \%$ had no index or indicator construction (Figure 4. 4), being based on overlay, cluster or regression analysis.

Fifty percent of studies relied on linear aggregation for index construction, $62 \%$ of which used weighting based on expert input or judgment of the researchers on the relative importance of indicators. Data reduction strategies appeared in $21 \%$ of studies, generally using principal components analysis (PCA) and subsequent linear aggregation. Other, less common, aggregation schemes included cluster analysis (3.5\%), spatial regression modeling (7\%), geometric mean (7\%), and geon or spatial segmentation (5\%). Five studies had insufficient methods description to determine the approach used, a major shortcoming. In some cases (e.g. Baum et al. 2009), PCA was used for the construction of a social vulnerability index, after which linear aggregation was used with the remaining indicators.

The statistics of index construction and the many alternative ways of constructing indices is the subject of a growing literature (Greco et al. 2018, Reckien 2018, Becker et al. 2017, Tate 2012, Rufat et al. 2015, Nardo et al. 2005), and issues at each stage of construction-the choice of indicators, analysis scale, measurement errors, transformation, normalization, factor retention (in PCA), and weighting - all influence results (Tate 2012). Much of the work in our case studies sample simply adapted methods or approaches from prior vulnerability mapping work, resulting in derivative approaches applied to new regions. Statistical best practices, such as uncertainty analysis/sensitivity analysis or validation (below), are underutilized. Exceptions included Mainali \& Pricope (2017) and de Sherbinin et al. (2014b), both of which compared results from linear aggregation and PCA and conducted sensitivity analyses. Lastly, many of the studies displayed scant awareness of the statistical implications of their index construction methods (e.g., issues of compensability or co-linearity in linear aggregation), a general failing across many studies of social vulnerability (Tate 2012).

Scale of Analysis. The choice of bounding box (level of analysis) and spatial unit of analysis are important, and have ramifications for the approach to data integration (given multiple formats and scales of data inputs) and the statistical properties of the inputs and outputs. A more complete review of scale issues in data integration are found in Fekete et al. (2010), Kienberger et al. (2013), 
and de Sherbinin (2014 and 2016). Fifty-five percent of our studies used administrative units, followed by grid cells (40\%), and geons (2\%). One study each used natural units or parcel/property. Ideally, the choice of spatial unit would be determined by the scale of action (Cao and Lam 1997), that is, the scale at which variation in vulnerability is best observed or at which decisions need to be made. All too often the choice of common scale for data integration is pragmatically dictated by the measurement scale of available and accessible data - which could be the coarsest or finest resolution data set - rather than the operational scale. While coarser resolution data sets can be resampled, that does not change the underlying or nominal scale. For example, climate projections may have grid cell sizes of 0.5 to 1 degree, and may be resampled at higher resolution to integrate with higher resolution data, but the result is blocks of rasters with the same values. Few studies addressed the implications of their level or unit of analysis on their results; one that did, Abson et al. (2012), found that results depended heavily on how the bounding box was drawn.

Treatment of uncertainty. It is widely accepted that uncertainty levels are high in studies of climate vulnerability, especially at the science-policy interface (Kunreuther et al. 2014). This is partly a function of the diverse data streams from social and natural sciences that are used to construct vulnerability maps, and the uncertainties that are contained in each type, and partly due to the emergent nature of vulnerability arising out of complex coupled systems (Holling 2001, Soares et al. 2012) which forces developers to use indicators as proxies (indirect measures) of the phenomenon of interest such as e.g., likely or potential harm from impacts (Hinkel 2011). Uncertainties are compounded when projections are used. Uncertainty results from lack of precision or accuracy in the measurement of the climatic, natural or socioeconomic variables that contribute to vulnerability, which in turn may be due to a host of factors such as poor instrumentation, systematic biases (sampling or model biases), and spatial interpolation of data between measurement points, all of which contribute to both systematic and random error. Table 4.2 characterizes different types of spatial, temporal and attribute uncertainties that may be present in different types of geospatial data. 
Table 4.2: Categories and components of uncertainty in geospatial data (after MacEachren et al. 2005).

\begin{tabular}{|c|c|c|c|}
\hline \multirow{2}{*}{ Category } & \multicolumn{3}{|c|}{ Components } \\
\hline & Space & Time & Attributes \\
\hline Accuracy/ error & $\begin{array}{l}\text { coordinates., } \\
\text { buildings }\end{array}$ & +/- 1 day & counts, magnitudes \\
\hline Precision & 1 degree & once per day & nearest 1000 \\
\hline Lineage & $\begin{array}{c}\text { geographic } \\
\text { sources/transforms }\end{array}$ & $\begin{array}{c}\text { time } \\
\text { sources/transforms }\end{array}$ & $\begin{array}{c}\text { attribute } \\
\text { sources/transforms }\end{array}$ \\
\hline Consistency & from / for a place & 5 say Mon; 2 say Tues & multiple classifiers \\
\hline Currency/ timing & age of maps & $\mathrm{C}=$ Tpresent - Tinfo & census data \\
\hline Credibility & knowledge of place & reliability of model & $\begin{array}{l}\text { U.S. analyst vs. } \\
\text { informant }\end{array}$ \\
\hline
\end{tabular}

Accuracy/error: difference between observation and reality; Precision: exactness of measurement; Lineage: conduit or processes through which information has passed; Consistency: extent to which information components agree; Currency/timing: time span from occurrence through information collection to use; Credibility: reliability of information source.

Uncertainty can be affected by data processing decisions made throughout the vulnerability mapping process, such as inclusion/exclusion of datasets, imputation of missing values (or lack thereof), spatial interpolation of data (to fill gaps), data normalization or scaling and the choice of weighting and aggregation schemes (Nardo et al. 2005). Only $40 \%$ of studies addressed uncertainty, with $20 \%$ providing textual discussion only, $18 \%$ providing additional quantitative assessment, and $2 \%$ presenting maps to support quantification (de Sherbinin et al. 2014b and Ludeke et al. 2014). Many studies do not address uncertainty at all. Those that do most often lack any quantification of uncertainty, or discuss the implications of the uncertainty for decision makers. Even fewer studies $(11 \%)$ quantify the individual source of uncertainty introduced by analytical decisions, data sources, etc. with regard to the output/model variance (so-called 
sensitivity analysis) (Saisana et al. 2005). The paucity in uncertainty and/or sensitivity analysis is most prevalent with regard to socioeconomic models or the combination of biophysical and socioeconomic data.

Uncertainty estimates are especially important when variables at differing scales are collected and overlaid for interpretation. The issue of error induced with the introduction of each variable can quickly render an analysis little more than "guesswork" if error is not mapped or in some other way accounted for, yet only $18 \%$ of studies discussed here provided any quantitative assessment of error and only $2 \%$ mapped error. Even when systematic measurement of uncertainty is not possible, authors would do well to acknowledge data issues that contribute to uncertainty, including spatial variation in uncertainty, owing to factors such as the density of measurement points (or input unit size), sampling errors in demographic data, and data quality issues across jurisdictions (de Sherbinin and Bardy 2016). Preston et al. (2011) summarized the issue well when they stated that the failure to address uncertainty "often results in questions regarding the validity, accuracy and precision of vulnerability maps, or, in other words, whether maps themselves represent sufficiently robust visions of vulnerability to guide stakeholders regarding the potential for harm."

Data citation. Vulnerability mapping is data-intensive. Disclosure of all data inputs, data processing, as well as assessment of data deficiencies, is important for the validity of results, understanding uncertainties and replication by others (Parsons et al. 2010). Fifty-five percent of studies provided only partial information on data inputs (e.g., through acronyms in a table of data inputs), and $8 \%$ omitted references entirely. All other studies followed best practice by providing full citations with URLs wherever possible or, better yet, full metadata on layers used.

The Map. Given the centrality of "the map" in vulnerability mapping, there is much room for improvement in map design and adherence to cartographic conventions. In the reviewed studies, maps are often too small, or suffer from common cartographic pitfalls such as poor color schemes and inadequate attention to color-blind readers (Brewer 1994), overcrowding, and lack of spatial reference information (major rivers, roads or settlements). Some of the cartographic limitations may stem from restrictions on figure sizes imposed by journals. Still, given the amount of analysis required to get to the point of producing maps, lack of attention to barriers that arise from poor 
cartography and risk communication means that many studies that desire to influence policy may fall short of their goal.

\subsection{Policy Relevance}

Most studies claimed to be policy relevant and emphasized the importance of vulnerability mapping to adaptation planning, but very few studies provided specific policy recommendations or engaged with policy makers and other stakeholders to frame the primary research questions or to assess outcomes. Such engagement requires working relationships and demands additional forms of inquiry such as interviews with stakeholders or follow-up research investigating the utility of the maps. Given the claims of policy relevance by many studies, it is worthwhile exploring the uptake of study results to gauge the transfer of research to practice as well as the efficacy of climate vulnerability maps.

While many studies were academic in nature, and thus not geared toward policy makers, those that claimed policy relevance often fell short of best practice. For example, several studies lacked specificity regarding the valued attribute or the climate hazard of focus (e.g., Acosta et al. 2013, Chakraborty and Joshi 2013, Hutton et al. 2011). Depending on the decision-maker and the intended usage, vaguely defined maps of "vulnerable populations" are unlikely to lead to concrete policy or implementation responses. Similarly, researchers often chose a multi-hazard approach to social vulnerability index development (e.g., Busby et al. 2014, Chakraborty and Joshi 2013, Yusuf and Francisco 2009). When it comes to implementation decisions, multi-hazard approaches with overly broad definitions of social vulnerability provide limited guidance compared to more hazardspecific vulnerability maps (e.g., vulnerability to flood, drought, heat stress, or cyclones), though they can be effective for resource prioritization or risk communication to broader audiences.

Similarly, the chosen spatial scale of maps should match that of the decisions for which they are likely relevant or useful. For example, in addition to providing gridded maps showing spatial variation in vulnerability, policy makers may be interested in results aggregated to and/or ranked by administrative units (e.g. rank position of average index scores), but this is rarely done (exceptions include de Sherbinin et al. 2017). In addition, many studies - particularly those covering large spatial extents - did not contextualize the results by elaborating on climate impacts on sectors, systems or groups. While such maps can be useful for general risk communication, their utility for decision making is limited. Without context or stakeholder engagement, maps may 
become an end in themselves, rather than an entry point for discussion or "boundary object" for discussion among stakeholders (de Sherbinin et al. 2017, Preston et al. 2011).

Only a few studies directly worked with decision makers (e.g. McCusker et al. 2016, Roy and Blasche 2015, Weber et al. 2015, de Sherbinin et al. 2014b, Collins et al. 2013, Kienberger 2012, Lindley et al. 2011, Preston et al. 2009). These studies generally found that the co-production of knowledge was important to the success of the project. The majority of studies were academic exercises driven by intellectual curiosity or methodological development. While this may be a function of research objectives or funding source requirements, lack of engagement with stakeholders may also stem from the fact that the co-production of knowledge takes time and a commitment to process (Meadow et al. 2015). This includes listening to concerns, joint problem identification and design of the analytical framework, choice of weighting schemes, interpretation of the map products, communication of uncertainty, and design of adaptation interventions. Praxis related activities often require a different skill set than the geospatial data integration and statistical skills possessed by most vulnerability mappers, but they can be learned (Stuart and Hovland 2004).

\section{RECOMMENDATIONS AND FUTURE DIRECTIONS}

During the workshop, expert participants were asked to present and defend their choice of their top two mapping studies, and time was set aside to discuss lessons from the identified studies that could inform mapping practice. The following is a distillation of recommendations and future directions for vulnerability mapping.

Improved cartography and decision support tools. As mentioned above, mapping conventions were not uniformly followed in the studies. Vulnerability mappers would do well to interact with decision makers to ensure that their map results can be easily understood by non-technical audiences (Ishikawa et al. 2005, de Sherbinin et al. 2017), as well as data scientists, visualization experts and cognitive scientists to evaluate different ways of mapping and visualizing vulnerability information (Padilla et al. 2017, Dasgupta et al. 2015). At a minimum, the field would benefit from the use of sequential color schemes in which a limited number of hues are used and the range is illustrated with a change in saturation. Only in cases where there is a clear mid-point in the data (e.g., z-scores or values that run both positive and negative) is it appropriate to use diverging color schemes with two hues (Brewer 1994). Similarly if the data are categorical, using more than one 
color is appropriate. In addition, well designed diagrams such as those included in Kienberger et al. (2016) (Figure 4.6) or Kienberger and Hagenlocher (2014) are particularly helpful in communicating the relationships among the elements of the framework.

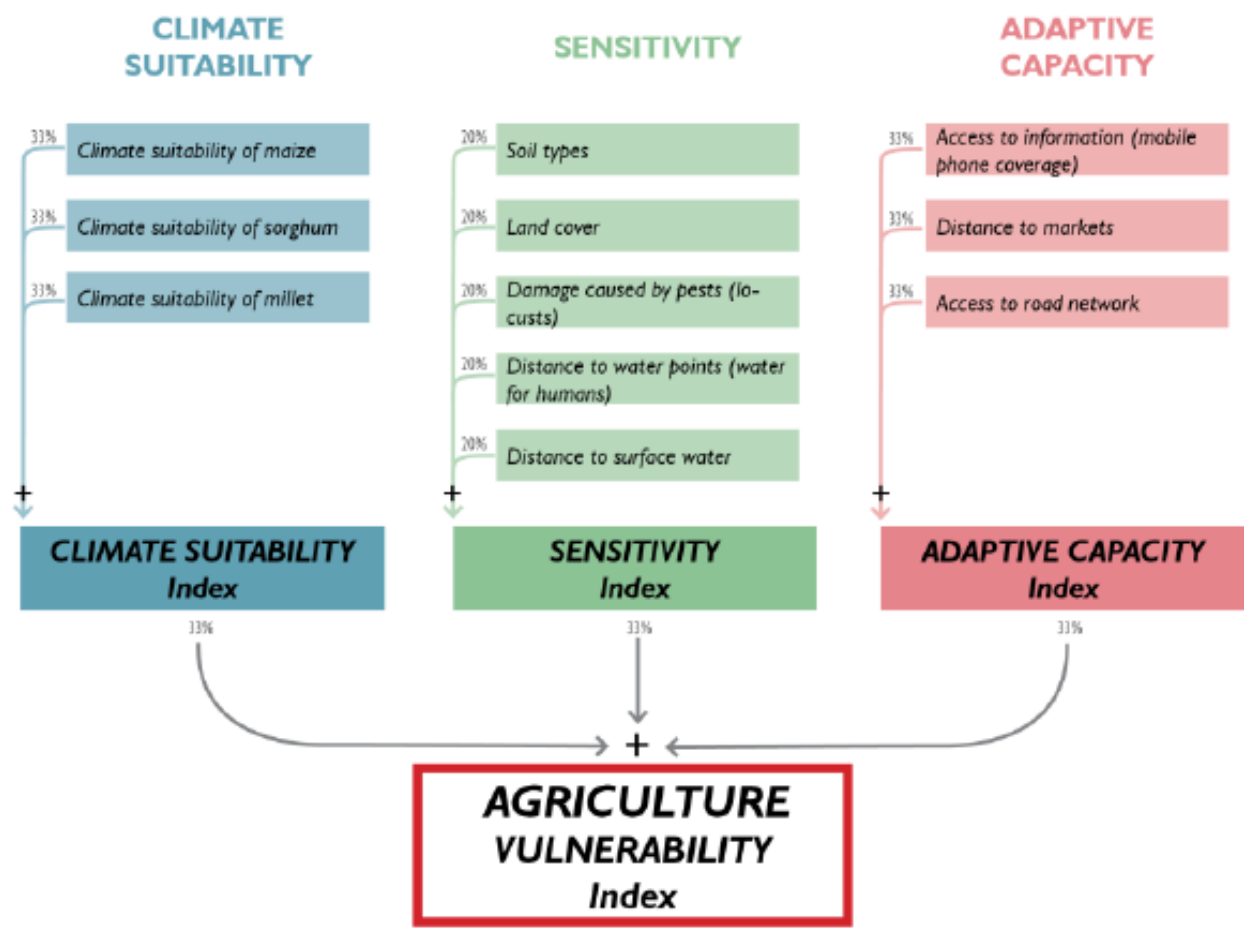

Figure 4. 6: Diagram from Kienberger et al. 2016 illustrating the elements contributing to an agricultural vulnerability index, including weighting of the variables and components

Maps should communicate uncertainty in the data and analysis. Retchless and Brewer (2016) suggest that including uncertainty information on the map is more effective than including it in an adjacent map, and that this inclusion does not interfere with map reading if done correctly. There are a number of common methods for cartographic communication of uncertainty: One is to cross hatch areas or increase the color saturation in areas where results are more certain, such as where multiple climate model scenarios agree (Kaye et al. 2012). Another is to create fuzzy boundaries (Kienberger 2012) or to run a low-pass filter (spatial averaging) over results. By interacting with the end users, map developers can identify the best way to portray uncertainty.

As maps become more interactive and web-based, practitioners may find advantages in decision support tools (DSTs). DSTs move beyond the presentation and representation of findings to help formulate or test hypotheses, identify unknowns, and support decisions under a variety of 
scenarios. Indeed geovisual analytics, as a field within GIScience, has identified the benefits of interactive decision support maps (Andrienko et al. 2007), however there is a need for more research in this domain that is focused on climate vulnerability mapping.

Beyond the map. Advanced data sources and statistical methods are moving beyond the mapping of hotspots to help elicit the drivers of vulnerability and, by extension, what interventions are possible (e.g., McCusker et al. 2016, van Weesenbeek et al. 2016). These approaches often use relatively recent survey data (e.g., Demographic and Health Surveys or Living Standards Measurement Surveys), tied to specific locations through the centroids of sample locations and interpolated using spatial kriging, to tease out the factors contributing to vulnerability, along with advanced statistics and geospatial analysis to target development interventions (e.g., Runfola et al. 2015).

As an example, livelihood-informed vulnerability analysis involves data analysis of large household surveys on shocks and shock responses to determine factors that correlate with resilience and vulnerability. McCusker et al. (2016) use three models -- logistic regression, spatial eigenvector filter logistic regression, and geographically weighted regression -- to tease out the drivers behind self-reported household shocks. Self-reported shocks were regressed with demographics and the socioeconomic characteristics of the households across the country, and results were mapped if significant in all the three models. This form of vulnerability mapping has the advantage of creating detailed maps, statistics and graphics of the distribution of selected variables and regression results over space.

Single index aggregation reduces the richness of information provided by the suites of individual vulnerability indicators on which the maps are based, and can produce similar scores in two locations where vulnerability is driven by very different processes. To gain a more holistic insight requires an understanding of how multiple factors that exacerbate or mitigate vulnerability to exogenous livelihood shocks vary in relation to each other (Abson et al. 2012). With additional understanding of the local context, researchers are able to understand the shocks (e.g., weather, food prices, financial, or health) that are most important to households, and determine appropriate responses (McCusker et al. 2016). This underscores an important point: a map can serve to point out differential vulnerability in a given area, but deeper field research is almost always required to develop appropriate adaptation responses. 
Mapping the future. Combining socioeconomic and climate scenarios will be increasingly important for understanding the relative contributions of both changes in human factors (demography, economic development, urbanization) and climatic factors in generating future impacts. A key element for future work will be the inclusion of socioeconomic scenarios such as those developed using the Shared Socioeconomic Pathways (SSPs) or similar approaches (O’Neill et al. 2014).

While decades of climate research have led to a improved understanding of changes in the climate system, albeit with limitations regarding climate sensitivity and extremes, very little has been achieved so far to comprehend the future dynamics of human systems and its influence on future vulnerability (Lutz and Muttarak 2017). Although projecting spatial socioeconomic characteristics of populations into the future is difficult (O'Neill and Gettleman 2018), a number of methods have already been developed (Rohat 2018) and the use of scenarios enables accounting for uncertainties in future socioeconomic development trends. Strader et al. (2017) provide a rare example of vulnerability mapping incorporating future scenarios. As such, the SSPs (O'Neill et al. 2014) offer an unprecedented opportunity to integrate socioeconomic projections - and their uncertainties under varying level of socioeconomic development - within assessments of future climate change vulnerability (Wilbanks and Ebi 2014). The world is far more dynamic than most vulnerability mapping efforts portray. Mapping efforts need to consider incorporating stochastic elements, such as extreme climate events, conflict, or other shocks to the system. Mapping will also need to acknowledge the dynamic connections between indicators, as well as linkages across scales (Jurgilevich et al. 2017).

Validation. Many authors have noted the importance of validating vulnerability maps and the lack of attention that such validation has received in studies to date (Preston et al. 2011, Hinkel 2011, Tate 2012, de Sherbinin 2013, Tellman et al. 2017). This is attributable to a number of factors: First, theoretical constructs of vulnerability are proxies for complex socio-ecological processes that are difficult to measure and, therefore, validate (Vincent 2004). Second, vulnerability maps often represent vulnerability in a generic sense - in the absence of the specific articulation of who or what is vulnerable and to what, it is not clear what the associated outcomes should be. Third, vulnerability maps attempt to represent an inherently uncertain future, for which there is no observable information or data to validate maps against. 
Given these challenges, a key question in vulnerability mapping is to what extent is validation necessary? This is largely a function of the objective of the mapping exercise and how the map(s) will subsequently be used. For maps generated as part of a research activity that is disconnected from adaptation practice or decision-making, there may be little incentive to pursue validation. Developing new methods or metrics for vulnerability analysis, for example, may not have a practical application that merits validation. Vulnerability maps can be used to open a dialogue around vulnerability, its meaning, and its causes (Preston et al. 2009). So, if the objective is to help stakeholders conceptualize rather than predict vulnerability, validation may be unnecessary.

Often, vulnerability maps are intended as tools to support decision-making regarding the prioritization and targeting of adaptation interventions and/or investments (Preston et al. 2011, de Sherbinin 2014). This creates potential incentives for stakeholders to manipulate the assessment of vulnerability in order to justify a priori policy objectives. In such situations, demonstrating that indices are robust to both data inputs and outcomes of interest, including the characterization of their uncertainties and limitations, is important (Saisana et al. 2005, Hinkel 2011, Tate 2012, Weeks et al. 2013). Vulnerability metrics that do not accurately reflect the underlying outcomes or processes of interest or that generate insights not reflected in other metrics significantly increase the risk of type I and II errors (false positives and false negatives, respectively) that could waste resources or prove maladaptive.

Specific methods for validation generally follow one of two approaches (Esnard et al. 2011, Tate 2012). The most common is external validation, where vulnerability metrics are validated against independent outcomes of interest such as past health outcomes or economic losses from extreme weather events (Patt et al. 2005, Preston et al. 2009, Preston et al. 2011, Tate 2012, Tellman et al. 2017). However, metrics that are validated against one type of outcome may not work for others. For example, a metric capable of predicting historical disaster losses may not perform well in predicting future health impacts or population displacement. There may also be biases in the economic loss data used to validate the metrics, and there are issues with the fact that while a hazard may impact all areas (e.g., floods or drought), the intensity of that hazard is likely to vary spatially such that there is not equal treatment across all units in order to understand the doseresponse function. Finally, in many parts of the developing world, the data necessary for external 
validation simply does not exist, nor is it likely to in the near future. Applications of external validation must be cognizant of these limitations.

Alternatively, some researchers have opted to use internal validation-statistical tests and sensitivity analysis - to assess the effects of metric construction on results (Tate 2012, Carrão et al. 2016, Heß 2017). Neither approach, however, overcomes the challenge of validating estimates of future vulnerability. This constraint should be acknowledged in the use of vulnerability metrics and consideration must be given to the relevance of vulnerability metrics to understanding the future implications of climate change.

Notwithstanding the difficulties of validation, it is important to continue to test methods of validation, and for policy-oriented vulnerability mapping efforts to seek to validate indices wherever possible, or the enterprise risks being discredited owing to claims that vulnerability maps are unable to predict future harm.

Value of information. There are a number of ways to assess the likely uptake or impact of vulnerability mapping for decision making, and we recommend that the community of researchers involved in vulnerability mapping more rigorously test and evaluate the value of the information provided. One approach, mentioned above, is to work directly with decision makers, data visualization experts, and cognitive scientists to understand how decision makers read maps and assimilate information. A number of promising future research directions include (a) semistructured individual or focus group interviews; (b) work observation; (c) think aloud protocols (whereby subjects will verbally express what they are thinking about as they explore maps); (d) online focus group or Delphi exercises (MacEachren et al. 2006); and (e) task analysis (de Sherbinin et al. 2017). The aim would be to gauge policy-maker comprehension of the information presented in maps, their preferences in map design (Retchless and Brewer 2015), their comfort level with the uncertainty in map products, and, ultimately, how and why the information presented in maps influenced their decisions.

In the field of economics, value of information research is demonstrating the societal benefit of information for decision making by examining the economic costs associated with decision making that was made prior to the introduction of new information, and measuring the economic benefits (net of the cost of the new information sources) of improved decisions. Economic costs could be measured in terms of lives lost, hospital visits, or economic damages. Recent work on 
the value of satellite remote sensing information (Bernknopf and Brookshire 2018, Cooke et al. 2014) provide examples of rigorous economic analyses that could be performed for vulnerability mapping.

\section{CONCLUSION}

Vulnerability mapping is growing field, and one that is likely to increase in importance given the magnitude of expected temperature increases and associated impacts (World Bank and PIK 2012). Such mapping acknowledges that the effects of climate change on society are not solely a function of exposure to temperature and precipitation changes or increases in the frequency or magnitude of extreme events, but that the sensitivity and adaptive capacity of societies to these changes will play a crucial role in influencing outcomes. Mapping also acknowledges that all the factors that contribute to vulnerability-e.g., exposure to extremes, land use and land cover, population density, relative wealth and poverty, and institutional effectiveness - vary spatially, and that there relative contributions to overall vulnerability are different from place to place (e.g., Nayak et al. 2017, Kienberger and Hagenlocher 2014). Thus, mapping can make significant contributions to enabling society to effectively adapt, or to signal where adaptation may face sufficiently high barriers that communities may be forced to migrate (Rigaud et al. 2018).

We find that vulnerability mapping as a field is maturing, but a number of issues remain that need to be addressed for the field to advance, including increasing the degree of collaboration with end users, greater attention to map communication, moving beyond the map as the final product, work on validation, and greater justification for mapping based on value of information research. This is all the more important as decision makers look to invest large sums of money in adaptation assistance, and to justify their choices based on scientific tools such as vulnerability maps. 


\section{Chapter 5: Conclusion}

This dissertation attempted to better understand deepening rural livelihood vulnerability in Malawi. The study took a multidimensional approach to better analyze rural livelihoods vulnerability in Malawi to leverage effective adaptation to climate change. Drawing on actual lived experiences and local knowledge/perceptions of the changing climatic conditions and reviewing the state-of-the-art literature on vulnerability analysis, the study has shown that rural livelihood vulnerability can better be discerned using multidimensional approaches - combining natural and social vulnerabilities. The dissertation has summarized the findings through 3 closely related articles which have stretched/extended the ways to understand worsening rural livelihood vulnerability. Local knowledge has shown that smallholders in Malawi are sensitive and knowledgeable of the changing climatic conditions/environmental context that mediate their rural livelihoods. Local farmers have observed changes with regard to onset, amount, length of season, intensity and distribution of rainfall. Their observations are consistent with meteorological records. Farmers perceptions reflect local vulnerabilities and concerns, i.e. actual impact of climate on livelihoods. Such detailed knowledge about changes in rainfall pattern can be harnessed to facilitate effective adaptation. Since research has shown local farmers react to change that they observe, adaptation efforts/initiatives that can be tailored to local farmers perceptions can enhance/ensure local agreement and participation to reduce the deepening rural livelihood vulnerabilities.

Through correlational analysis the dissertation has shown that the changing environmental context i.e. rainfall variability and dry conditions over Malawi are linked to teleconnections - SST over Indian Ocean and El Nino conditions. The study further established that the association is not uniform across, it varies spatially. Interventions therefore need to consider spatial variability. In addition, the dissertation has also revealed that rainfall variability is not distributed evenly throughout the rainy season. The beginning and end of the rain season are most prone to failure/more sensitive to SST anomalies implying shortening of the growing season. As rural livelihoods in Malawi are heavily dependent on rainfall and with maize as the staple crop which is sensitive to moisture deficits increased rainfall variability and shortening of the rain season pushes rural livelihoods further to the edge. This does not portend well for rural livelihoods with the understanding that anthropogenic warming of the Indian Ocean will persist. 
Through review of current practices in vulnerability analysis and mapping the dissertation has highlighted that effects of climate change on society are not solely a function of exposure to climate hazard, but that the sensitivity and adaptive capacity of societies to climate shocks will play a crucial role in influencing outcomes. The dissertation has also pointed out that all the factors that contribute to vulnerability vary spatially, and that their relative contributions to overall vulnerability are different from place to place. Thus, mapping can make significant contributions to enabling society to effectively adapt. The dissertation however has found that a number of issues remain that need to be addressed for vulnerability mapping to be more effective and fruitful, including increasing the degree of collaboration with end users, greater attention to map communication, moving beyond the map as the final product, work on validation, and greater justification for mapping based on value of information research. As maps have become part of the standard tool-kit for communicating the risks of climate change to society and decision makers depend more on maps to justify their choices of where to invest large sums of money in adaptation assistance, it is more important that better and suitable approached to vulnerability mapping are used and consequently good vulnerability maps are developed.

The research was not without challenges. One challenge was language. While I am fluent in the languages that are widely spoken in Malawi (including study areas) some people in study areas prefer to speak language that I am not familiar with. Another challenge was the terrain of the study areas particularly in the north, Nkhata Bay. Nkhata Bay is mountainous and dwelling places are distances apart with no means of transport. It was practically impossible to access the communities in the rain season. This demanded a substantial amount of time to gather data. We had to put in place a good and realistic work plan to minimize loss of time inefficiencies and make good use of the available opportunities. We sourced a motorcycle to reach inaccessible area to mobilize the communities beforehand. We also had to engage and train a considerable number of research assistants to assist with data collection. The research assistants were recruited from the study areas to help with the problem of language.

While we had no difficulties accessing gatekeepers due to our familiarity with the local culture, we had challenges with local peoples' expectation. Local populations thought we had come to address the deepening and worsening livelihoods crisis they are experiencing. The pointed out (particularly in Nkhata Bay) that we were the first to come to their communities and talk to them 
about their livelihoods challenges they are facing and thought we had come to train them on what they should be doing to address these challenges. So, it was difficult for them to believe that we have no knowledge, but we had come to gain knowledge from them on challenges they are facing and how they are addressing them. When we had explained our position to them they pleaded with us that we have to report their situation to government so that they could be assisted. We planned to share with the communities the results of our research and were able to go back to a few communities but were not able to real all due to resources. In addition to these challenges, we did not have meteorological observation for recent years. The meteorological data we obtained was only up to 2014 .

From this research, I have investigated the changing environmental conditions that mediate rural livelihood vulnerability and reviewed current practices in vulnerability analysis ad mapping. The research is continuing. We are building on the systematic review of current practices in vulnerability analysis and mapping to advance a new approach to better analyze and map rural livelihoods vulnerability to climate change in Malawi to understand the geography of rural livelihood and their underlying factors and the ways households transform coping strategies to past weather events into climate change adaptation pathways. In the immediate future, I will focus my research on adaptation pathways. Some of the avenues I want to explore are: how effective are the adaptation pathways by smallholders. Along similar lines, I want to extend livelihoods adaptation research to include small-scale fishers' and fish workers livelihoods. Since I will be working on a research project on fish trade and food security in Malawi Which aims to enhance knowledge on issues of gender, food security and small-scale fish workers' livelihoods I will be able carry on with this research with relative ease and little funding. 


\section{BIBLIOGRAPHY}

Abson, D. J., Dougill, A. J., \& Stringer, L. C. (2012). Using Principal Component Analysis for information-rich socio-ecological vulnerability mapping in Southern Africa. Applied Geography, 35(1-2), 515-524. doi: 10.1016/j.apgeog.2012.08.004

Abson, D., Dougill, A., and Stinger, L. 2012. Using Principal Component Analysis for information-rich socio-ecological vulnerability mapping in Southern Africa. Applied Geography 35:515-524.

Akukwe, T. I., \& Ogbodo, C. (2015). Spatial Analysis of Vulnerability to Flooding in Port Harcourt Metropolis, Nigeria. SAGE Open, 5(1), 1-19. doi: 10.1177/2158244015575558

Allan, R.J., Reason, C.J.C., Lindesay J.A., Ansell, T.J., (2003) Protracted ENSO episodes and their impacts in the Indian Ocean region. Deep-Sea Res 50:2331-2347

Andrienko, G., N. Andrienko, P. Jankowski, D. Keim, M.-J. Kraak, A. MacEachren, and S. Wrobel (2007). Geovisual analytics for spatial decision support: Setting the research agenda. International Journal of Geographical Information Science, 21(8), 839-857. DOI: $10.1080 / 13658810701349011$

April 2000, Pages 107-119

Arthur, A.M., (2003) Targeting Climate Forecasts for Agricultural Applications in Sub-Saharan Africa: Situating Farmers in User-Space. Climatic Change 58: 73-92

Asfaw, S. et al. (2017. Impacts of modifying Malawi's farm input subsidy programme targeting. FAO Agricultural Development Economics Working Paper 17-05. Rome, FAO.

Asfaw, S., Cattaneo, A., Pallante, G. \& Palma, A. 2017. Impacts of modifying Malawi's farm input subsidy programme targeting. FAO Agricultural Development Economics Working Paper 17-05. Rome, FAO.

Aubrecht, C., \& Özceylan, D. (2013). Identification of heat risk patterns in the US National Capital Region by integrating heat stress and related vulnerability. Environment International, $56,65-77$.

Barsugli, J. J., et al., 2013: The Practitioner's Dilemma: How to assess the credibility of downscaled climate projections EOS, 94, 424-425.

Basistha, A. et al. (2009) Analysis of historical changes in rainfall in the Indian Himalayas. INTERNATIONAL JOURNAL OF CLIMATOLOGY Int. J. Climatol. 29: 555-572 (2009)

Becker, W., M. Saisana, P. Paruolo, I. Vandecasteele. (2017). Weights and importance in composite indicators: Closing the gap. Ecological Indicators 80: 12-22

Behanzin, I. D., Thiel, M., Szarzynski, J., \& Boko, M. (2016). GIS-based mapping of flood vulnerability and risk in the Bénin Niger River Valley. International Journal of Geomatics and Geosciences, 6(3), 1653-1669. 
Benson, C. and Clay, E. J., (1998) The impact of drought on sub-Saharan economies. World Bank Technical Paper No. 401, World Bank, Washington DC, U. S. A.

Bernknopf, R., and D. Brookshire. 2018. The Value of Remotely Sensed Information: The Case of a GRACE-Enhanced Drought Severity Index. Weather, Climate and Society. https://doi.org/10.1175/WCAS-D-16-0044.1

Berrang-Ford L, Pearce T and Ford JD (2015). Systematic review approaches for climate change adaptation research, Regional Environmental Change 15 755-69

Blaikie, P., T. Cannon, I. Davis, and B. Wisner. (1994). At Risk: natural hazards, people's vulnerability and disasters. London: Routledge, $284 \mathrm{pp}$.

BMZ (German Federal Ministry for Economic Cooperation and Development). (2014). The Vulnerability Sourcebook: Concept and guidelines for standardised vulnerability assessments. Berlin, Germany: GIZ.

Boissiere, M. et al (2013) Local Perceptions of Climate Variability and Change in Tropical Forests of Papua, Indonesia. Ecology and Society 18(4): 13.

Brewer, C.A. (1994). Color use guidelines for mapping and visualization. Visualization in Modern Cartography, 2, 123-148.

Brooks, S., (2014) Enabling adaptation? Lessons from the new 'Green Revolution' in Malawi and Kenya. Climatic Change 122:15-26

Busby, J. W., Cook, K. H., Vizy, E. K., Smith, T. G., \& Bekalo, M. (2014). Identifying hot spots of security vulnerability associated with climate change in Africa. Climatic Change, 124(4), 717 731. doi: 10.1007/s 10584-014-1142-z

Busby, J., Cook, K., Vizy, E., Smith, T. and Bekalo, M. 2014. Identifying hot spots of security vulnerability associated with climate change in Africa. Climatic Change 124: 717-731. Davis, B. 2003. Choosing a Method for Poverty Mapping. FAO: Rome.

Byg and Salick (2009) Local Perspectives on Global Phenomenon-Climate Change in Eastern Villages. Global Environmental Change, 19 (2009) 156-166.

Campos, M. et al. (2014) Land-users' perceptions and adaptations to climate change in Mexico and Spain: commonalities across cultural and geographical contexts. Reg Environ Change (2014) $14: 811-823$

Cao, C. and N. Lam. (1997). Understanding the Scale and Resolution Effects in Remote Sensing and GIS, in Scale in Remote Sensing and GIS, Editor. 1997, CRC Press: Boca Raton FL. p. 5772.

Cardona OD, van Aalst MK, Birkmann J, Fordham M, McGregor G, \& Mechler R (2012).

Determinants of risk: Exposure and vulnerability. In: Managing the Risks of Extreme Events and Disasters to Advance Climate Change Adaptation. Eds. Field, CB, Barros, V \& Stocker, TF, Cambridge: Cambridge University Press. 
Carney, D. (1998a). Sustainable rural livelihoods: What contribution can we make? In D. Carney (Ed.), Department for International Development's Natural Resources Advisers' Conference. London: DFID.

Carr, E. and McCusker, B. (2009). The co-production of land use and livelihoods change: Implications for development interventions. Geoforum. 40. 568-579.

10.1016/j.geoforum.2009.04.010.

Carrão, H., Naumann, G., \& Barbosa, P. (2016). Mapping global patterns of drought risk: An empirical framework based on sub-national estimates of hazard, exposure and vulnerability. Global Environmental Change, 39, 108-124.

Chakraborty, A., \& Joshi, P. K. (2014). Mapping disaster vulnerability in India using analytical hierarchy process. Geomatics, Natural Hazards and Risk, 7(1), 308-325. doi: $10.1080 / 19475705.2014 .897656$

Chan, R.Y., et al., (2008) 'Intraseasonal precipitation variability on Kilimanjaro and the East African region and its relationship to the large-scale circulation', Theoretical and Applied Climatology 93: 149-165

Chibwana, C. et al. (2012) Cropland allocation effects of agricultural input subsidies in Malawi. World Development, 40(1), 124-133

Chinsinga, B. (2011) Seeds and subsidies: The political economy of input programmes in Malawi. IDS Bulletin, 42, 59-68.

Chinsinga, B. et al. (2012) Climate Change and Agricultural Policy Processes in Malawi. Working Paper 046. Brighton: Future Agricultures.

Chinsinga, B., Mangani, R. \& Mvula, P. 2011. The Political Economy of Adaptation through Crop Diversification in Malawi. IDS Bulletin, 42, 110-117.

Chirwa E.W. et al. (2005) Agricultural Marketing Liberalisation and the Plight of the Poor in Malawi. Working Paper No. 2005/08. Department of Economic, University of Malawi, Chancellor College

Chirwa, E. W., Dorward, A. \& Matita, M. 2011. Conceptualising Graduation from Agricultural Input Subsidies in Malawi. Working Paper 29. Brighton: FAC

Collins, T. W., Grineski, S. E., Ford, P., Aldouri, R., Lourdes Romo Aguilar, M., VelázquezAngulo, G., . . . Lu, D. (2013). Mapping vulnerability to climate change-related hazards: children at risk in a US-Mexico border metropolis. Population and Environment, 34(3), 313-337. doi: 10.1007/s11111-012-0170-8

Cook C. et al., (2004) Wet and Dry Spells within Particularly Wet and Dry Summers in the South African summer rainfall region. Climate Research 26:17-31

Cooke, R., Wielicki, B. A., Young, D. F., \& Mlynczak, M. G. (2014). Value of information for climate observing systems. Environment Systems and Decisions, 34(1), 98-109. 
Corobov, R., Sirodoev, I., Koeppel, S., Denisov, N., \& Sirodoev, G. (2013). Assessment of Climate Change Vulnerability at the Local Level: A Case Study on the Dniester River Basin (Moldova). Scientific World Journal, 2013, 173794-173794. doi: 10.1155/2013/173794

Coulibaly, J. Y., Mbow, C., Sileshi, G. W., Beedy, T., Kundhlande, G., \& Musau, J. (2015).

Mapping vulnerability to climate change in malawi: spatial and social differentiation in the Shire River Basin. American Journal of Climate Change, 4(03), 282.

Crick, F., Serrao-Neumann, S., Choy, D. L., Sano, M., \& Baum, S. (2012). A Region at Risk: Policy Determination Through Vulnerability Hotspot Assessment. In K. Otto-Zimmermann (Ed.), (pp. 15-24). New York: Springer, Dordrecht.

Cutler, P. (1986) The response to drought of Beja famine refugees in Sudan Disasters, 1986 https://doi.org/10.1111/j.1467-7717.1986.tb00586.

Cutter, S. L. (1996). Vulnerability to environmental hazards. Progress in human geography, 20(4), 529-539.

Dasgupta, A., Jorge Poco, Yaxing Wei, Robert Cook, Enrico Bertini, and Claudio T. Silva. (2015). Bridging Theory with Practice: An Exploratory Study of Visualization Use and Design for Climate Model Comparison. IEEE Transactions on Visualization and Computer Graphics, 21(9): 996-1013

Davies, R. A. G., Midgley, S. J. E., \& Chesterman, S. (2010). Climate Risk and Vulnerability Mapping for Southern Africa. Cape Town, SA: Regional Climate Change Programme for Southern Africa.

de la Vega M.C et al. (2009). "The Bourguignon and Chakravarty multidimensional poverty family: A characterization," Working Papers 109, ECINEQ, Society for the Study of Economic Inequality.

de Sherbinin, A. (2013). Climate Change Hotspots Mapping: What Have We Learned? Climatic Change, 123(1): 23-37.

de Sherbinin, A. (2014). Spatial Climate Change Vulnerability Assessments: A Review of Data, Methods and Issues. Technical Paper for the USAID African and Latin American Resilience to Climate Change (ARCC) project. Washington, DC: USAID.

de Sherbinin, A. (2016). "Remote Sensing and Socioeconomic Data Integration: Lessons from the NASA Socioeconomic Data and Applications Center", In: Integrating Scale in Remote Sensing and GIS, D.A. Quattrochi, E.A. Wentz, N. Lam, and C. Emerson eds. Boca Raton FL: CRC Press.

de Sherbinin, A., \& Bardy, G. (2016). Social vulnerability to floods in two coastal megacities: New York City and Mumbai. Vienna Yearbook of Population Research 2015. 13:131-165.

de Sherbinin, A., A. Apotsos, and J. Chevrier (2017). Mapping the Future: Policy Applications of Climate Vulnerability Mapping in West Africa. The Geographical Journal. DOI:

10.1111/geoj.12226 
de Sherbinin, A., T. Chai-On, M. Jaiteh, V. Mara, L. Pistolesi, E. Schnarr, S. Trzaska. (2015). Data Integration for Climate Vulnerability Mapping in West Africa. ISPRS International Journal of Geo-Information. 4, 2561-2582. http://dx.doi.org/10.3390/ijgi4042561.

de Sherbinin, A., T. Chai-Onn, A. Giannini, M. Jaiteh, M. Levy, V. Mara, L. Pistolesi, and S. Trzaska. (2014b). Mali Climate Vulnerability Mapping. Technical Paper for the USAID African and Latin American Resilience to Climate Change (ARCC) project. Washington, DC: USAID.

de Sherbinin, A., T. Chai-Onn, M. Jaiteh, V. Mara, L. Pistolesi, and E. Schnarr. (2014a). Mapping the Exposure of Socioeconomic and Natural Systems of West Africa to Coastal Climate Stressors. Technical Paper for the USAID African and Latin American Resilience to Climate Change (ARCC) project. Washington, DC: USAID.

Deichmann, U. 1999. Geographic aspects of inequality and poverty. World Bank Research Paper. Accessed at http://www.worldbank.org/poverty/inequal/index.htm.

Deressa, T.T. et al. (2011) Climate Change and Agriculture Paper Perception of and Adaptation to Climate Change by Farmers in the Nile Basin of Ethiopia. Journal of Agricultural Science (2011), 149, 23 -31.

Desanker, P.V. and Justice, C.O., (2001) Africa and global climate change: critical issues and suggestions for further research and integrated assessment modeling. Clim Res 17: 93-103

Dickin, S. K., Schuster-Wallace, C. J., \& Elliott, S. J. (2013). Developing a Vulnerability Mapping Methodology: Applying the Water-Associated Disease Index to Dengue in Malaysia. PLoS ONE, 8(5), 1-11.

Dickin, S., Schuster-Wallace, C. and Elliott, S. 2013. Developing a vulnerability mapping methodology: Applying the Water-Associated Disease Index to dengue in Malaysia. PLOSOne 8(5):1-11.

Dorward, A., \& Chirwa, E. 2011. The Malawi agricultural input subsidy programme: 2005/06 to 2008/09. International journal of agricultural sustainability, 9(1), 232-247.

Ebert, A., Kerle, N., \& Stein, A. (2008). Urban social vulnerability assessment with physical proxies and spatial metrics derived from air- and spaceborne imagery and GIS data. Natural Hazards, 48(2), 275-294. doi: 10.1007/s11069-008-9264-0

Edwards, J., Gustafsson, M., \& Naslund-Landenmark, B. (2007). Handbook for vulnerability mapping. Swedish Rescue Services Agency, Karlstad, Sweden.

Esnard, A. M., Sapat, A., \& Mitsova, D. (2011). An index of relative displacement risk to hurricanes. Natural Hazards, 59(2), 833.

ESPON. (2013). Climate Climate Change and Territorial Effects on Regions and Local Economies. Luxembourg: ESPON. 
Fekete, A. (2009). Validation of a social vulnerability index in context to river-floods in Germany. Natural Hazards and Earth System Science, 9(2), 393-403. doi: 10.5194/nhess-9-3932009

Fekete, A. (2012). Spatial disaster vulnerability and risk assessments: challenges in their quality and acceptance. Natural Hazards. 61(3): 1161-1178.

Fekete, A. 2012. Spatial disaster vulnerability and risk assessments: Challenges in their quality and acceptance. Natural Hazards 61:1161-1178.

Fekete, A., Damm, M., Birkmann, J. (2010). Scales as a challenge for vulnerability assessment. Nat Hazards, 55:729-747.

Filho, J. P. D., Lapola, D. M., Torres, R. R., \& Lemos, M. C. (2016). Socio-climatic hotspots in Brazil: how do changes driven by the new set of IPCC climatic projections affect their relevance for policy? Climatic Change, 136(3-4), 413-425. doi: 10.1007/s10584-016-1635-z

Funk, C. et al., (2008) Warming of the Indian Ocean threatens eastern and southern African food security. PNAS 105, 32: 11081-11086

Füssel, H.-M. (2007). Vulnerability: A generally applicable conceptual framework for climate change research. Global Environmental Change, 17(2), 155-167.

Fussel, Hans-Martin. 2009. Development and climate change : review and quantitative analysis of indices of climate change exposure, adaptive capacity, sensitivity, and impacts (English). World Development Report background papers ; 2010. Washington, DC: World Bank.

Gall, M., K.H. Nguyen, and S.L. Cutter. (2015). Integrated research on disaster risk: Is it really integrated? International Journal of Disaster Risk Reduction, 12: 255-267.

Goddard, L. et al. (2001). Current Approaches to Seasonal-to-Interannual Climate Predictions. International Journal of Climatology. 21. 1111 - 1152. 10.1002/joc.636.

Goddard, L., and Graham, N.E. 1999: The importance of the Indian Ocean for simulating rainfall anomalies over eastern and southern Africa. J. Geophys. Res., 104, 19 099-19 116

GRAIN 2010 Unravelling the Miracle of Malawi’s Green Revolution. https://www.grain.org/article/entries/4075-unravelling-the-miracle-of-malawi's-green-revoultion

Greco, S., A. Ishizaka, M. Tasiou, G. Torrisil. (2018). On the Methodological Framework of Composite Indices: A Review of the Issues of Weighting, Aggregation, and Robustness. Social Indicators Research, https://doi.org/10.1007/s11205-017-1832-9

Hagenlocher, M., \& Castro, M. C. (2015). Mapping malaria risk and vulnerability in the United Republic of Tanzania: a spatial explicit model. Population Health Metrics, 13(1), 2.

Hansen, J. et al. (2004) Earth's Energy Imbalance: Confirmation and Implications. www.sciencexpress.org / 28 April 2004 / Page 1/ 10.1126/science.1110252 
Heaton, M. J., Sain, S. R., Greasby, T. A., Uejio, C. K., Hayden, M. H., Monaghan, A. J., . . . Nepal, V. (2014). Characterizing urban vulnerability to heat stress using a spatially varying coefficient model. Spatial and Spatio-Temporal Epidemiology, 8, 23-33.

Held, T.L. et al. (2005) Simulation of Sahel drought in the 20th and 21st centuries. PNAS December 13, 2005102 (50) 17891-17896; https://doi.org/10.1073/pnas.0509057102

Heß, V. D. C. (2017). Weighting the dimensions of social vulnerability based on a regression analysis of disaster damages. Hazards Earth Syst Sci Discuss Nat. doi, 10.

Hinkel J. (2011). "Indicators of vulnerability and adaptive capacity": Towards a clarification of the science-policy interface" Global Environmental Change 21 (1), 198-208

Holling, C.S. (2001). Understanding the Complexity of Economic, Ecological, and Social Systems. Ecosystems 4:390-405.

Holsten, A., \& Kropp, J. P. (2012). An integrated and transferable climate change vulnerability assessment for regional application. Natural Hazards, 64(3), 1977-1999. doi: 10.1007/s11069012-0147-z

Hulme, M. (1992) 'Rainfall Changes in Africa: 1931-1960 to 1961-1990', Int. J. Climatology 12: 685-699.

Hulme, Mike. et al. (2001). African Climate Change: 1900-2100. CLIMATE RESEARCH. 17. 145-168. 10.3354/cr017145.

IPCC (2012). Managing the Risks of Extreme Events and Disasters to Advance Climate Change Adaptation. A Special Report of Working Groups I and II of the Intergovernmental Panel on Climate Change [Field, C.B., V. Barros, T.F. Stocker, D. Qin, D.J. Dokken, K.L. Ebi, M.D. Mastrandrea, K.J. Mach, G.-K. Plattner, S.K. Allen, M. Tignor, and P.M. Midgley (eds.)]. Cambridge University Press, Cambridge, UK, and New York, NY, USA, 582 pp.

Ishikawa, T., A.G. Barnston, K.A. Kastens, P. Louchouarn and C.F. Ropelweski (2005). Climate forecast maps as a communication decision-support tool, Cartography and Geographic Information Science 32, 3-16

Islam, A. K. M. N., Deb, U. K., Al Amin, M., Jahan, N., Ahmed, I., Tabassum, S., . . Bantilan, C. (2013). Vulnerability to Climate Change: Adaptation Strategies and Layers of Resilience Quantifying Vulnerability to Climate Change in Bangladesh. Andhra Pradesh, India: International Crops Research Institute for the Semi-Arid Tropics (ICRISAT). 36 pp.

Jakobsen, K. 2013. Livelihood asset maps: a multidimensional approach to measuring riskmanagement capacity and adaptation policy targeting - a case study in Bhutan. Regional Environmental Change 13: 219-233.

Janowiak. J.E (1988) An Investigation of Interannual Rainfall Variability in Africa.Climate Analysis Center, NMC/NWS/NOAA, Washington, DC 
Johnson, D. P., Stanforth, A., Lulla, V., \& Luber, G. (2012). Developing an applied extreme heat vulnerability index utilizing socioeconomic and environmental data. Applied Geography, 35(12), 23-31.

Johnson, D. P., Wilson, J. S., \& Luber, G. C. (2009). Socioeconomic indicators of heat-related health risk supplemented with remotely sensed data. International Journal of Health Geographics, 8(1), 57-57. doi: 10.1186/1476-072X-8-57

Jurgilevich, A., A. Räsänen, F. Groundstroem and S. Juhola (2017). A systematic review of dynamics in climate risk and vulnerability assessments. Environ. Res. Lett. 12 (2017) 013002

Jury, M.R., Gwazantini, M.E., (2002) Climate variability in Malawi, part 2: sensitivity and prediction of lake levels. Int J Climatol 22:1303-1312

Jury, M.R., Mwafulirwa, N.D., (2002) Climate variability in Malawi, part 1: dry summers, statistical associations and predictability. Int J Climatol 22:1289-1302

Kaye, N.R., A. Hartley, and D. Hemming. (2012). Mapping the climate: guidance on appropriate techniques to map climate variables and their uncertainty. Geoscience Model Development, 5:245-256. www.geosci-model-dev.net/5/245/2012/

Kienberger, S. (2012). Spatial modelling of social and economic vulnerability to floods at the district level in Búzi, Mozambique. Natural Hazards, 64:2001-2019.

Kienberger, S., \& Hagenlocher, M. (2014). Spatial-explicit modeling of social vulnerability to malaria in East Africa. International Journal of Health Geographics, 13(1), 29.

Kienberger, S., Blaschke, T., \& Zaidi, R. Z. (2013). A framework for spatio-temporal scales and concepts from different disciplines: the 'vulnerability cube'. Natural Hazards, 68(3), 1343-1369.

Kienberger, S., Blaschke, T., Zaidi, R. 2013. A framework for spatio-temporal scales and concepts from different disciplines: the vulnerability cube. Natural Hazards 68:1343-1369.

Kienberger, S., Borderon, M., Bollin, C., \& Jell, B. (2016). Climate change vulnerability assessment in Mauritania: reflections on data quality, spatial scales, aggregation and visualizations, GI_Forum, 1: 167-175. DOI: 10.1553/giscience2016_01_s167

Kim, H., Park, J., Yoo, J., \& Kim, T.-W. (2015). Assessment of drought hazard, vulnerability, and risk: A case study for administrative districts in South Korea. Journal of Hydro-environment Research, 9(1), 28-35. doi: 10.1016/j.jher.2013.07.003

Klein RJT (2009) Identifying countries that are particularly vulnerable to the adverse effects of climate change: an academic or a political challenge? Carbon and Climate Law Review 3:284291.

Knutti, R., G. Abramowitz, M. Collins, V. Eyring, P.J. Gleckler, B. Hewitson, and L. Mearns. (2010). Good Practice Guidance Paper on Assessing and Combining Multi Model Climate Projections. In: Meeting Report of the Intergovernmental Panel on Climate Change Expert Meeting on Assessing and Combining Multi Model Climate Projections [Stocker, T.F., D. Qin, 
G.-K. Plattner, M. Tignor, and P.M. Midgley (eds.)]. IPCC Working Group I Technical Support Unit, University of Bern, Bern, Switzerland.

Kok, M. T. J., Lüdeke, M. K. B., Sterzel, T., Lucas, P. L., Walter, C., Janssen, P., \& Soysa, I. d. (2010). Quantitative analysis of patterns of vulnerability to global environmental change. The Hague, Netherlands: PBL Netherlands Environmental Assessment Agency.

Krisjanson, P., Radeny, M., Baltenweck, I., Ogutu, J., Notenbaet, A. 2005. Livelihood mpaaing and poverty correlates at a meso-level in Kenya. Food Policy 30: 568-583.

Kunreuther H., S. Gupta, V. Bosetti, R. Cooke, V. Dutt, M. Ha-Duong, H. Held, J. LlanesRegueiro, A. Patt, E. Shittu, and E. Weber. (2014). Integrated Risk and Uncertainty Assessment of Climate Change Response Policies. In: Climate Change 2014: Mitigation of Climate Change. Contribution of Working Group III to the Fifth Assessment Report of the Intergovernmental Panel on Climate Change [Edenhofer, O., R. Pichs-Madruga, Y. Sokona, E. Farahani, S. Kadner, K. Seyboth, A. Adler, I. Baum, S. Brunner, P. Eickemeier, B. Kriemann, J. Savolainen, S. Schlömer, C. von Stechow, T. Zwickel and J.C. Minx (eds.)]. Cambridge University Press, Cambridge, United Kingdom and New York, NY, USA

Lam, N. S. N., Qiang, Y., Arenas, H., Brito, P., \& Liu, K.-b. (2015). Mapping and assessing coastal resilience in the Caribbean region. Cartography and Geographic Information Science, 42(4), 315-322. doi:10.1080/15230406.2015.1040999

LaRovere, R., Keulen, H., Hiernaux, P., Szonyi, J., and Schipper, R. 2008. Intensification Scenarios in South-Western Niger: Implications for Revisiting Fertilizer Policy. Food Policy 33: 156-164.

Lawal, O., \& Arokoyu, S. B. (2015). Modelling social vulnerability in sub-Saharan West Africa using a geographical information system. Jàmbá: Journal of Disaster Risk Studies, 7(1), 1-11.

Le Dang, H. et al (2014) Farmers' perceptions of climate variability and barriers to adaptation: lessons learned from an exploratory study in Vietnam. Mitig Adapt Strateg Glob Change (2014) 19:531-548 DOI 10.1007/s11027-012-9447-6

Lindesay, J.A., (1988) South Africa rainfall, the Southern Oscillation and a Southern Hemisphere semi-annual cycle. J Climatol 8:17-30

Lissner, T. K., Holsten, A., Walther, C., \& Kropp, J. P. (2012). Towards sectoral and standardised vulnerability assessments: The example of heatwave impacts on human health. Climatic Change, 112(3-4), 687-708. doi: 10.1007/s10584-011-0231-5

Liu, J., Fritz, S., Wesenbeeck, C. F. A. v., Fuchs, M., You, L., Obersteiner, M., \& Yang, H. (2008). A spatially explicit assessment of current and future hotspots of hunger in Sub-Saharan Africa in the context of global change. Global and Planetary Change, 64(3-4), 222-235. doi: 10.1016/j.gloplacha.2008.09.007

Lüdeke, M. K. B., Walther, C., Sterzel, T., Kok, M. T. J., Lucas, P., Janssen, P., \& Hilderink, H. (2014). Understanding change in patterns of vulnerability. Potsdam, Germany. 
Lutz, W., \& Muttarak, R. (2017). Forecasting societies' adaptive capacities through a demographic metabolism model. Nature Climate Change, 7(3):177.

MacEachren, A. M., Robinson, A., Hopper, S., Gardner, S., Murray, R., Gahegan, M., \& Hetzler, E. (2005). Visualizing geospatial information uncertainty: What we know and what we need to know. Cartography and Geographic Information Science, 32(3), 139-160.

MacEachren, A.M., Pike, W., Yu, C. et al. (2006). Building a GeoColloaboratory Computers, Environment and Urban Systems, 30, 201-225.

Maddison, D. (2006) The Perception of and Adaptation to Climate Change in Africa. CEEPA. Discussion paper No. 10, Centre for Environmental Economics and Policy in Africa, University of Pretoria, Pretoria.

Magliocca, N.R., Rudel, T.K., Verburg, P.H., McConnell, W.J., Mertz, O., Gerstner, K., Heinimann, A., Ellis, E.C. (2015). Synthesis in land change science: methodological patterns, challenges, and guidelines. Reg Environ Change (2015) 15:211-226 DOI 10.1007/s10113-0140626-8.

Mainali, J., \& Pricope, N.G. (2017). High-resolution spatial assessment of population vulnerability to climate change in Nepal. Applied Geography 82:66-82.

Malcomb, D., Weaver, E. and Krakowka, R. 2014. Vulnerability modeling for sub-Saharan Africa: An operationalized approach in Malawi. Applied Geography 48: 17-30.

Malcomb, D.W. et al., (2014) Vulnerability modeling for sub-Saharan Africa: An operationalized approach in Malawi. Applied Geography 48: 17-30

Mani, M., Bandyopadhyay, S., Chonabayashi, S., Markandya, A., \& Mosier, T. (2018) South Asia's Hotspots: The impact of temperature and precipitation changes on living standards. Washington DC: World Bank.

McCusker, B., Essam, T. and Conley, J. 2016. Spatial policymaking: Using large, public datasets to illustrate spatial patterns of human vulnerability in Niger. Proceedings of the 13th International Conference on Social Implications of Computers in Developing Countries. Negombo, Sri Lanka. May 2015.

Meadow, A. M., Ferguson, D. B., Guido, Z., Horangic, A., Owen, G., \& Wall, T. (2015).

Moving toward the deliberate coproduction of climate science knowledge. Weather, Climate, and Society, 7(2), 179-191.

Mertz, O. et al, (2009) Adaptation to Climate Change in Developing Countries. Environmental Management 43: 743-752 D 103

Moise A. F. and Hudson D.A. (2008) Probabilistic predictions of climate change for Australia and southern Africa using the reliability ensemble average of IPCC CMIP3 model simulations. Journal of Geophysical Research, Vol. 113, D15113, Doi:10.1029/2007jd009250, 2008 
Muccione, V., S.K. Allen, C. Huggel and J. Birkmann. (2016). Differentiating regions for adaptation financing: the role of global vulnerability and risk distributions. WIRES Climate Change. doi: $10.1002 / \mathrm{wcc} .447$

Müller, C., Waha, K., Bondeau, A., \& Heinke, J. (2014). Hotspots of climate change impacts in sub-Saharan Africa and implications for adaptation and development. Global Change Biology, 20(8), 2505-2517. doi: 10.1111/gcb.12586

Mvula, P. M. et al. (2003) Poverty and Social Impact Assessment in Malawi: Closure of ADMARC Markets, Report submitted to World Bank and GTZ

Nardo, M., Saisana, M., Saltelli, A., Tarantola, S., Hoffman, A., \& Giovannini, E. (2005). Handbook on constructing composite indicators. Paris: OECD. doi:10.1787/533411815016.

Nash D.J. and Endfield G.H., (2008) Splendid rains have fallen': links between El Niño and rainfall variability in the Kalahari, 1840-1900. Climatic Change 86: 257-290

Nayak, S. G., Shrestha, S., Kinney, P. L., Ross, Z., Sheridan, S. C., Pantea, C. I., ... \& Hwang, S. A. (2018). Development of a heat vulnerability index for New York State. Public Health, 161, 127-137.

Ngongondo, C., et al., (2011) Evaluation of spatial and temporal characteristics of rainfall in Malawi: a case of data scarce region. Theor Appl Climatol (2011) 106:79-93

Ngongondo, C.S., (2006) An analysis of rainfall trends, variability and groundwater availability in Mulunguzi river Catchment area, Zomba Mountain, Southern Malawi. Quat Int 148:45-50

Nguyen, T. T. X., \& Woodroffe, C. D. (2016). Assessing relative vulnerability to sea-level rise in the western part of the Mekong River Delta in Vietnam. Sustainability Science, 11(4), 645-659. doi: 10.1007/s11625-015-0336-2

Nicholson, S. E., Klotter, D., and Chavula, G., (2014) A detailed rainfall climatology for Malawi, Southern Africa. International Journal of Climatology 34: 315-325 (2014)

Notenbaert, A., Massawe, S., \& Herrero, M. (2010). Mapping risk and vulnerability hotspots in the COMESA region: Technical Report. ReSAKSS Working Paper No. 32. Nairobi, Kenya: IFPRI.

O’Neill, B. C., Kriegler, E., Riahi, K., Ebi, K. L., Hallegatte, S., Carter, T. R., ... \& van Vuuren, D. P. (2014). A new scenario framework for climate change research: the concept of shared socioeconomic pathways. Climatic Change, 122(3), 387-400.

O’Neill, B.C., Kriegler, E., Ebi, K. L., Kemp-Benedict, E., Riahi, K., Rothman, D. S., . . Kok, K. (2017). The roads ahead: narratives for shared socioeconomic pathways describing world futures in the 21st century. Global Environmental Change, 42, 169-180.

O'Brien, Karen \& Eriksen, Siri \& Nygaard, Lynn \& Schjolden, Ane. (2007). Why different interpretations of vulnerability matter in climate change discourses. Climate Policy. 7. 73-88. 10.3763/cpol.2007.0706. 
Ogalleh, S.A. et al (2012) Local Perceptions and Responses to Climate Change and Variability: The Case of Laikipia District, Kenya. Sustainability 2012, 4, 3302-3325; doi:10.3390/su4123302

Okonya, J. et al (2013). Farmers' Perception of and Coping Strategies to Climate Change: Evidence From Six Agro-Ecological Zones of Uganda. Journal of Agricultural Science. 5. 252262. 10.5539/jas.v5n8p252.

O'Neill, B.C., Gettelman, A. (2018). An introduction to the special issue on the Benefits of Reduced Anthropogenic Climate changE (BRACE). Climatic Change 1-9. DOI: 10.1007/s10584-017-2136-4.

Oppenheimer, M., M. Campos, R.Warren, J. Birkmann, G. Luber, B. O’Neill, and K. Takahashi (2014). Emergent risks and key vulnerabilities. In: Climate Change 2014: Impacts, Adaptation, and Vulnerability. Part A: Global and Sectoral Aspects. Contribution of Working Group II to the Fifth Assessment Report of the Intergovernmental Panel on Climate Change [Field, C.B., V.R. Barros, D.J. Dokken, K.J. Mach, M.D. Mastrandrea, T.E. Bilir, M. Chatterjee, K.L. Ebi, Y.O. Estrada, R.C. Genova, B. Girma, E.S. Kissel, A.N. Levy, S. MacCracken, P.R. Mastrandrea, and L.L.White (eds.)]. Cambridge University Press, Cambridge, United Kingdom and New York, NY, USA, pp. 1039-1099.

Ovuka, M. and Lindqvist, S. (2000) Rainfall Variability in Murang'a District, Kenya: Meteorological Data and Farmers' Perception. Geografiska Annalwer Volume82, Issue1

Padilla, L.M., I.T. Ruginski, and S.H. Creem-Regehr. 2017. Effects of ensemble and summary displays on interpretations of geospatial uncertainty data. Cognitive Research: Principles and Implications 2:40, https://doi.org/10.1186/s41235-017-0076-1

Pahl-Wostl, C., C. Giupponi, K. Richards, C. Binder, A. de Sherbinin, D. Sprinz, T. Toonen, and C. van Bers. (2012). Transition towards a new global change science: Requirements for methodologies, methods, data and knowledge. Environmental Science and Policy, 28: 36-47.

Panda, A (2016) Exploring climate change perceptions, rainfall trends and perceived barriers to adaptation in a drought affected region in India. Nat Hazards (2016) 84:777-796

Papathoma-Köhle, M., Neuhäuser, B., Ratzinger, K., Wenzel, H., \& Dominey-Howes, D. (2007). Elements at risk as a framework for assessing the vulnerability of communities to landslides. Natural Hazards and Earth System Science, 7(6), 765-779. doi: 10.5194/nhess-7-765-2007

Parry, M.L., O.F. Canziani, J.P. Palutikof, et al. 2007. Technical Summary. Climate Change 2007: Impacts, Adaptation and Vulnerability. Contribution of Working Group II to the Fourth Assessment Report of the Intergovernmental Panel on Climate Change. M.L. Parry, O.F. Canziani, J.P. Palutikof, P.J. van der Linden and C.E. Hanson (Eds.). Cambridge, UK: Cambridge University Press, pp. 23-78.

Parsons, M. A., Duerr, R., \& Minster, J. B. (2010). Data citation and peer review. Eos, Transactions American Geophysical Union, 91(34), 297-298. 
Patt, A., Klein, R. J., \& de la Vega-Leinert, A. (2005). Taking the uncertainty in climate-change vulnerability assessment seriously. Comptes Rendus Geoscience, 337(4), 411-424.

Patt, A., Klein, R. J., \& de la Vega-Leinert, A. (2005). Taking the uncertainty in climate-change vulnerability assessment seriously. Comptes Rendus Geoscience, 337(4), 411-424.

Piontek, F., Müller, C., Pugh, T. A., Clark, D. B., Deryng, D., Elliott, J., . . Franssen, W. (2014). Multisectoral climate impact hotspots in a warming world. Proceedings of the National Academy of Sciences, 111(9), 3233-3238.

Poompavai, V., \& Ramalingam, M. (2013). Geospatial analysis for coastal risk assessment to cyclones. Journal of the Indian Society of Remote Sensing, 41(1), 157-176.

Preston B, Yuen EJ, Westaway RM (2011) Putting vulnerability to climate change on the map: a review of approaches, benefits, and risks. Sustain Sci 6:177-202.

Preston, B. L. et al. (2011) Westaway Putting vulnerability to climate change on the map: a review of approaches, benefits, and risks. Sustain Sci DOI 10.1007/s11625-011-0129-1

Preston, B. L., Brooke, C., Measham, T. G., Smith, T. F., \& Gorddard, R. (2009). Igniting change in local government: lessons learned from a bushfire vulnerability assessment. Mitigation and Adaptation Strategies for Global Change, 14(3), 251-283.

Preston, B. L., Smith, T. F., Brooke, C., Gorddard, R., Meashan, T. G., Withycombe, G., . . . Abbs, D. (2008). Mapping Climate Change Vulnerability in the Sydney Coastal Councils Group (pp. 124-124). Sydney.

Preston, B., Yuen, E., Westaway, R. 2011. Putting vulnerability to climate change on the map: a review of approaches, benefits, and risks. Sustainability Science 6: 177-202.

Preston, Yuen, and Westaway (2011) Preston, B.L., Westaway, R.M. \& Yuen, E.J. (2011)

Climate adaptation planning in practice: an evaluation of adaptation plans from three developed nations. Mitig Adapt Strateg Glob Change (2011) 16: 407. https://doi.org/10.1007/s11027-010-9270-x

PROVIA (Programme on Vulnerability, Impacts and Adaptation). (2013). Research Priorities on Vulnerability, Impacts and Adaptation: Responding to the Climate Change Challenge. Nairobi, Kenya: UNEP.

Qin, H., and M.E. Grigsby (2016). A Systematic Review and "Meta-Study" of Meta-Analytical Approaches to the Human Dimensions of Environmental Change, Human Ecology Review, 22(2): 109-136.

Ram, K. 2013. Git can facilitate greater reproducibility and increased transparency in science. Source Code for Biology and Medicine 8(7), 1-8.

Rasanen, A., S. Juhola, A. Nygren, M. Kakonen, M. Kallio, A. Monge Monge, and M. Kanninen. (2016). Climate change, multiple stressors and human vulnerability: a systematic review. Reg Environ Change, 16:2291-2302, DOI 10.1007/s10113-016-0974-7 
Reckien, D. (2018). What is in an index? Construction method, data metric, and weighting scheme determine the outcome of composite social vulnerability indices in New York City. Regional Environmental Change, online first: https://doi.org/10.1007/s10113-017-1273-7

Reid, C. E., O'Neill, M. S., Gronlund, C. J., Brines, S. J., Brown, D. G., Diez-Roux, A. V., \& Schwartz, J. (2009). Mapping community determinants of heat vulnerability. Environmental Health Perspectives, 117(11), 1730-1736.

Retchless, D.P., \& Brewer, C. A. (2016). Guidance for representing uncertainty on global temperature change maps. International Journal of Climatology, 36(3), 1143-1159.

Ribot, J., (2011) Vulnerability before adaptation: Towards transformative climate action. Global Environmental Change 21: 1160 -1162

Rigaud, K.K., de Sherbinin, A., Jones, B., Bergmann, J., Clement, V., et al. (2018). Groundswell: Preparing for Internal Climate Migration. Washington DC: World Bank.

Robbins, P, (2011) Critical Introductions to Geography: Political Ecology (2nd Edition). Hoboken, NJ, USA: John Wiley \&amp; Sons,

Robbins, P. 2004. Political Ecology: A Critical Introduction. Blackwell (2004)

Rocha, A. and Simmonds I., (1997) Interannual Variability of South-Eastern African Summer Rainfall. Part 5II. Modeling the Impact of Sea-Surface Temperatures on Rainfall and Circulation. International Journal of Climatology 17: 267-290

Rohat, G. (2018). Projecting drivers of human vulnerability under the Shared Socioeconomic Pathways. International journal of environmental research and public health, 15(3), 554.

Ropelewski, C. F. and Halpert, M. S. (1987). Global and regional scale precipitation patterns associated with the El Niño/Southern Oscillation. Monthly Weather Review, 115(8), 1606-1626.

Ropelewski, C. F. and Halpert, M. S. (1989). Precipitation patterns associated with the high index phase of the Southern Oscillation. Journal of climate, 2(3), 268-284.

Roy, D. C., \& Blaschke, T. (2015). Spatial vulnerability assessment of floods in the coastal regions of Bangladesh. Geomatics, Natural Hazards and Risk, 6(1), 21-44. doi: 10.1080/19475705.2013.816785

Rufat, S., E. Tate, C.G. Burton, A.S. Maroof. (2015). Social vulnerability to floods: Review of case studies and implications for measurement. International Journal of Disaster Risk Reduction, 14(4): 470-486

Runfola, D.M., S. Ratick, J. Blue, E. Axinia et al. (2015). A multi-criteria geographic information systems approach for the measurement of vulnerability to climate change. Mitig Adapt Strateg Glob Change, DOI 10.1007/s11027-015-9674-8

Saisana, M., Saltelli, A. \& Tarantola, S. (2005). "Uncertainty and Sensitivity Analysis

Techniques as Tools for the Quality Assessment of Composite Indicators." Journal of the Royal Statistical Society A, 168(2), 1-17. 
Sanchez-Cortes, M.S. and Chavero, E.L. (2011)Indigenous perception of changes in climate variability and its relationship with agriculture in a Zoque community of Chiapas, Mexico. Climatic Change, (2011) 107: 363. https://doi.org/10.1007/s10584-010-9972-9

Scheuer, S., Haase, D., \& Meyer, V. (2011). Exploring multicriteria flood vulnerability by integrating economic, social and ecological dimensions of flood risk and coping capacity: from a starting point view towards an end point view of vulnerability. Natural Hazards, 58(2), 731-751.

Shongwe, M.E. et al. (2009). Projected Changes in Mean and Extreme Precipitation in Africa under Global Warming. Part I: Southern Africa. Journal of Climate. 22. 10.1175/2009JCLI2317.1.

Simmonds, I. and Hope, P. (1997) Persistence Characteristics of Australian Rainfall Anomalies. International Journal of Climatology. Volume17, Issue6, May 1997 Pages 597-613

Sivakumar M.V.K. et al., (2005) Impacts of Present and Future Climate Variability and Change on Agriculture and Forestry in the Arid and Semi-Arid Tropics. Climatic Change 70: 31-72

Soares, M.B., A.S. Gagnon, and R.M. Doherty. (2012). Conceptual elements of climate change vulnerability assessments. International Journal of Climate Change Strategies and Management, 4(1):6-35.

Start, D., and I. Hovland. (2004). Tools for Policy Impact: A Handbook for Researchers.

London, UK: Overseas Development Institute.

http://web.worldbank.org/archive/website01031/WEB /IMAGES/TOOLS_HA.PDF

Strader, S. M., Ashley, W. S., Pingel, T. J., \& Krmenec, A. J. (2017). Projected 21st century changes in tornado exposure, risk, and disaster potential. Climatic Change, 141(2), 301-313.

Tadross, M. et al. (2009) Growing-season rainfall and scenarios of future change in southeast Africa: implications for cultivating maize. Climate Research 40: 147-161, 200

Tapia, C., Abajo, B., Feliu, E., Mendizabal, M., Martinez, J. A., Fernández, J. G., ... \& Lejarazu, A. (2017). Profiling urban vulnerabilities to climate change: An indicator-based vulnerability assessment for European cities. Ecological Indicators, 78, 142-155.

Tate, E. (2012). Social vulnerability indices: a comparative assessment using uncertainty and sensitivity analysis. Natural Hazards, 63(2), 325-347.

Tellman, E., C. Schank, B. Schwarz, P. Howe. (2017). Societal Sensitivity to Flood Death and Damage in the U.S.A.: Validation of Vulnerability Assessments. Paper presented at the 2017 annual meeting of the American Association of Geographers, Boston MA, April 2017.

Tesso, Gutu \& Emana, Bezabih \& Ketema, Mengistu. (2012). Analysis of vulnerability and resilience to climate change induced shocks in North Shewa, Ethiopia. Agricultural Sciences. 03. 871-888. 10.4236/as.2012.36106. 
Teye et al 2014 local farmers' experiences and perceptions of cliate change in the northern savanna zone of ghana. Interational journal of climate change strategies and management 2015 vol:7(3)pp: $327-347$

Thayn, J.B., and Simanis, J., 2013. Accounting for spatial autocorrelation in linear regression models using spatial filtering with eigenvectors. Annals of the Association of American Geographers 103(1), 47-66.

Thornton, P. K., Jones, P. G., Owiyo, T., Kruska, R. L., Herrero, M., Orindi, V., . . Omolo, A. (2008). Climate change and poverty in Africa: Mapping hotspots of vulnerability. African Journal of Agriculture and Resource Economics (AfJARE), 2(1), 24-44.

Torres, R. R., Lapola, D. M., Marengo, J. A., \& Lombardo, M. A. (2012). Socio-climatic hotspots in Brazil. Climatic Change, 115(3-4), 597-609. doi: 10.1007/s10584-012-0461-1

Trzaska, S., and E. Schnarr (2014). A Review of Downscaling Methods for Climate Change Projections, USAID Technical paper, Washington, DC, pp. 56, https://www.climatelinks.org/resources/review-downscaling-methods-climate-changeprojections

Udoh, J. C. (2015). Multi-Hazard Vulnerability Mapping: An Example from Akwa Ibom State, Nigeria. European Scientific Journal, 11(29), 293-300.

UNDP. (2010). Mapping Climate Change Vulnerability and Impact Scenarios: A Guide Book For Sub-National Planners. New York: United Nations Development Program.

Usman, M.T. and Reason C.J.C., (2004) Dry Spell Frequencies and the variability over southern Africa. Climate Research 26:199-211

Van Aalst, M.K. et al. (2008). Community Level Adaptation to Climate Change: The Potential Role of Participatory Community Risk Assessment. Global Environmental Change. 18. 165-179. 10.1016/j.gloenvcha.2007.06.002.

Van Loon, H. and Shea, D.J (1985) The Southern Oscillation. Part IV: The Precursors South of $15^{\circ} \mathrm{S}$ to the Extremes of the Oscillation. National Center for Atmospheric Research, Boulder, CO 80307

van Wesenbeeck, C. F. A., Sonneveld, B. G. J. S., \& Voortman, R. L. (2016). Localization and characterization of populations vulnerable to climate change: Two case studies in Sub-Saharan Africa. Applied Geography, 66, 81-91. doi: 10.1016/j.apgeog.2015.11.001

Vincent, K. (2004). Creating an index of social vulnerability to climate change for Africa. Tyndall Center for Climate Change Research. Working Paper, 56(41).

Volume 28, September 2014, Pages 325-336

Wang, C., \& Yarnal, B. (2012). The vulnerability of the elderly to hurricane hazards. Natural Hazards, 63(2), 349-373. doi: 10.1007/s11069-012-0151-3 
Weber, E.U. (2010) What shapes perceptions of climate change? Wires climate change. Volume7, Issue1 Pages 125-134

Weber, S., Sadoff, N., Zell, E., \& Sherbinin, A. D. (2015). Policy-relevant indicators for mapping the vulnerability of urban populations to extreme heat events: A case study of Philadelphia. Applied Geography, 63, 231-243. doi: 10.1016/j.apgeog.2015.07.006

Weeks, E. S., Walker, S., Overton, J. M., \& Clarkson, B. (2013). The value of validated vulnerability data for conservation planning in rapidly changing landscapes. Environmental Management, 51(5), 1055-1066.

Wilbanks, T. J., \& Ebi, K. L. (2014). SSPs from an impact and adaptation perspective. Climatic change, 122(3), 473-479.

WMO (World Meteorological Organization) (1988) Analyzing long time series of hydrological data with respect to climate variability. WCAP-3, WMO/TD No. 224, p 12

World Bank and the Potsdam Institute for Climate Impact Research (PIK). (2012). Turn Down the Heat: Why a Four Degree Warmer World Must be Avoided. Washington DC: World Bank.

Yohe, G. \& Tol, R.S.J. (2002) Indicators for social and economic coping capacity-moving toward a working definition of adaptive capacity. Global environmental change, 2002 - Elsevier

Yu, M., Yang, C., \& Li, Y. (2018). Big Data in Natural Disaster Management: A Review. Geosciences, 8(5), 165.

Yusuf, A. A., \& Francisco, H. (2009). Climate Change Vulnerability Mapping for Southeast Asia (pp. 32-32). Singapore: Economy and Environment Program for Southeast Asia.

Zhao, Y. et al., (2005) Impacts of Present and Future Climate Variability on Agriculture and Forestry in the Humid and Sub-Humid Tropics. Climatic Change 70: 73-116 